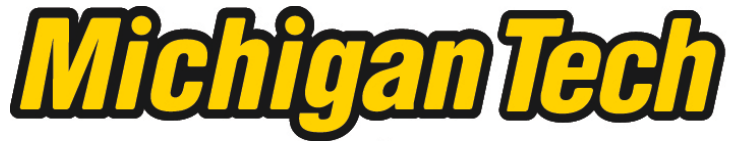 \\ Michigan Technological University Create the Future Digital Commons @ Michigan Tech
}

\section{Hydrologic monitoring of an integrated low impact development (LID) underdrained stormwater management system}

Nancy-Jeanne Bachmann

Michigan Technological University

Follow this and additional works at: https://digitalcommons.mtu.edu/etds

Part of the Civil and Environmental Engineering Commons

Copyright 2007 Nancy-Jeanne Bachmann

Recommended Citation

Bachmann, Nancy-Jeanne, "Hydrologic monitoring of an integrated low impact development (LID) underdrained stormwater management system ", Master's Thesis, Michigan Technological University, 2007.

https://doi.org/10.37099/mtu.dc.etds/217

Follow this and additional works at: https://digitalcommons.mtu.edu/etds

3 Part of the Civil and Environmental Engineering Commons 


\author{
HYDROLOGIC MONITORING OF AN \\ INTEGRATED LOW IMPACT DEVELOPMENT (LID) \\ UNDERDRAINED STORMWATER MANAGEMENT SYSTEM
}

By

NANCY-JEANNE BACHMANN

\begin{abstract}
A THESIS
Submitted in partial fulfillment of the requirements

For the degree of

MASTER OF SCIENCE IN ENVIRONMENTAL ENGINEERING
\end{abstract}

MICHIGAN TECHNOLOGICAL UNIVERSITY

2007

Copyright @ Nancy-Jeanne Bachmann 2007 
This thesis, "Hydrologic Monitoring of an Integrated Low Impact Development (LID) Underdrained Stormwater Management System," is hereby approved in partial fulfillment for the Degree of MASTER OF SCIENCE IN ENVIRONMENTAL ENGINEERING.

DEPARTMENT of Civil and Environmental Engineering

Signatures:

Thesis Co-Advisor

(Dr. David W. Watkins)

Thesis Co-Advisor

(Dr. John S. Gierke)

Department Chair

(Dr. Neil J. Hutzler)

Date 


\section{ABSTRACT}

In 2005, Wetland Studies and Solutions, Inc. (WSSI) installed an extensive Low Impact Development (LID) stormwater management system on their new office site in Gainesville, Virginia. The 4-acre site is serviced by a network of LID components: permeable pavements (two proprietary and one gravel type), bioretention cell / rain garden, green roof, vegetated swale, rainwater harvesting and drip irrigation, and slow-release underground detention. The site consists of heavy clay soils, and the LID components are mostly integrated by a series of underdrain pipes. A comprehensive monitoring system has been designed and installed to measure hydrologic performance throughout the LID, underdrained network. The monitoring system measures flows into and out of each LID component independently while concurrently monitoring rainfall events. A sensitivity analysis and laboratory calibration has been performed on the flow measurement system. Field data has been evaluated to determine the hydrologic performance of the LID features. Finally, hydrologic models amenable to compact, underdrained LID sites have been reviewed and recommended for future modeling and design. 


\section{ACKNOWLEDGEMENTS}

I would like to acknowledge the generous support of the following groups and individuals. Thank you to Wetland Studies and Solutions, Inc. (WSSI) for initiating and completing the design and installation of the integrated LID stormwater management system. I am grateful to Mike Rolband for his grand vision of the site design. Thank you for including me in the initial phases of on-site research. Next, I am particularly grateful for the supervision and guidance provided by Jennifer Brophy-Price and Kelly Stanforth. In addition, this project could not have succeeded without the on-site work (and sweat) of the following people (in alphabetical order): Beth Armitstead, Jason Beeler, Larry Brissing, John Connelly, Dan Fisk, Roy Van Houten, and Chuck Knaggs. Thanks for the installation and troubleshooting. And thank you, thank you, thank you, to Rustom Meyer and Russ Dudley for their persistent troubleshooting of the system electronics, communication network, and measurement accuracy. You were my outstanding link to the site after departing Gainesville.

This project was funded by WSSI, the National Science Foundation, the Michigan Technological University (MTU) Department of Civil and Environmental Engineering, the Michigan Stormwater-Floodplain Association, the MTU Department of Geological and Mining Engineering and Sciences' Earth and Hydro-Science Outreach (EH-SO), and the MTU Center for Water and Society. Without your generous support, this project would not have been possible. Thank you many times over.

Thank you to MTU's Subsurface Remediation Laboratory for the laboratory space. And I especially thank Rob Fritz and Chris Wojick for their technical support along the way. Thank you to my committee members Brian Barkdoll and Thomas Pypker for their review and comment on this thesis. Their thoughtful, big-picture contributions as well as 
their attention to detail are much appreciated. Thank you Tom for tapping into my favorite element of LID design, plant ecology.

Finally, I want to thank my co-advisors at MTU John S. Gierke and David W. Watkins (in alphabetical order). You stuck with me throughout the project - from project conception to the detailed editing and re-editing of my thesis. Thank you (among many other things) for the long hours, last-minute meetings, and thoughtful insight. 
$\underline{1}$ INTRODUCTION $1-1$

$\underline{2}$ PREVIOUS WORK $2-6$

2.1 INDIVIDUAL LID COMPONENTS 2-6

2.2 WATER QUANTITY CONTROL 2-6

2.3 MECHANISMS OF LID SYSTEM FUNCTION 2-7

2.4 Post-Construction Monitoring 2-8

2.5 Models Applied To Design AND StUdy $\quad$ 2-11

2.6 LONG-TERM ANALYSES $\quad$ 2-15

2.7 WATER QUALITY TREATMENT

$\begin{array}{lll}2.7 .1 & \text { NitROGEN } & 2-15\end{array}$

2.7.2 PHOSPHORUS 2-16

2.7.3 HEAVY METALS (COPPER, LEAD, AND ZINC) 2-17

$\begin{array}{llr}2.8 & \text { RESEARCH NEEDS } & \text { 2-18 }\end{array}$

$\underline{3}$ FLOW MONITORING OF AN LID UNDERDRAINED STORMWATER MANAGEMENT NETWORK

3.1 OBJECTIVES FOR THE FLOW MONITORING 3-20

3.2 SITE DESCRIPTION 3-21

3.3 DEVELOPMENT AND DESIGN OF INSTALlED MONITORING SYSTEM 3-27

3.3.1 TECHNiCAl REVIEW OF MONITORING TECHNOLOGIES 3-27

3.3.2 MONITORING LOCATIONS 3-30

3.3.3 MEASUREMENT TECHNIQUeS 3-32

$\underline{4}$ UNDERDRAIN MEASUREMENT SYSTEM SENSITIVITY ANALYSIS AND

\begin{tabular}{lr} 
CALIBRATION & $4-43$ \\
\hline
\end{tabular}

4.1 SENSITIVITY OF THE UNDERDRAIN HYDROLOGIC MEASUREMENT SYSTEM 4-43

4.2 CAlibration OF MANNING's $N \quad$ 4-47

4.2.1 LABORATORY METHODS 4-48

4.2.2 RESUlTS AND DISCUSSION 4-49

$\begin{array}{lll}\text { 4.2.3 CONCLUSIONS 4-58 } & \text { 4. }\end{array}$ 
5.1 IDENTIFICATION OF THE ZERO-FLOW DEPTH 5-65

5.2 RESULTS AND DisCUSSION

5.2.1 MONITORING POINT DP4 - NORTHEAST OUTFALL 5-66

5.2.2 MONitORING POINT DP3 - West OUTFALL 5-71

5.2.3 COMPARISON OF HYDROGRAPH SHAPES FROM POROUS PAVEMENT RUNOFF (DP3) AND

CISTERN EMERGENCY OVERFLOW (C3) 5-77

5.2.4 Monitoring Point GR - GreEn RoOF SUBWATERSHED 5-78

5.2.5 Cistern WATER BALANCE FOR THE 3 JUNE STORM EVENT 5-83

5.2.6 MONITORING POINT C3 - CiSTERN EMERGENCY OVERFLOW 5-86

5.2.7 MONITORING POINT RG - RAIN GARDEN 5-87

5.2.8 MONitORing Point BS - SUBWATERSHEd INCLUding BiOSWALE 5-90

5.2.9 MONITORING POINTS ORI AND DP2 - SiTE OUTFALL 5-93

5.3 HYDROLOGIC RETENTION IDENTIFIED IN OTHER STUDIES FOR COMPARISON TO THE

GAINESVILLE SITE

5.3.1 BiORETENTION AND BIOSWALES 5-95

5.3.2 GREEN ROOFS 5-96

5.4 Summary and Conclusions: MaXimizing LID Hydrologic Performance 5-97

5.5 Findings RELATED TO THE HydROLOGIC MEASUREMENT SYSTEM 5-104

$\underline{6}$ MODELS APPLICABLE TO SITE-SCALE LID NETWORKS WITH \begin{tabular}{lr} 
UNDERDRAINS & $6-107$ \\
\hline
\end{tabular}

6.1 MODELS DEVELOPED SPECIFICALLY FOR LID 6-111

6.1.1 BMP MOdULE 6-111

6.1.2 RECARGA 6-112

6.1.3 LOW IMPACT FEASIBILITY (LIFE ${ }^{\mathrm{TM}}$ ) MODEL 6-113

6.2 EXISTING MODELS WITH RECENT INCORPORATION OF AND/OR APPLICATION TO LID6113

6.2.1 Simulating WATER FlOW AND SOLUTE TRANSPORT IN TWO-DimENSIONAL VARIABLy

SATURATED MEDIA (SWMS_2D) 6-113

6.2.2 MODEL FOR URBAN STORMWATER IMPROVEMENT CONCEPTUALIZATION (MUSIC) 6-114 
6.3 MODELS WITHOUT EXPLICIT REPRESENTATION OF LID

6.3.1 EPA STORM WATER MANAGEMENT MODEL, VERSION 5 (SWMM)

6.3.2 INSTITUTE OF HYDROLOGY DistRIBUTED MODEL (IHDM)

6.3.3 MOUSE

6.3.4 INTEGRATED HYdROLOGIC MODEL (INHM)

6-119

6.3.5 TOPOG_SBM (SIMPLE BUCKET MODEL)

6-120

6.3.6 HYDRUS_2D

6-121

6.3.7 COMSOL

$6-122$

6.4 Prognosis For FUtURE Modeling OF LID

6-122

\section{$\underline{7}$ CONTRIBUTIONS OF THIS RESEARCH TO OVERALL LID RESEARCH NEEDS 7-124}

7.1 REVIEW OF MEASUREMENT TECHNOLOGIES 7-124

7.2 DESign, CALIBRATION, AND INSTALLATION OF AN UNDERDRAIN-FLOW MONITORING SYSTEM 7-124

7.3 HYDROLOGIC DATA FROM AN INTEGRATED LID NETWORK 7-124

7.4 CONTINUOUS DATA COLLECTION 7-125

7.5 LONG-TERM DATA ANALYSIS 7-125

7.6 LID MODELING 7-126 


\section{List of Figures}

FiguRE 1. LID MONITORING SITE AT GAINESVILle, ViRginia, OWNED By WeTLAND STUdies AND Solutions, Inc. Photo taken June 21, 2006, (Copyright 2006, Roger W. SNyder). $3-22$

FIGURE 2. LID SYSTEM FEATURES (HATCHED AREAS) AND GENERAL FLOW PATHS (BOLD BLUE ARROWS INDICATE DIRECTION OF FLOW THROUGH DRAINS; LIGHT BLUE ARROWS INDICATED DIRECTION OF OVERLAND FLOW IN OUTLINED SUBWATERSHEDS), (COPYRIGHT 2006, WETLAND STUDIES AND SOLUTIONS, INC.).

Figure 3. SCHEMATIC OF FLOW THRough LID site IN GAinESVILLE, VA, (Copyright 2006, WeTLAND STUDIES AND SOLUTIONS, INC.). $3-27$

FIGURE 4. LINE MODIFICATION MEASUREMENT SYSTEM (TRAP SYSTEM) THAT CREATES FULL PIPE CONDITIONS AND UTILIZES A MEASUREMENT TECHNOLOGY SUCH AS THE GLOBAL WATER EX80 ELECTROMAGNETIC METER AS PICTURED HERE. A CLEANOUT IS INCLUDED IN THE DESIGN. FLOW IS FROM LEFT TO RIGHT.

FIGURE 5. LINE MODIFICATION MEASUREMENT SYSTEM (GOOSENECK SYSTEM) THAT CREATES FULL PIPE, PRESSURIZED, UPWARD FLOW CONDITIONS AND UTILIZES A MEASUREMENT TECHNOLOGY* SUCH AS THE GLOBAL WATER IF200 IMPELLER METER. FLOW IS FROM LEFT TO RIGHT. $3-29$

Figure 6. ALL MONITORING LOCATIONS AND IDs (RED) AT THE GAINESVILLE SITE. BLUE LINES ARE UNDERDRAINS, (COPYRIGHT 2006, WETLAND STUDIES AND SOLUTIONS, INC.). 3-32

FIGURE 7. STILLING WELL AND LEVEL SENSOR MOUNTING DESIGN FOR DEPTH-OUTFLOW MEASUREMENT IN PVC UNDERDRAINS AT THE GAINESVILLE SITE. 3-37

FiguRE 8. PHOTO OF THE FABRICATED PVC FITTING (8" SIZE) USED FOR STILLING WELL INSTALLATION IN EXISTING PIPE AT THE GAINESVILLE SITE (PROFILE - LEFT, AERIAL - RIGHT). 3-37

FIGURE 9. INSTALLATION OF FABRICATED FITTING AND STILLING WELL AT MONITORING LOCATION DP4 TOWARDS THE NORTH END OF THE SITE. PHOTO TAKEN SEPTEMBER 27, 2006, (COPYRIGHT 2006, WETLAND STUDIES AND SOLUTIONS, INC.). 3-38

FigURE 10. INSTALLATION OF MODEL 8000 LEVEL SENSOR INTO STILLING WELL (TWO LOCATIONS PICTURED HERE). SENSOR IS MOUNTED ON SEMI-FLEXIBLE CABLE EXTENDING TO THE TOP ACCESS POINT OF THE 
PVC design. Photos taken in November 2006, (Copyright 2006, Wetland Studies AND SOLUTIONS, INC.). 3-38

FIGURE 11. POWER AND COMMUNICATION EQUIPMENT SET-UP USING THE CR206 DATALOGGER BY

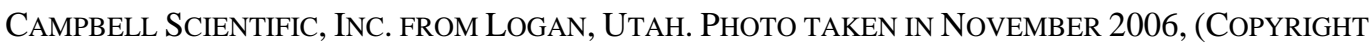
2006, WeTLAND STUDIES AND SOLUTIONS, INC.). 3-39

Figure 12. GRATE REPLACED AT DP3 (AND DP4) IN SPRING 2007, RAT GuARDS ${ }^{\text {TM }}$ By AgRiDRAiN COORPORATION MODELS RG06 AND RG04, RESPECTIVELy. PHOTO TAKEN APRIL 2007, (COPYRIGHT 2007, WeTLAND STUDIES AND SOLUTIONS, INC.). 3-39

FIGURE 13. RATING CURVE ESTABLISHED FOR MONITORING LOCATION ORI BASED ON HYDROLOGIC ROUTING CALCULATIONS By URBAN ENGINEERING \& ASSOCIATES, INC. (2004). 3-41

FIGURE 14. SEAMETRICS TX101 TURBINE METER INSTALLATION SPECIFICATIONS AS PREPARED BY WETLAND STUDIES AND SOLUTIONS, INC. FLOW IS FROM RIGHT TO LEFT. $3-42$

FiguRE 15. THIRTY-DEGREE V-NOTCH WEIR AND MODEL 8000 DEPTH SENSOR INSTALLATION WITH POWER AND COMMUNiCATION HOOKUP. PHOTO TAKEN IN NOVEMBER 2006, (COPYRight 2006, WETLAND STUDIES AND SOLUTIONS, INC.). $3-42$

FIGURE 16. DETERMINATION OF THE CUMULATIVE RUNOFF EFFECTS OF VARYING MANNING'S N (ORIGINALLY 0.009) FOR A 17-HR, 0.65-INCH STORM EVENT (0.04 IN/HR) AT MEASUREMENT POINT DP4. STORM FREQUENCY EXCEEDS THE 1-YR, 2-HR STORM EVENT FOR THE REGION. THE BASELINE DIVIDES THE OPPOSING EFFECTS TO THE FLOW: OVER- (+) AND UNDER-ESTIMATES (-). 4-45

FIGURE 17. DETERMINATION OF THE CUMULATIVE RUNOFF EFFECTS OF VARYING THE ZERO-FLOW DEPTH (ORIGINALLY 12.93 IN) FROM A 17-HR, 0.65-INCH STORM EVENT (0.04 IN/HR) AT MEASUREMENT POINT DP4. STORM FREQUENCY EXCEEDS THE 1-YR, 2-HR STORM EVENT FOR THE REGION. THE BASELINE DIVIDES THE OPPOSING EFFECTS TO THE FLOW: OVER- (+) AND UNDER-ESTIMATES (-)...................... 4-46 FiguRE 18. DETERMINATION OF THE CUMULATIVE RUNOFF EFFECTS OF VARYING THE PIPE SLOPE (ORIGINALLY 0.029 FT/FT) FROM A 17-HR, 0.65-INCH STORM EVENT (0.04 IN/HR) AT MEASUREMENT POINT DP4. STORM FREQUENCY EXCEEDS THE 1-YR, 2-HR STORM EVENT FOR THE REGION. THE BASELINE DIVIDES THE OPPOSING EFFECTS TO THE FLOW: OVER-(+) AND UNDER-ESTIMATES (-)..... 4-46 
FIGURE 19. LABORATORY DATA FROM 4-INCH DIAMETER SET-UP SIMULATING STILLING WELL MEASUREMENT SYSTEM AT THE GAINESVILLE SITE. DATA ILLUSTRATED IN RED REPRESENTS FITTED MANNING'S EQUATION SOLUTIONS. AT CONSTANT SLOPE $(S=0.029)$, MANNING'S $N=0.0107$ (SSD = 4.92); WHEN $S=$ VARIABLE,$N=0.0105(\mathrm{SSD}=0.91)$ 4-51

FIGURE 20. WATER SURFACE PROFILES MEASURED IN THE LABORATORY WITH 4-INCH DIAMETER PVC. UPSTREAM TO DOWNSTREAM IS REPRESENTED FROM LEFT TO RIGHT. ERROR BARS REPRESENT 95\% CONFIDENCE INTERVALS. 4-52

FIGURE 21. WATER SURFACE PROFILES MEASURED IN THE LABORATORY WITH 6-INCH DIAMETER PVC. UPSTREAM TO DOWNSTREAM IS REPRESENTED FROM LEFT TO RIGHT. ERROR BARS REPRESENT 95\% CONFIDENCE INTERVALS

FIGURE 22. WATER SURFACE PROFILE EXPERIMENTAL DATA FOR THE 6-INCH DIAMETER DATA AND HECRAS MODEL RESULTS. NARROW ERROR BARS ON EXPERIMENTAL (EXP) DATA REPRESENT 95\% CONFIDENCE INTERVALS; WIDE ERROR BARS ON MODEL DATA REFLECT AUTOMATED ROUNDING WITHIN HEC-RAS MODELING SOFTWARE.................................................................................... $4-53$

FIGURE 23. LABORATORY DATA FOR THE 4-INCH DIAMETER PIPE SIZE COMPARING DEPTH-OUTFLOW DATA UNDER UNIFORM FLOW WITH AND WITHOUT THE PRESENCE OF THE STILLING WELL (SW). ERROR BARS REPRESENT A 95\% CONFIDENCE REPLICATE CALIPER MEASUREMENTS AND REPORTED ACCURACY OF PRESSURE TRANSDUCER. 4-56

FIGURE 24. LABORATORY DATA FOR THE 6-INCH DIAMETER PIPE SIZE COMPARING DEPTH-OUTFLOW DATA UNDER UNIFORM FLOW WITH AND WITHOUT THE PRESENCE OF THE STILLING WELL (SW). ERROR BARS REPRESENT 95\% CONFIDENCE. 4-56

FIGURE 25. ZERO-FLOW DEPTH DETERMINATION OF 1.34 INCHES FROM SENSOR DEPTH READINGS AT MEASUREMENT POINT DP3, ALREADY OFFSET BY APPROXIMATELY 16 INCHES FOR THE STILLING WELL. PRECIPITATION BEGAN 3 JUNE 2007 AND RESULTED IN 0.8 INCHES OF RAIN. 5-65

FIGURE 26. RUNOFF HYDROGRAPH GENERATED FROM DATA RECORDED AT MEASUREMENT POINT DP4 (POROUS CONCRETE PAVERS AND NATIVE VEGETATION) FOR PRECIPITATION BEGINNING 16 MAY 2007. 
FIGURE 27. RUNOFF HYDROGRAPH GENERATED BY DATA RECORDED AT MEASUREMENT POINT DP4 (POROUS PAVEMENT AND NATIVE VEGETATION) FOR PRECIPITATION BEGINNING 18 MAY 2007. 5-69

FIGURE 28. RUNOFF HYDROGRAPH GENERATED FROM DATA RECORDED AT MEASUREMENT POINT DP4 (POROUS PAVEMENT AND NATIVE VEGETATION) ILLUSTRATING RESPONSES TO BOTH PRECIPITATION AND CISTERN IRRIGATION. $5-70$

FIGURE 29. RUNOFF HYDROGRAPH GENERATED FROM DATA RECORDED AT MEASUREMENT POINT DP4 (POROUS PAVEMENT AND NATIVE VEGETATION) FOR PRECIPITATION EVENT BEGINNING 29 JUNE 2007. $5-70$

FIGURE 30. RUNOFF HYDROGRAPH GENERATED FROM DATA RECORDED AT MEASUREMENT POINT DP3 (ASPHALT, POROUS PAVEMENT, NATIVE VEGETATION) FROM PRECIPITATION BEGINNING 5 MAY 2007.574

FIGURE 31. RUNOFF HYDROGRAPH GENERATED FROM DATA RECORDED AT MEASUREMENT POINT DP3 (ASPHALT, POROUS PAVEMENT, NATIVE VEGETATION) FROM PRECIPITATION BEGINNING 12 MAY 2007. $5-74$

FIGURE 32. RUNOFF HYDROGRAPH GENERATED FROM DATA RECORDED AT MEASUREMENT POINT DP3 (ASPHALT, POROUS PAVEMENT, NATIVE VEGETATION) FROM PRECIPITATION BEGINNING 3 JUNE 2007.575

FIGURE 33. RUNOFF HYDROGRAPH GENERATED FROM DATA RECORDED AT MEASUREMENT POINT DP3 (ASPHALT, POROUS PAVEMENT, NATIVE VEGETATION) FROM PRECIPITATION BEGINNING 4 JUNE 2007.575

FIGURE 34. RUNOFF ACROSS WATERSHED MONITORED AT MEASUREMENT POINT DP3, ILLUSTRATING THE HIGH INFILTRATION RATE OF GRAVELPAVE2 POROUS PAVEMENT (LEFT IN PHOTO) RECEIVING RUNOFF FROM THE IMPERVIOUS ASPHALT (RIGHT IN PHOTO). THE FLOW BYPASSING THE DP3 MONITORING POINT BETWEEN THE PARKING ABUTMENT AND THE ORANGE CURB IS ALSO EVIDENT, (COPYRIGHT 2006, WETLAND STUDIES AND SOLUTIONS, INC.). $5-76$

FIGURE 35. CHARACTERIZATION OF FLOW DEPTH AND MAGNITUDE OF RUNOFF BYPASSING MEASUREMENT POINT DP3, (COPYRIGHT 2006, WETLAND STUDIES AND SOLUTIONS, INC.) $5-76$ 
FIGURE 36. RUNOFF HYDROGRAPHS GENERATED FROM DATA RECORDED AT MONITORING POINTS DP3 AND C3 FROM PRECIPITATION BEGINNING 3 JUNE 2007. $5-77$

FIGURE 37. RUNOFF HYDROGRAPHS GENERATED FROM DATA RECORDED AT MONITORING POINTS DP3 AND C3 FROM PRECIPITATION BEGINNING 4 JUNE 2007. $5-78$

FIGURE 38. SENSOR DEPTH READINGS FROM MONITORING POINT GR DEMONSTRATING THE EFFECTS OF EXCESS GREEN ROOF IRRIGATION ON CISTERN DEPTH. CISTERN OVERFLOW TO THE RAIN GARDEN (MONITORING POINT C2) ONLY BREACHES THE MINIMUM READABLE FLOW RATE DURING A RAIN EVENT, THOUGH THE CISTERN IS OVERFLOWING DAILY (APPROXIMATELY 2.2 GPM) FROM 6 JUNE THROUGH 12 JUNE. 5-82

FIGURE 39. DETERMINATION OF ZERO-FLOW DEPTH (0.11 INCHES) FOR THE CISTERN EMERGENCY OVERFLOW MONITORING POINT (C3) FROM PRECIPITATION EVENTS BEGINNING 3 JUNE AND 4 JUNE. THE TRENDLINE IS USED TO DEMONSTRATE THAT DATA BELOW THE IDENTIFIED ZERO-FLOW DEPTH REPRESENT A REALISTIC LEAKAGE RATE FROM THE STILLING WELL (7.6E-6 GPM OR 2 IN/MIN)....... 5-85

FIGURE 40. OUTFLOW HYDROGRAPHS AND DEPTH MEASUREMENTS GENERATED FROM DATA RECORDED IN THE CISTERN (CIS) AND AT THE CISTERN EMERGENCY OUTFLOW (C3) AND FOR THE OUTFLOW TO THE RAIN GARDEN MULTIPLIED BY A FACTOR OF 3.2 (C2) FROM PRECIPITATION BEGINNING 3 JUNE 2007. . 586

FIGURE 41. OUTFLOW HYDROGRAPH FROM MEASUREMENT POINT C3 FROM A RAIN EVENT TOTALING 0.24 INCHES (AVERAGE INTENSITY - 0.03 IN/HR, DURATION - 8.75 HRS, ANTECEDENT DRY CONDITIONS 6.48D, FREQUENCY - > 1-YR 2-HR)

FIGURE 42. COMPARISON OF HYDROGRAPH SHAPES GENERATED FROM DATA RECORDED AT MONITORING POINTS DP3, C3, RG, AND CIS FROM PRECIPITATION BEGINNING 22 DECEMBER 2006. 5-89

FIGURE 43. COMPARISON OF HYDROGRAPH SHAPES GENERATED FROM DATA RECORDED AT MONITORING POINTS DP3, DP4, AND RG FROM PRECIPITATION BEGINNING 22 DECEMBER 2006. 5-89

FIGURE 44. DETERMINATION OF ZERO-FLOW DEPTH FOR THE WEIR AT THE BIOSWALE (BS).... $5-91$

FIGURE 45. RUNOFF HYDROGRAPH GENERATED FROM DATA RECORDED AT THE WEIR BELOW THE BIOSWALE (BS) FROM PRECIPITATION BEGINNING 3 JUNE 2007. $5-92$ 
FIGURE 46. RUNOFF HYDROGRAPHS GENERATED FROM DATA RECORDED AT THE BIOSWALE (BS) AND DP3 FROM PRECIPITATION BEGINNING 4 JUNE 2007.

Figure 47. OUTFLOW HYDROGRAPH FROM THE ORIFICE (ORI). PRECIPITATION EVENTS BEGINNING 3 AND 4 JUNE 2007 ARE COMBINED. $5-94$

Figure 48. CHANGE IN ELEVATION BETWEE THE RIVER STAGE ADJACENT TO THE GAINESVILLE SITE AND THE ORIFICE AT MEASURING POINT ORI. PRECIPITATION EVENTS BEGINNING 3 AND 4 JunE 2007 ARE COMBINED. 5-94

FIGURE 49. RESULTS SUMMARY FOR PERCENT RETENTION EXPERIENCED AT THE WEST OUTFALL (DP3), NORTHEAST OUTFALL (DP4), AND THE BIOSWALE (BS).

FIGURE 50. PROPORTION OF INFLOW TO THE CISTERN FROM RAIN EVENT BEGINNING 3 JUNE 2007 (0.8 INCHES, 20 HOURS, 0.04 IN/HR). 5-101

FIGURE 51. PROPORTION OF OUTFLOW FROM THE CISTERN FROM PRECIPITATION EVENT BEGINNING 3 JUNE 2007 (0.8 INCHES, 20 HOURS, 0.04 IN/HR) 5-101 


\section{List of Tables}

TABLE 1. IN-LINE, CLOSED PIPE FLOW MEASUREMENT TECHNOLOGIES REVIEWED FOR THE MONITORING SYSTEM AT THE GAINESVILLE SITE.

TABLE 2. IN-LINE, OPEN PIPE FLOW MEASUREMENT TECHNOLOGIES REVIEWED FOR THE MEASUREMENT SYSTEM AT THE GAINESVILLE SITE.

TABLE 3. IN-LINE, COMBINED FLOW MEASUREMENT TECHNOLOGIES REVIEWED FOR THE MEASUREMENT SYSTEM AT THE GAINESVILLE SITE.

TABLE 4. FUNCTIONALITY OF FLOW MEASUREMENT TECHNOLOGIES WITH RESPECT TO THE GAINESVILLE SITE AND PERTINENT TO ANY UNDERDRAINED LID SYSTEM. DATA HEREIN IS BASED UPON THE AUTHOR’S TECHNICAL REVIEW. 3-36

TABLE 5. EXISTING PIPE DIAMETERS AND SLOPES AT STILLING WELL MONITORING LOCATIONS IN GAINESVILLE AND THEIR EXPECTED MAXIMUM FLOW RATES FOR A 1-YR, 2-HR STORM EVENT AS COMPARED TO FULL PIPE FLOW RATES. PEAK FLOWRATES ARE BASED UPON THE AUTHOR'S RATIONAL METHOD CALCULATIONS. $3-37$

TABLE 6. WAVE AMPLITUDE DURING SUPERCRITICAL, UNIFORM FLOW WATER SURFACE PROFILE MEASUREMENTS.

TABLE 7. SUBCATCHMENT CHARACTERISTICS WITH RESPECT TO MONITORING POINTS. DATA WERE GENERATED WITH AUTOCAD FILES CREATED BY WETLAND STUDIES AND SOLUTIONS, INC.

TABLE 8. SLOPE AND DIAMETER DATA GENERATED FOR THE CALCULATION OF FLOW FROM DEPTH DATA PROVIDED AT EACH STILLING-WELL-GAGED MEASUREMENT POINT, AND THE PIPE LENGTH USED FOR GENERATION OF THE SLOPE DATA.

TABLE 9. HYDROLOGIC CHARACTERISTICS OF PRECIPITATION AND DP4 SUBWATERSHED. RANGES ARE GENERATED BY ADJUSTING THE ZERO-FLOW DEPTH BY +/- 0.03 INCHES. $5-71$

TABLE 10. HYDROLOGIC CHARACTERISTICS OF PRECIPITATION AND DP3 SUBWATERSHED. $5-73$

TABLE 11. HYDROLOGIC CHARACTERISTICS OF PRECIPITATION AND GR WATERSHED INCLUDING THE EFFECTS OF IRRIGATION. RANGES ARE GENERATED BY ADJUSTING THE ZERO-FLOW DEPTH BY +/- 0.03 INCHES. 5-82 
TABLE 12. CISTERN WATER BALANCE FOR PRECIPITATION EVENT BEGINNING 3 JUNE.

TABLE 13. HYDROLOGIC CHARACTERISTICS OF THE BIOSWALE (BS) WATERSHED ASSUMING A WEIR HEIGHT OF 5.0 INCHES. $5-92$

TABLE 14. PRECIPITATION CHARACTERISTICS FOR STORM EVENTS BEGINNING ON THE FOLLOWING DATES IN THE YEAR 2007

TABLE 15. CURVE NUMBERS (CN) AND RATIONAL METHOD C-VALUES GENERATED FROM FIELD DATA AT THE GAINESVILLE Site COMPARED TO C-VALUES USED By URBAN ENGINEERING \& AsSoCiATES (2004) IN THE SITE DESIGN. 5-103

TABLE 16. SUMMARY GENERATED OF LID MODELS APPLICABLE TO THE GAINESVILLE SITE AND OTHER SITE-

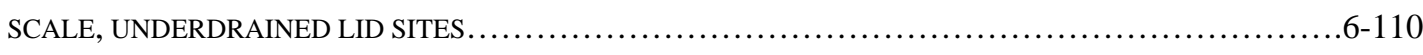




\section{Introduction}

Low impact development (LID) is an on-site stormwater management technique for capturing runoff, controlling rates of discharge, and reducing peak flows. LID systems replace curb-and-gutter conveyance with a distributed network of small-scale, on-site features. LID technologies include pervious pavement, rain gardens ${ }^{1}$, vegetated swales, and green roofs that foster hydrologic processes that can include various combinations of retention, infiltration, evaporation, transpiration, groundwater recharge, and storage.

LID is being used increasingly in response to the effects of municipal development: overburdened storm sewers, combined sewer overflows (CSOs), downstream flooding, streambank sloughing, and reduction of groundwater recharge. Limitations of traditional control measures, such as detention basins as studied by Emerson et al. (2005), have generated interest in developing alternatives to conventional practices. Recent prototypical projects include the Kansas City KC-One (Almai and Ports 2004), Dane County, Wisconsin St. Francis subdivision (Morzaria-Luna et al. 2004), and Milwaukee Metropolitan Sewerage District (MMSD) recent regulations (Koch 2005).

$\mathrm{KC}-\mathrm{One}$ is a comprehensive citywide stormwater management mission to create a single coordinated program that establishes stormwater management priorities, provides timelines and schedules, clarifies city responsibilities, and recommends funding sources. The plan objectives include: flood control, water quality management, natural resource

${ }^{1}$ Rain gardens consist of soil media (potentially stratified) with a high-infiltration capacity, and they are vegetated. They accept stormwater runoff from the upstream catchment or rooftops. Ponding is generally designed to occur up to a depth equal to the inundation constraints of the vegetation. Rain gardens may also be called bioretention cells, biodetention cells, and bioinfiltration cells. Incorporation of an underdrain sometimes distinguishes the latter two terms. 
protection, and "minimizing the adverse impacts from new developments" (Almai and Ports 2004).

The St. Francis subdivision is a prototype for the implementation of stormwater management ordinances that require LID techniques. Of note is that the water quality monitoring data from the site has contributed to the establishment of both stormwater quantity and quality ordinances, the first in Wisconsin to address both. In retrospect, Morzaria-Luna et al. (2004) found that the ordinance and governance structure were the biggest obstacles to implementation of bioretention techniques. These ordinances precluded the replacement of traditional practices with bioretention. Instead, bioretention was implemented in addition to traditional practices. Rain gardens could not be included in the plans because maintenance requirements could not be forced on the homeowners due to deed restrictions. However, homeowners are presented the option to have a rain garden constructed on their property at no cost and with provision for maintenance instruction (Morzaria-Luna et al. 2004).

The MMSD has implemented new site-scale stormwater management regulations for any development or redevelopment that causes an increase in the impervious surface area of a half-acre or more. Two alternative design approaches are allowed: 1) the Unit Release Rate (URR) or 2) the Volumetric Design Procedure (VDP). The URR regulation requires stormwater management plans to demonstrate that peak flows will not exceed 0.5 and 0.15 cfs /ac for the $1 \%$ and $50 \%$ annual exceedance probability storms, respectively. The VDP requires that the runoff volume does not exceed the predevelopment runoff volume during a certain critical period of a design storm event. Critical periods and design storms have been previously identified in the region of the MMSD (Koch 2005). 
LID is also being recognized for its capacity for water quality treatment. Mechanisms for treatment may include sediment trapping, nutrient uptake, and chemical or biological degradation of nutrients or heavy metals. Hseih and Davis (2005) studied nutrient removal in 18 bioretention columns and six existing bioretention field sites. Kim et al. (2003) studied a rain garden design that induces a saturated zone for improved nitrate removal. Dietz and Clausen (2006) studied nitrogen and phosphorus uptake in two different rain garden designs, one of which was related to the Kim et al. (2003) design. Hunt et al. (2006) and Mason et al. (1999) also studied nutrient removal in bioretention. The studies conducted by Hseih and Davis (2005) and Mason et al. (1999) also studied removal of heavy metals.

Little is known, from a design perspective, about the volume and flow control provided by specific LID features, and even less is understood about water quality treatment. MMSD URR and VDP regulations result in added costs to construction, so inaccurately accounting for the benefits of LID has economic repercussions (Koch 2005). Conservative designs for water quantity control are either guided loosely by simple water balances, infiltration rates, and void space calculations; or by basic rainfall-runoff transformation equations such as the rational method or the Natural Resources Conservation Service (NRCS) Curve Number (CN) model (Wurbs and James 2002). The most highly referenced and utilized set of design guidelines, Prince George's County, Maryland LID design manual, uses Technical Release (TR) - 55 as its principle model (PGCM 1997). The MMSD LID Quicksheet (implemented September 2005) was established based on a variation of TR-20 to account for the retention and peak flow reduction benefits of LID (Koch 2005). The Site Evaluation Tool (SET) model also uses the NRCS unit hydrograph approach for design and decision-support (Job 2007). Prince George's County, Maryland also developed the Best 
Management Practices (BMP) Module to quasi-mechanistically simulate LID systems (Cheng et al. 2004).

Academic researchers are studying the mechanisms driving LID systems and models applicable to the systems. Controlled settings for research purposes are more frequently at the laboratory scale, and studies are conducted on individual LID components rather than as an integrated system; for example, bioretention columns studies (Hseih and Davis 2005), rain garden studies (Dietz and Clausen 2006), or bioswale revegetation studies (Mazer et al. 2001). Research-focused modeling is being conducted from a variety of approaches, including a unit-process based approach (Davis 2007) or relating bioretention to groundwater flow and recharge using RECARGA (Dussaillant et al. 2004).

LID system design and installation is currently proliferated by innovative local governments and consulting firms. In addition, homeowners are installing rain gardens and rain barrels. However, LID systems do not yet have the strong scientific foundation that conventional stormwater management systems have. Design and performance prediction are dependent upon field data from LID installations and effective hydrologic models. Of particular interest is the ability to retrofit existing urban centers with compact LID techniques such that the hydrologic benefits are effective and predictable.

The project presented here involves the design and installation of a flow monitoring system for an integrated LID underdrained stormwater management system on a 3.87-ac site in northern Virginia (City of Gainesville). The design techniques used are amenable to urban retrofits. This thesis begins with a review of previous work in the field of LID (Chapter 2) and the design and installation of the LID monitoring system (Chapter 3). Chapter 4 is a sensitivity analysis and calibration of the monitoring system. Preliminary results illustrative of the hydrologic performance of the LID site features are then presented in Chapter 5. 
Chapter 6 consists of a review of hydrologic models with specific applicability to constraints at the Gainesville site and other site-scale LID installations. Each chapter contains specific conclusions related to the findings therein. Concluding remarks are made in Chapter 7 regarding the contributions of this research to overall LID research needs. 


\section{Previous Work}

This chapter identifies previous work in the field of LID and, in some cases, suggests topics that lack substantial research. Representative studies are organized by subject area. Additional details and findings specifically related to the Gainesville study are referenced throughout later chapters.

\subsection{Individual LID Components}

Several studies have provided valuable information on individual LID techniques. Robert Traver constructed a bioinfiltration traffic island at Villanova University that has led to both monitoring and modeling studies (Heasom 2005). For the purposes of studying pollutant retention in bioretention, Dietz and Clausen (2006) installed two rain gardens based upon the Prince George’s County Bioretention Manual (PGCM 1993). Barber et al. (2003) constructed a full-scale bioswale, for monitoring and modeling. These studies have increased the depth of knowledge in individual LID systems. However, few studies have addressed more than one LID component at a time with respect to the variable hydrologic impacts of each or the impacts of one LID feature on another occurring downstream.

\subsection{Water Quantity Control}

Water quantity control has been the primary research area in LID systems. Dietz and Clausen (2006) measured the retention capacity of underdrained rain gardens, and overall the systems retained $3.7 \%$ of all inflow in a two-year period. The retention was assumed to be through evapotranspiration. In contrast, a study conducted in Burnsville, Minnesota by Barr Engineering Company identified an approximately $82 \%$ reduction in runoff (compared to a traditional stormwater management system) from a series of 17 rain gardens on 14 adjacent properties (Trimbath 2006). These systems were designed to capture street runoff in many 
cases through cutting the curbs between the curbside rain gardens and the street pavement. No underdrains were used (see Section 2.3 Paragraph 1 for a description of the use underdrains). Runoff reduction was mostly through infiltration.

A variety of causes exist for discrepancies in runoff reductions. Objectives vary among LID designs. Some prioritize water retention through groundwater recharge or evapotranspiration, and others optimize water detention and decreased flow rates off the site. Some designs include underdrains. In addition, site conditions including topography, existing soils, and design soils vary widely. Finally, there exists a recent understanding that the extent of directly connected impervious area has a greater impact on runoff hydrology than the total impervious area within any given watershed (Lee and Heaney 2003). This principle arguably revolutionizes the way an engineer approaches an urban retrofit: instead of determining increased infiltration infeasible due to limited acreage for contiguous green space, impervious areas can be spliced with runoff-accepting traffic islands and bioswales.

\subsection{Mechanisms of LID System Function}

Physical processes within LID systems are being studied in the field and laboratory. Barber et al. (2003) studied the vadose zone of an underdrained bioswale to determine the parameters affecting runoff infiltration behavior (particularly peak runoff reduction and delay time). Parameters included slope, antecedent moisture conditions, storm size and distribution, and infiltration media. Abida and Sabourin (2006) have recently analyzed the effects of orifice size and depth of flow on exfiltration rates from entrenched perforated pipes beneath bioswales. The purpose of their proposed perforated underdrain design is meant to enhance infiltration within the surrounding trench through exfiltration from the underdrain. Alternatively, perforated underdrains are used strictly to capture subsurface flow beneath LID features (e.g., bioswales, biodetention cells) and convey the flow to a single 
discharge point. This technique is generally employed in regions where clay soils preclude sufficient infiltration.

Another important physical process within LID infiltration devices is temporal and spatial clogging of the media. Clogging of the subsurface and sedimentation on the top layer have not been widely addressed in relation to LID technologies (Barber et al. 2003). Changes in hydraulic conductivity due to development of biofilms have been more widely studied in relation to wastewater management, for example Beach et al. (2005). A study of the longterm evolution of a set of bioinfiltration basins that were 10 to 21 years old found sufficient infiltration capacities and low hydraulic resistance. The study did not indicate significant trends between age, hydraulic resistance, and soil and groundwater pollution relating to system failure (Dechesne et al. 2005). The dynamic impact of root growth on infiltration rates and hydraulic conductivity within the organic layer of a bioinfiltration basin is unknown.

\subsection{Post-Construction Monitoring}

In general, data is not gathered from integrated LID installations after construction (Clar 2005), though these sites are constructed with specific hydrologic design goals and calculations. In particular, data of this kind are rarely published in peer-reviewed journals and are more commonly published in conference proceedings and layman's journals (e.g., Cheng et al. 2003 and Trimbath 2006).

Schneider and McCuen (2006) have evaluated the extent of data that is needed from individual BMPs to accurately assess if they are meeting design goals. The evaluation methodology applied to a cistern design concludes that approximately 92 storm events are needed for proper understanding of system performance. Few installations have measured 
that number of storm events, if any. Time and cost are the primary causes for this lack of data.

LID research is more frequently conducted in laboratories, on an individual LID feature, or through computer models. For example, Villarreal and Bengtsson (2004) used modeling instead of monitoring to determine the watershed-wide runoff control provided by infiltration BMPs. This is a common method to get informed results at a lower cost.

The lack of data collection may mostly be a result of the challenges to obtaining reliable measurements from an integrated stormwater management system that has variable physical flow regimes ranging from overland sheet flow to underground, piped flow. Each installation has unique constraints due to existing topography, soils, geology, and local stormwater management and water resource regulations.

Monitoring LID installations requires a variety of procedures and instrumentation, either in retrofit situations or, less frequently, integrated into site construction. Due to the variability of site characteristics and LID components, applying reliable monitoring practices is a complex endeavor. Flow regimes throughout a system may include open channel flow in both natural channels (e.g., bioswales) and PVC pipe of variable size; sheet flow; and full pipe flow; as well as dynamic storage volumes and interaction between system components (e.g., a cistern with multiple free flowing inputs and outputs as well as automated withdrawals). After beginning with a review of 150 potential field sites for data collection, North Carolina State University (NCSU) researchers found only 7 sites fitting research criteria for amenability to monitoring (Smith et al. 2005). Brown et al. (1995) finds openchannel flow monitoring, in particular, a challenging flow regime from which to obtain sufficiently accurate and precise data. 
Select study sites provide some information on monitoring instrumentation and measurement methodologies. NCSU researchers utilize a network of weir boxes catching the outflow from aboveground pipe outlets as well as the ISCO 4230 flow-weighted sampler to gather water samples while measuring flow rates throughout a storm event (Smith et al. 2005). Burch and Phillips (1995) discuss and recommend the technology, application, and accuracy of acoustic multi-path transit-time flowmeters. Villanova researchers utilize a tipping-bucket rain gage, ultrasonic level sensor, V-notch weir, soil moisture meters, and lysimeters (Heasom 2005). Flow measurement devices are challenging to adapt to pipes flowing partially full (Brown et al. 1995). Measurements for model validation of a watershed model were taken every five minutes, providing helpful guidance for scaling up the monitoring site and measurement methods (Heasom 2005).

One recent action to address the need for field data and technical documentation for LID installations is an online database of monitoring results submitted by researchers and practitioners, the International Stormwater Best Management Practices Database at www.bmpdatabase.org. The site was initiated in 1996 by the American Society of Civil Engineers (ASCE) and U.S. Environmental Protection Agency and is now also sponsored by, among others, the Water Environment Research Foundation, Environmental and Water Resources Institute of the ASCE, Federal Highway Administration, and American Public Works Association. The database includes technical documents and software to better inform BMP design and implementation and to coordinate and promote scientifically based data collection and management. The site strives to standardize BMP monitoring, reporting, and performance protocols. It is anticipated to be an effective collaborative to coordinate the efforts of the BMP design and implementation community. 
Post-construction monitoring is equally important with regard to the stability of the LID feature and its physical characteristics. Mazer et al. (2001) published an article in Ecological Engineering that took a unique approach to post-construction monitoring. The authors monitored the environmental factors that affect the establishment of bioswale vegetation. The need for vegetation establishment (particularly native vegetation) is known among ecologists, but the techniques for doing so are not frequently studied.

\subsection{Models Applied to Design and Study}

A few models are currently being employed for design of LID systems and/or for research. Many of these models are mentioned here to provide an overview of progress and challenges in LID modeling today. Section 6 identifies hydrologic models that are specifically applicable to the Gainesville site.

Most of the models for LID design/decision-support are empirically based. The Prince George's County LID design manual is the most highly referenced and utilized set of design guidelines. It employs the U.S. Army Corps of Engineers empirically based Technical Release - 55 as its principle hydrologic model. The use of traditional, empirical hydrologic models has produced successful installations but arguably perpetuate overly conservative designs because the applicability of these models to small-scale LID systems has not yet been scientifically confirmed. Pembroke Woods in Fredericksburg, Maryland was the first subdivision comprehensively designed in accordance with the Prince George's County LID design manual (PGCM 1997).

Another empirical model specifically created for LID comes out of Tetra Tech, Inc. and is called Site Evaluation Tool or SET (Job 2007). The model is spreadsheet-based and uses the NRCS unit hydrograph approach with a water quality (mainly event mean 
concentration) component. No hydrologic routing is incorporated within the model, and it is suitable only for post-development modeling. It was calibrated with the HSPF model.

Water resources engineers use the NRCS Curve Number model and TR-55 almost as frequently as the rational method for LID design today. Valavala et al. (2006) conducted a set of field studies to calculate area-rated rational method C-values for Portland cement porous concrete.

A few models incorporate to varying degrees physically based mechanisms for runoff generation from LID systems. Prince George's County incorporates some physical characteristics (e.g., infiltration rates, effective porosity) into LID modeling with the creation of the BMP module (Cheng et al. 2004). RECARGA, an adaptation of the Richards Equation (Dussaillant et al. 2004) and the Hydrologic Engineering Center Hydrologic Modeling System (HEC-HMS) (Scharffenberg and Fleming 2006) are two additional models that are physically based. The latter two models tend to require a large number of parameter values and/or analytical solutions such as that achieved by Chen et al. (2001) for the Richards Equation. The LIFE ${ }^{\mathrm{TM}}$ model (Low Impact Feasibility Evaluation Model) was developed by CH2MHill (Patwardham et al. 2004). The LIFE ${ }^{\mathrm{TM}}$ model is a continuoussimulation model and uses a volume-based approach for evaluating LID design options. The model is based on physical processes that occur in individual LID components (e.g., permeable pavers, green roofs, bioswales, and stormwater planters) (Patwardham et al. 2004).

The Vadose Zone Model out of Penn State University is a two-dimensional model and includes parameters such as organic matter content, soil $\mathrm{pH}$, permeability, and vadose zone thickness (Clark 2007). The water quality component treats pollutants as separate ions, modeling mechanisms such as ion exchange, hydrolysis, complexation, adsorption, 
absorption, and volatilization. The model is largely based on mechanisms used in agricultural models of pesticide fate.

Many models are used for LID design but few have been tested. The Villanova traffic island is one of the few sites for which a model has been developed enabling comparison to field measurements. Surface flow from turf and impervious asphalt flows across the watershed in gutter and pipe flow and is discharged across the surface of the bioinfiltration cell (rain garden). Data from the site show high correlation with the HECHMS model predictions (Heasom 2005). For modeling purposes, rapid initial infiltration within the rain garden is represented as a diversion element in HEC-HMS. Subsequent steady infiltration and outflow (weir flow) are modeled using a reservoir component. Each steady infiltration rate is related to a particular storage and stage based on prior field measurements. For each steady infiltration value for a given climate (based on month of the year), the model can predict water surface elevations and outflow due to infiltration and flow over the weir. Infiltration within the catchment is modeled using the Green-Ampt loss model (Wurbs and James 2002).

Some new models are being investigated and/or employed for LID and were recently presented at the $2^{\text {nd }}$ National Low Impact Development Conference in March 2007. Villanova University and Mississippi State University are working on modeling methodologies and model development (He 2007; Wilkerson 2007). Davis (2007) is investigating (with Dr. He) bioretention modeling through the methods of conventional unit process modeling using a model called COMSOL (COMSOL, Inc. 2007). Wilkerson has been involved in the creation of LATIS, a decision support system for site-scale LID techniques. Jarrett et al. (2007) developed a new spreadsheet based model that has been 
applied to green roof hydrology. A mechanistic model introduced by Mikula et al. (2007) is specifically designed for unsaturated flow in the vadose zone.

Christianson et al. (2004) recently developed a model that combines the removal of nutrients with infiltration, sorption of metals, and degradation of organic compounds in bioretention cells. It is a rare model in that it considers phytoremediation along with other more conventional processes for pollution treatment. The model uses the TR-55 rainfallrunoff model combined with evapotranspiration, rainfall probability, phytoremediation, and biodegradation.

The vast majority of LID site designs are based on design storms and event-based simulation, which precludes a full understanding of system response to inter-event periods and antecedent moisture conditions. Some models are capable of accounting for variations in initial water content distributions, including HEC-HMS, which includes a Soil Moisture Accounting model (Fleming 2004) and RECARGA.

Kronaveter et al. (2001) is one of a few researchers to create a model that functions at the so-called micro-scale, as small as individual housing lots. The hydrological micromodel (HMM) is partially physically based and is capable of modeling the site-scale common to LID and extrapolating information from the model to evaluate effects on what the authors call the neighborhood scale.

Modeling of stormwater infiltration devices is also occurring at the watershed scale. Several studies have been published on the optimal location of detention ponds for water quantity control (Mays and Bedient 1982; Zhen et al. 2004). Accordingly, a new set of literature is identifying methods to optimally locate bioretention facilities for stormwater management (Perez-Pedini et al. 2005). 


\subsection{Long-Term Analyses}

Due to the novelty of LID techniques, long-term performance studies do not exist (Coffman 2002). Studies that assure continuous hydrologic analyses are important to obtain long-term reliability data.

While industry continues to grow in its confidence of LID, long-term economic analyses are also needed. Currently, rough estimates and conflicting comparisons between conventional and LID stormwater management system costs exist. Economic cost estimates vary widely for capital, maintenance, environmental, social, and renewal costs.

\subsection{Water Quality Treatment}

Pollutant treatment in a bioretention device with organics in the subsoil (e.g., rain gardens) occurs through many mechanisms that are dependent upon the constituent. Major constituents include nutrient and heavy metals, specifically, nitrogen, phosphorus, zinc, lead, and copper.

\subsubsection{Nitrogen}

The nitrogen cycle in a terrestrial ecosystem represents the conversion of nitrogen into its many forms (Van Veen et al. 1978). Ammonium $\left(\mathrm{NH}_{4}^{+}\right)$is nitrified (oxidized) by aerobic bacteria and converted into nitrite $\left(\mathrm{NO}_{2}{ }^{-}\right)$and then nitrate $\left(\mathrm{NO}_{3}{ }^{-}\right)$. Nitrate can leach through the system readily (Dietz and Clausen 2006). Alternatively, it can become denitrified and released into the atmosphere as nitrogen $\left(\mathrm{N}_{2}\right)$ and nitrous oxide $\left(\mathrm{N}_{2} \mathrm{O}\right)$. Nitrite/ nitrate and ammonium can remain in the soil due to biological uptake, sometimes called immobilization. The organic nitrogen pool in the biota can be mineralized back into ammonium. 
Since the conversion and loss of nitrate through denitrification occurs only under anoxic conditions and nitrate ions leach readily, researchers like Kim et al. (2003) and Dietz and Clausen (2006) are testing rain garden designs that induce a saturated zone in the lower soil layers. Sometimes this is done by installing an overdrain; putting a 90-degree upward bend in from the underdrain before running the pipe to the discharge point (Kim et al. 2003). Dietz and Clausen (2006) observed an increase in denitrification in the partially saturated rain garden as compared to the completely unsaturated one. Total nitrogen (TN) (ammonium, nitrate and nitrite) was 51\% retained by both rain gardens for two years (only one rain garden was saturated for one year, otherwise they were unsaturated); mulch retained $33 \%$ of the TN inputs and plants retained only $0.3 \%$. Results show that the soil was actually a source for nitrogen while mulch acted as a sink. In the Hunt et al. (2006) rain gardens, annual TN reduction was $40 \%$, but one winter more nitrogen left the rain garden than entered it. Certainly the variable presence of aerobic and anaerobic conditions is a cause for the variable data across these studies.

Mason et al. (1999) also studied the fate of nitrogen (and heavy metals) through roof runoff infiltration. Results indicated that nitrate acted essentially conservatively, and ammonium decreased due to nitrification. In a study by Kim et al. (2003), in which they utilized an overdrain to maintain saturated conditions at the bottom of the bioretention cell, nitrate and nitrite mass removals of 70 to $80 \%$ were achieved.

\subsubsection{Phosphorus}

Phosphorus can be removed by adsorption. If there is a major source of iron, phosphorus in wet conditions could also be settled out with iron oxides. This could occur during ponding or in pore spaces. If plant litter accumulates on the surface of the bioretention cell, phosphorus can be leached by infiltration (Hunt et al. 2006). 
In particular, phosphorus adsorbs to mulch as a top layer on the rain garden; in the Dietz and Clausen (2006) rain gardens, the mulch retained $117 \%$ of the total phosphorus inputs. However, Dietz and Clausen (2006) found rain garden soils (below the mulch) to be a source of phosphorus such that concentrations increased from inflow to outflow.

Practitioners are warned to choose soils with a low phosphorus index to either avoid this situation completely or at least minimize soil stabilization time (Hunt et al. 2006). Hseih and Davis (2005) conducted a study to address this issue directly by testing a variety of bioretention soils and stratifications such that water quality treatment (also including nitrogen, lead, and TSS, for example) is maximized. They measured pollutant uptake in 18 bioretention columns without plants and six existing bioretention field sites. The column tests (six hours in duration) resulted in varying levels of phosphorus removal (up to $99 \%$ ). Not surprisingly, the authors found phosphorus removal rates in mulch to be high and recommend mulch as the top layer in bioretention media.

\subsubsection{Heavy Metals (Copper, Lead, and Zinc)}

Many factors account for the fate and transport of metals. Copper, lead, and zinc are some commonly considered constituents in terrestrial systems. In general, the retention of metals in soils can occur through adsorption on the surfaces of soil minerals and organic matter or through precipitation. Physical and chemical soil properties, $\mathrm{pH}$, and redox conditions influence metal fate and transport. Microbial processes can mobilize or immobilize heavy metals by their influence on the aforementioned characteristics (Mason et al. 1999). These constituents may also be oxidized in the rhizosphere or the mulch layer.

A two-year study measured that mulch retained copper, lead, and zinc by $98 \%, 36 \%$ and $16 \%$, respectively (Dietz and Clausen 2006). Plants only removed $0.1,0$, and $0.2 \%$ of the inputs, respectively. The data suggested that reducing conditions in the saturated rain garden 
caused zinc to be complexed and, therefore, less mobile. However, copper and lead were retained similarly in both the saturated and unsaturated rain gardens. In a study by Mason et al. (1999), copper was found to be highly mobile as a result of complexation by ligands (compounds that bind to a receptor) in solution, a process that competes with sorption processes. Hunt et al. (2006) observed high (over 80\%) copper, lead, and zinc mass removal from three North Carolina rain gardens.

Some other considerations of bioretention soil properties and their effects on water quality treatment ought to be mentioned. Microbe populations play the primary roles in converting organics and inorganics to energy and nutrients. Total suspended solids (TSS) are readily filtered out of the water through bioretention media; for example, Hseih and Davis (2005) observed TSS removal rates of 72 to $99 \%$. Filter fabrics are increasingly common in bioretention installations and also act as a mechanism for filtering out TSS.

\subsection{Research Needs}

Previous LID research serves as the foundation for future work to improve system function understanding, design, and performance. The following bullets highlight current research needs, essentially a synthesis of Section 2 . The bold bullets represent those to which this study contributes.

- Performance of multiple LID components as an integrated system;

- Increased knowledge of water retention capacity;

- An understanding of the primary physical characteristics that maximize hydrologic performance;

- Improved understanding of the design features that facilitate specific objectives such as groundwater recharge or reduction in peak runoff rates; 
- Standardization of hydrologic performance measurement techniques;

- Understanding the science of spatial and temporal clogging of bioinfiltration features;

- Effectiveness of and applications for underdrained systems;

- In-field post-construction data collection from actual storm events;

- Knowledge of existing technologies amenable to monitoring the wide range of flow regimes exhibited in LID unique from industry standards;

- Evaluation of effects of inter-event periods and antecedent moisture conditions on system performance;

- Effective and accessible (even standardized) modeling tools for stormwater management designers;

- Studies that facilitate long-term analyses to inform LID design lifetime;

- A clearer designation of materials and construction costs and sources of variability;

- Analysis of social and aesthetic benefits;

- A continued understanding of water quality benefits, elucidating inconsistencies found, for example, in nitrogen and phosphorus removal;

- An understanding of the effects of vegetation in LID systems;

- A wider scientific basis for the use of native vegetation and the dissemination of that knowledge. 


\section{Flow Monitoring of an LID Underdrained Stormwater Management Network}

\subsection{Objectives for the Flow Monitoring}

Flow monitoring of an LID underdrained stormwater management network in Gainesville, Virginia, is intended to address portions of the current needs in LID research (listed above). The specific contributions this research makes to science with regard to LID systems are related thereto. The potential for continued research at the Gainesville site is substantial.

The specific objectives related to the development and establishment of a flow monitoring system are:

- Provide a technical review of monitoring instruments amenable to a variety of LID flow regimes encountered in the field;

- Design and install a monitoring system to produce LID hydrologic data for researchers and the general public;

- Conduct laboratory calibration of innovative measurement techniques employed onsite;

- Evaluate the sensitivity of the flow data collection method and results with specific regard to the uniqueness of the underdrained network.

The Gainesville site is of particular significance to LID flow monitoring design and hydrologic performance because of the LID site layout. The 3.87-acre site (described in detail in Section 3.2) is a network of several traditional LID features (e.g., porous pavement, rain garden, green roof, bioswale, cistern, native vegetation). Buried underdrain pipes connect many of the features such that they function in series. Urban areas are most prone to high-intensity hydrologic regimes causing flooding, erosion, and conveyance of pollutants. 
Small urban and suburban building sites need effective compact solutions to on-site stormwater management to reduce rapid conveyance of storm surges. Sites like Gainesville are experimenting with the possibilities of integrated underdrained systems on relatively small sites that are amenable to retrofitting existing sites. An understanding of the effectiveness of these systems is essential to their economic feasibility and implementation. With the onset of stormwater utilities, accuracy in field measurement in particular (either for direct billing or supporting research) is a direct necessity. Consulting firms, townships, and municipalities are also eager to more accurately determine the functionality of their bioretention systems due to the liability of meeting new, stricter stormwater regulations (e.g., Cosgrove and Bergstrom 2001).

\subsection{Site Description}

The integrated LID system on which research is being conducted is located in Gainesville, Virginia, circumscribing the office building of Wetland Studies and Solutions, Inc. (WSSI), an environmental and cultural resources consulting firm (Figure 1). Located in northern Virginia, the new office is a product of the fast-growing District of Columbia suburbs. The adjacent Loudon County was listed $8^{\text {th }}$ among the top 100 fastest-growing U.S. counties by percentage growth (July 1, 2004 to July 1, 2005) and was one of three Virginia counties in the top ten (Christie 2006). 


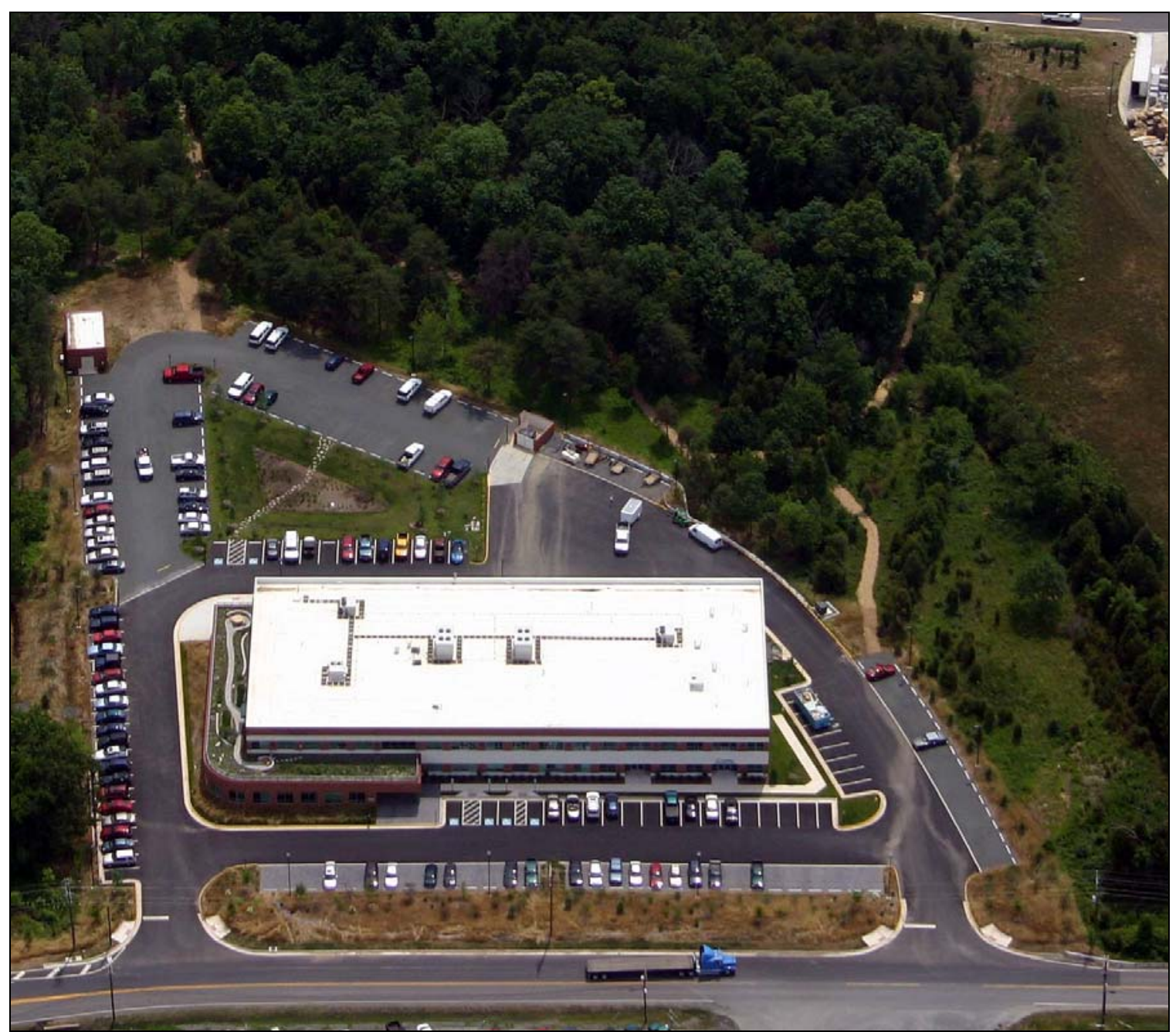

Figure 1. LID monitoring site at Gainesville, Virginia, owned by Wetland Studies and Solutions, Inc. Photo taken June 21, 2006, (Copyright 2006, Roger W. Snyder). 
The LID system, designed by Urban Engineering \& Associates, Inc., was incorporated early in the site design when WSSI moved to Gainesville. The system is a network of a variety of LID components (Figure 2). Each feature is designed to perform certain hydrologic functions. They are listed below.

- Green roof - infiltration, evapotranspiration, detention;

- Cistern - retention for irrigation water source;

- Rain garden - infiltration, evapotranspiration, detention;

- Orifice-controlled gravel bed detention - infiltration, detention, storage;

- Pervious pavement - infiltration, detention;

o GravelPave2 by Invisible Structures, Inc.

o Gravel pavement

o Concrete pavers

- Bioswale - infiltration, evapotranspiration, detention.

Infiltration is an inherent hydrologic process within each system except the cistern. Due to the prevalence of low-permeability, clay soils, northern Virginia LID systems (including this one) usually employ underdrains. Therefore at this site, design goals include reduction in peak runoff rate through primarily detention and storage.

Many of the system components act in series (Figure 3). Those LID features located aboveground (rain garden, green roof, pervious pavement, bioswale) experience inflow from rainfall, irrigation, and runoff from the impervious pavement surrounding them. The extensive underdrain network collects drainage from most LID features and conveys flow through the system, eventually to discharge into the existing floodplain at discharge points 1 and 3. Discharge points 2 and 4 discharge immediately into the adjacent stream. 
A traditional stormwater management facility already services the site. WSSI established the LID system for the following purposes: further reducing impacts to receiving water bodies, education, and research. The site is designed to provide 24 hours of detention for the 1-yr, 24-hour storm (Urban Engineering 2004). The majority of the LID site was designed using the Northern Virginia BMP Handbook (NVPDC and ESI 1992) that uses two conventional rainfall-runoff models: the rational method and the Natural Resource Conservation Service's (NRCS) Curve Number method (see Equations 1 and 2, respectively) (Wurbs and James 2002). Models were used for determining storage requirements to reduce runoff rates toward pre-development values. The site required 50\% removal of phosphorus according to the current version of the Prince William County Design and Construction Standards Manual (PWCDA 1985), and removal estimates were dependent upon the curve number parameters in the NRCS Curve Number model. Overall phosphorus removal was calculated according to Volume 1 of the Virginia State Stormwater Management Handbook (DCR 1999) using weighted curve numbers and surface areas and predicted percent removal from each subwatershed. Predicted phosphorus removal from each land type was obtained from the same handbook (DCR 1999). Urban Engineering \& Associates, Inc. obtained rational method C-values and NRCS model curve numbers for each LID component and landcover type from product manufacturers or literature. 


\section{$Q=C i A$}

$Q$ - Peak outflow (cfs);

C - Rational method coefficient representing watershed

characteristics dependent on rain event recurrence intervals, e.g.,

0.7 represents asphalt and 0.1 represents parks for the 2-year

recurrence interval (Wurbs and James 2002);

$i$ - Peak rainfall intensity for a duration equal to the time of

concentration (in $/ \mathrm{hr})$;

$A$ - Watershed area (acres).

$$
\begin{aligned}
V_{R}= & \frac{(P-0.2 S)^{2}}{(P+0.8 S)}, \\
& S=\frac{1000}{C N}-10, \text { where } P \geq I_{A}=0.2 S
\end{aligned}
$$

$V_{R}$ - Depth of runoff (in);

$P \quad$ - Precipitation depth (in);

$\mathrm{CN}$ - Curve number value representing watershed characteristics, e.g., 98 represents asphalt and 30 represents woods with good ground cover (Wurbs and James 2002);

$I_{A}-$ Initial abstraction (in). 


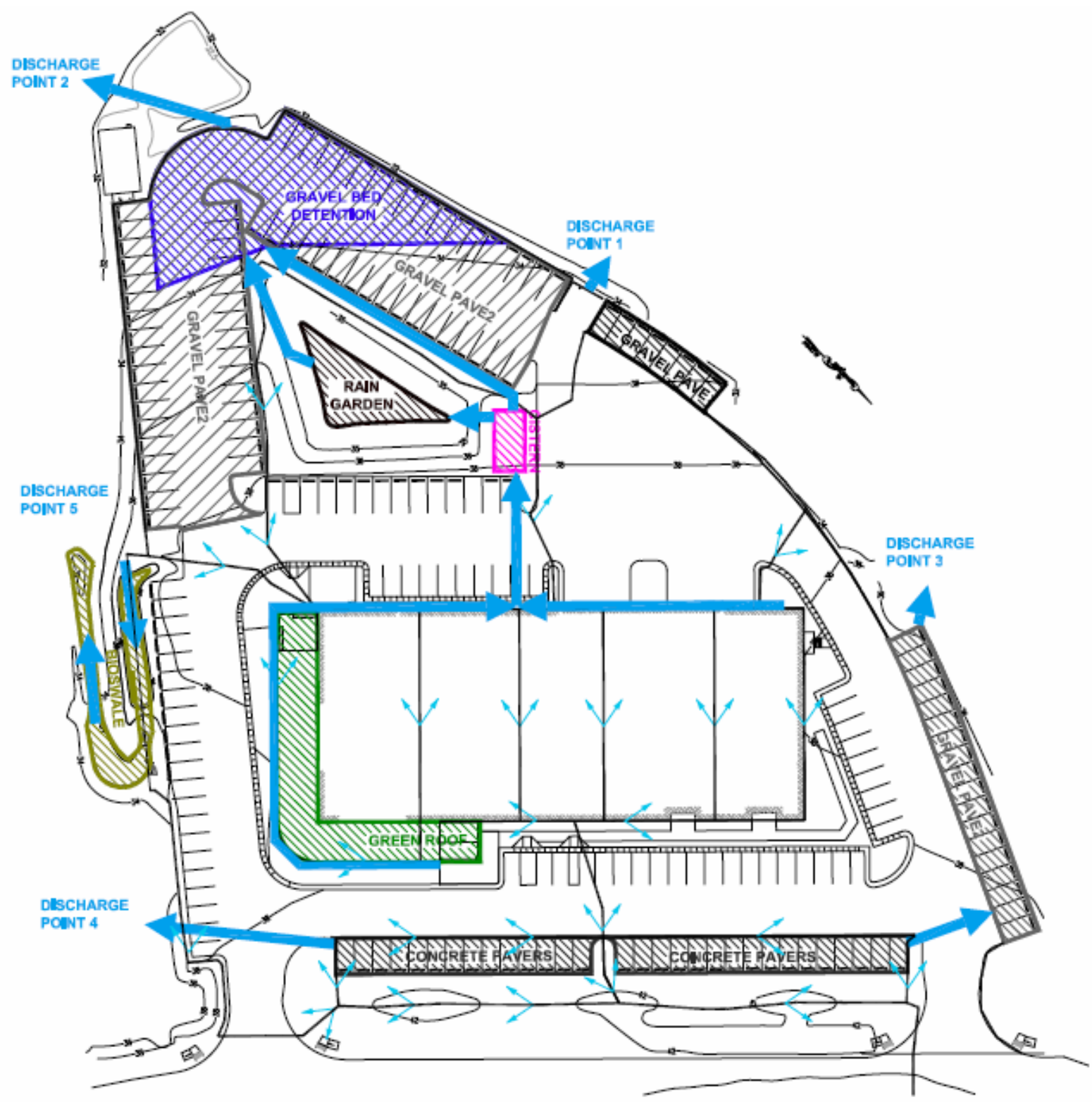

Figure 2. LID system features (hatched areas) and general flow paths (bold blue arrows indicate direction of flow through drains; light blue arrows indicated direction of overland flow in outlined subwatersheds), (Copyright 2006, Wetland Studies and Solutions, Inc.). 


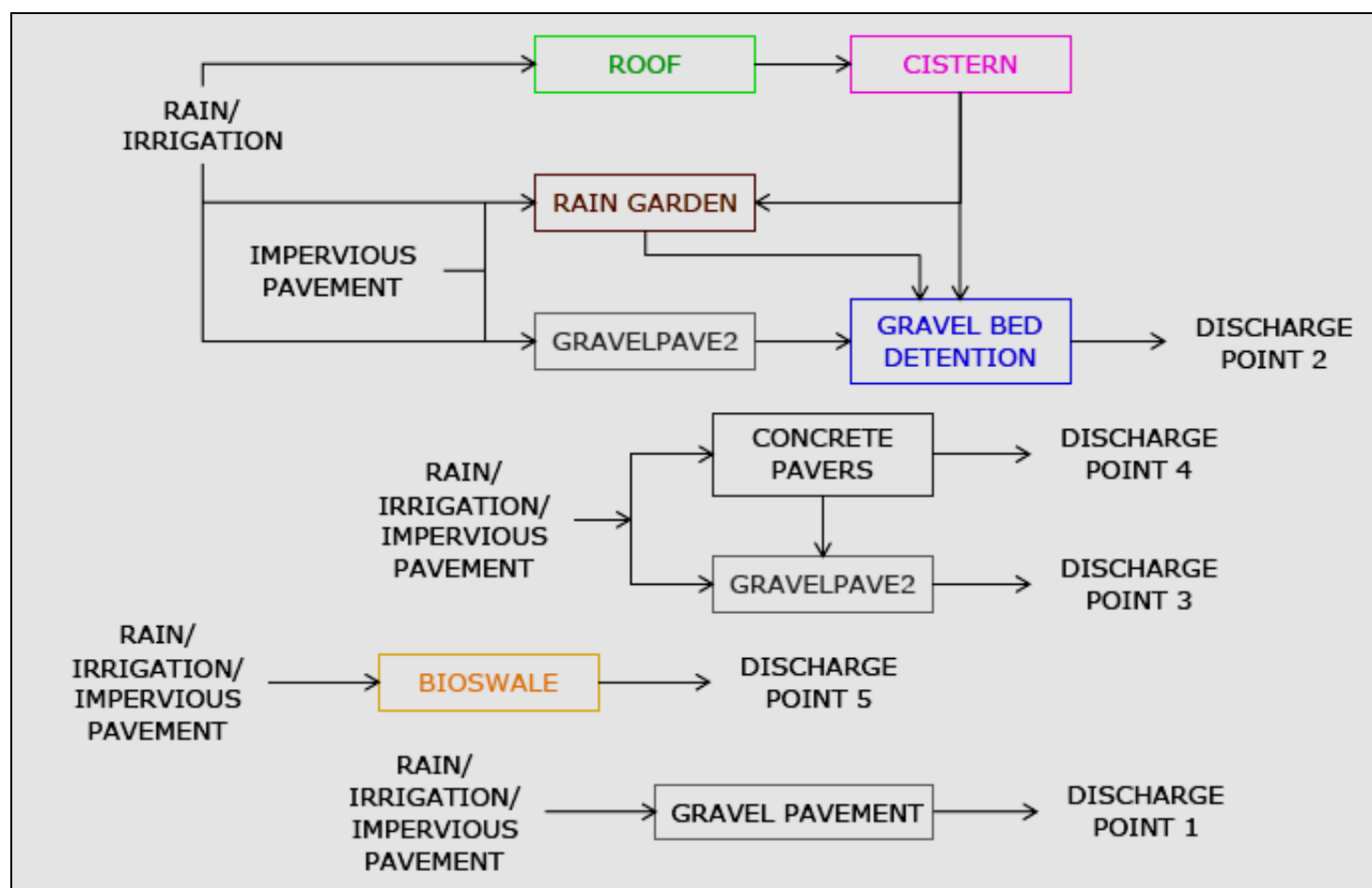

Figure 3. Schematic of flow through LID site in Gainesville, VA, (Copyright 2006, Wetland Studies and Solutions, Inc.).

\subsection{Development and Design of Installed Monitoring System}

\subsubsection{Technical Review of Monitoring Technologies}

In order to design the monitoring regime utilized in Gainesville, information was collected on commercially available flow measurement technologies. Major manufacturers including Marsh-McBirney, Global Water, and Campbell Scientific, and others, develop instruments utilizing a variety of direct and indirect flow measurement principles including Doppler ultrasonic, pressure, propeller rotation, bubbler, and stage-discharge relationships. Each measurement principle is limited to particular flow regimes (e.g., open channel, fullpipe) and constrained by fluid and site characteristics such as total suspended solids or pipe size. Given any combination of constraints there exists a feasible set of physical meters that vary in design according to installation amenability. A $\$ 25,000$ budget was set for sensors, 
data loggers, the communication system, and construction materials. The following are the

details on the available measurement technologies.

\subsubsection{In-line Technology}

Single technologies for closed pipes are those technologies that require full pipe

conditions at all times with few exceptions (see Table 1). Single technologies for open pipes

require open channel conditions (dry to partially full) (see Table 2). Specific manufacturers

have produced flow measurement devices that enable the combination of open channel and

full pipe flow measurement technologies (see Table 3).

Table 1. In-line, closed pipe flow measurement technologies reviewed for the monitoring system at the Gainesville site.

\begin{tabular}{|c|c|}
\hline $\begin{array}{l}\text { Single } \\
\text { Technologies for } \\
\text { Closed Pipes }\end{array}$ & Measurement Mechanism \\
\hline $\begin{array}{l}\text { Electromagnetic } \\
\text { meters }\end{array}$ & $\begin{array}{l}\text { Flow velocity is proportional to the electromagnetic current induced by the flow of an } \\
\text { electrically conductive fluid; }\end{array}$ \\
\hline Transit meters & $\begin{array}{l}\text { Flow velocity is proportional to the difference between the acoustic transit time } \\
\text { traveling upstream and downstream, using ultrasonic technology; }\end{array}$ \\
\hline Doppler meters & $\begin{array}{l}\text { Flow velocity is proportional to frequency shift of acoustic wave reflection off of } \\
\text { particles in the fluid (Doppler effect), using ultrasonic technology; }\end{array}$ \\
\hline Rotameters & $\begin{array}{l}\text { A variable-area measurement technology where velocity is proportional to the level of } \\
\text { a float, as determined by differential density and pressure in vertical, upward flow, }\end{array}$ \\
\hline $\begin{array}{l}\text { Turbine/impeller/ } \\
\text { propeller meters }\end{array}$ & Flow velocity is proportional to angular velocity of rotor; \\
\hline Positive & $\begin{array}{l}\text { Flow rate is related to the number of discrete volumes of fluid passed through a } \\
\text { rotating chamber. }\end{array}$ \\
\hline
\end{tabular}

Table 2. In-line, open pipe flow measurement technologies reviewed for the measurement system at the Gainesville site.

\begin{tabular}{|c|c|}
\hline $\begin{array}{l}\text { Single } \\
\text { Technologies for } \\
\text { Open Pipes }\end{array}$ & Measurement Mechanism \\
\hline Weirs & $\begin{array}{l}\text { A variable-area measurement technology where flow rate is proportional to height of } \\
\text { water above crest of weir; }\end{array}$ \\
\hline Flumes & $\begin{array}{l}\text { A variable-area measurement technology where critical depth is created in the throat } \\
\text { and is proportional to the flow rate. }\end{array}$ \\
\hline $\begin{array}{l}\text { Depth Sensing } \\
\text { Technologies }\end{array}$ & (For independent use or in conjunction with weirs or flumes) \\
\hline Ultras & $\begin{array}{l}\text { Depth is proportional to the time required for the reflection of an acoustic wave to } \\
\text { reach the transmitter; }\end{array}$ \\
\hline Pressure & Depth is proportional to the pressure induced by the water column; \\
\hline & $\begin{array}{l}\text { Depth is proportional to the pressure required to transmit an air bubble through a dry } \\
\text { line into the water column. }\end{array}$ \\
\hline
\end{tabular}


Table 3. In-line, combined flow measurement technologies reviewed for the measurement system at the Gainesville site.

\begin{tabular}{|l|l|l|}
\hline $\begin{array}{l}\text { Combined Technologies for } \\
\text { Closed and Open Pipes }\end{array}$ & Open Pipe Technology & $\begin{array}{l}\text { Closed Pipe } \\
\text { Technology }\end{array}$ \\
\hline $\begin{array}{l}\text { Marsh McBirney Flow-Dar with } \\
\text { surcharge velocity sensor }\end{array}$ & $\begin{array}{l}\text { Doppler ultrasonic velocity meter } \\
\text { and ultrasonic depth sensor }\end{array}$ & $\begin{array}{l}\text { electromagnetic } \\
\text { velocity meter }\end{array}$ \\
\hline $\begin{array}{l}\text { American Sigma 950 } \\
\text { Area-Velocity Sensor }\end{array}$ & $\begin{array}{l}\text { Dopper ultrasonic } \\
\text { velocity meter }\end{array}$ \\
\hline DataGator & bubbler level sensor & Venturi tube \\
\hline
\end{tabular}

\subsubsection{Line Modification}

Two designs were considered to create full pipe conditions at all times as a means to exclude the additional need for open channel flow measurement: the trap system (Figure 4) and the gooseneck system (Figure 5). The idea for the gooseneck system was contributed in part by Lehrer (2006). Both use conventional plumbing fittings and include cleanouts in the design.

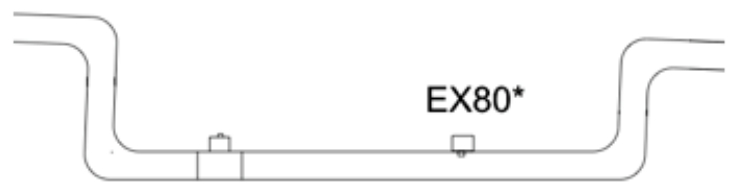

Figure 4. Line modification measurement system (trap system) that creates full pipe conditions and utilizes a measurement technology such as the Global Water EX80 electromagnetic meter as pictured here. A cleanout is included in the design. Flow is from left to right.

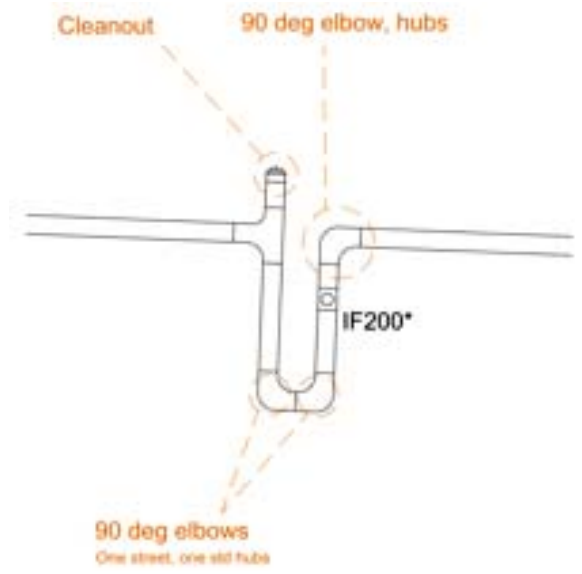

Figure 5. Line modification measurement system (gooseneck system) that creates full pipe, pressurized, upward flow conditions and utilizes a measurement technology* such as the Global Water IF200 impeller meter. Flow is from left to right. 


\subsubsection{Monitoring Locations}

Monitoring points were determined based upon an iterative process that included identifying access points to the flow network, the existence of feasible measurement instrumentation for each monitoring point (e.g., access configuration and flow regime), and locations that enable inflow and outflow data from each LID technique. If inflow and outflow measurements are not feasible for any single LID component, then monitoring locations enable back calculation of the desired data. Figure 6 illustrates the location of each monitoring site. Figure 6 also illustrates subwatersheds that are designated by solid black lines and corresponding arrows indicating the direction of flow. A brief description of each monitoring point is listed below (where appropriate, pipe slopes and diameters of monitoring locations can be found in Chapter 5, Table 8). Precipitation data is collected on site in 6-minute intervals from a tipping bucket rain gage.

- DP2, DP3, DP4 - Discharge Points. These monitoring locations are the three end-of-pipe discharges from the site. DP3 and DP4 are both near the outlet of near-surface polyvinyl chloride (PVC) pipe that is connected to underdrain highdensity polyethylene (HDPE) pipe beneath LID features. DP2 is located in the streambed for reference stream gage measurements. NOTE: DP1 was removed from monitoring and from subsequent diagrams in this document due to its underdrain connection with DP2 prior to which water can exfiltrate into the adjacent floodplain. The underdrain is inaccessible because it lies under a main thoroughfare for site utility lines.

- ORI - Orifice. This monitoring location is within the manhole that contains a 1.625-inch orifice on the downstream side to control the rate of release of water 
stored in the upstream gravel bed detention. The water level within the manhole is equal to the water level within the gravel bed detention (disregarding potential time-variability due to routing), enabling calculation of storage volume within the gravel bed.

- RG - Rain Garden. RG is within the PVC downstream of the rain garden underdrain. Its purpose is to calculate the outflow from the rain garden.

- $\mathrm{C} 2, \mathrm{C} 3$ - Cistern. Locations tagged with a C indicate flow into or out of the cistern. C2 is located within the PVC pipe that conveys water from the cistern into the rain garden, measuring inflow to the rain garden. C3 measures overflow within the PVC pipe from the cistern directly to the gravel bed detention. C1 formerly existed within the PVC that drains roof water into the cistern. The site constraints presented challenges for this monitoring site. Through alternate measurements, this value can be back-calculated instead.

- CIS - Cistern. This is a monitoring location within the cistern to determine the storage volume.

- LIR - Landscape Irrigation. This monitoring location is on the line that pumps water from the cistern to be used for irrigation throughout the ground level landscaping.

- GR - Green Roof. Monitoring location GR is within the PVC pipe that conveys water from the green roof to the cistern.

- GIR - Green Roof Irrigation. Like LIR, GIR measures irrigation onto the green roof within a line connected to the city water system.

- $\quad$ BS - Bioswale. This monitoring site is located at the downstream point of the bioswale before discharge into the adjacent stream. 


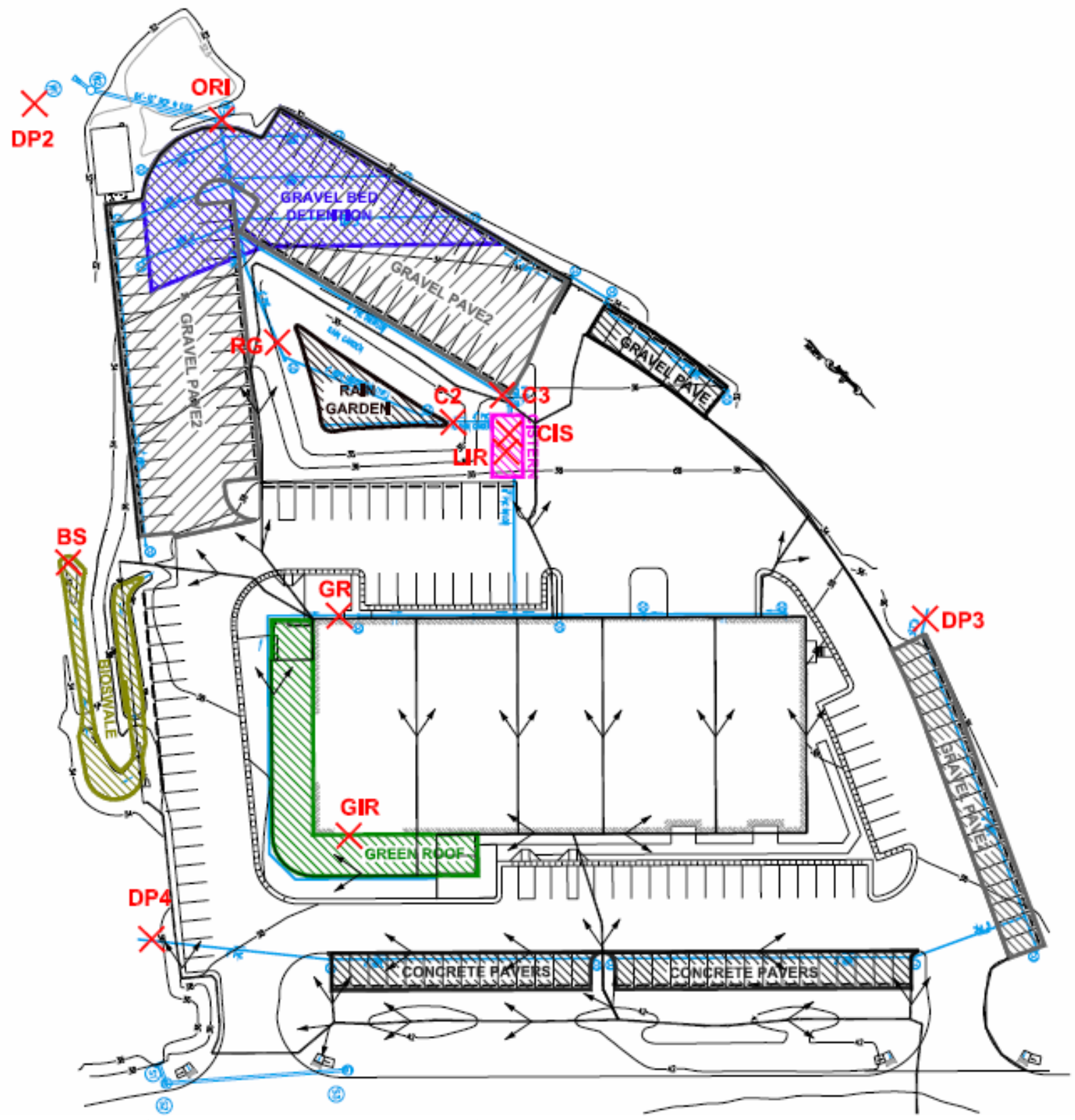

Figure 6. All monitoring locations and IDs (red) at the Gainesville site. Blue lines are underdrains, (Copyright 2006, Wetland Studies and Solutions, Inc.).

\subsubsection{Measurement Techniques}

Some literature provided insight into various monitoring technologies used today for

LID and open channel flow. These were mentioned in Section 2.4 Post-Construction

Monitoring. Combinations of site and instrumentation constraints limit monitoring to

indirect flow measurements at the Gainesville site. Nearly every measurement site was 
reviewed individually to determine the appropriate measurement technique. Measurement within underdrain network, in particular, constrains instrumentation options and is the focus of the following sections.

\subsubsection{Underdrain Network (DP3, DP4, RG, C3, GR)}

Each measurement technology was evaluated for applicability to the underdrain network. The following objectives were evaluated against each measurement technology. Results are shown in Table 4. The first four objectives are critical; if any single one of these objectives could not be met, the technology was not necessarily evaluated against all objectives.

o Measure open channel flow either directly or indirectly;

o Measure flow rates in 4- to 8-inch diameter pipe sizes;

o Allow continued accessibility (for removal, cleaning, and adjustment) to measurement instrument installed in underground pipes that are in line with a downstream LID feature and do not break daylight at either end;

o Stay within budget;

o Minimize impact to the LID flow regime;

o Maintain flow regime existent in the pipe;

o Measure flow rates down to zero and up through full pipe flow.

Based on the findings in Table 4, the only flow measurement technology applicable to the underdrained system (satisfying the first four critical objectives) is taking a depth measurement with a pressure transducer and converting that depth to an outflow via an applicable mathematical model. 
Manning's equation (Equation 3) is the model considered for the stage-discharge relationship (Wurbs and James 2002). Manning's equation is limited to open channel conditions. By selecting a depth measurement technology, the ability to measure full pipe flow is forfeited. Smaller, high-frequency storm events are expected to be captured completely by the LID stormwater management network without full pipe flow based on Urban Engineering \& Associate's design. It is imperative to obtain data from storms of this size. Flow rates expected during the 1-yr, 2-hr storm event (a relatively frequent storm) were calculated using the rational method and C-values from Urban Engineering \& Associates, Inc. (Urban Engineering 2004). Flow rates expected when the pipe is full just before surcharge conditions were calculated using Manning's equation and compared to the 1-yr, 2hr storm flow rates (see Table 5). Table 5 also indicates the return period of the full-pipe flow events. The findings confirm that open channel flow conditions will occur under most storm events. When surcharge flows occur, and Manning's equation flow calculations become invalid, system overflow is occurring simultaneously. In this event, water exits the site as sheet-flow at unmonitored locations, and data collected from the monitoring points is less significant in the effort of obtaining a hydrologic budget. A runoff event like this could instead be estimated by rainfall-runoff modeling.

$$
Q=\frac{1.49}{n}\left(\frac{A}{P}\right)^{\frac{2}{3}} S^{\frac{1}{2}} A
$$

Q- Flow rate (cfs);

$n$ - Manning's roughness value;

$A-$ Cross-sectional area of flow $\left(\mathrm{ft}^{2}\right)$;

$P$ - Wetted perimeter $(\mathrm{ft})$;

$S$ - Slope of channel ( $\mathrm{ft} / \mathrm{ft})$. 
Depth measurements were taken by Spectre Sensors' Model 8000 Precision

Submersible level sensor ${ }^{2}$. It was submerged in a retrofit, 2-inch diameter PVC stilling well connected to the existing pipe with a fabricated tee (Figure 7 and Figure 8). The stilling well isolates the pressure sensor from the flow stream, preventing velocity effects on the sensor's pressure reading. Figure 9, Figure 10, and Figure 11 are photos from the installation of the fabricated PVC fitting, the mounted sensor, and the power and communication equipment set-up, respectively. Figure 12 is an image of the new grate (Rat Guards ${ }^{\mathrm{TM}}$ by AgriDrain Coorporation) installed at the DP3 and DP4 to minimize effects on flow.

${ }^{2}$ Accuracy $<+-0.05 \%$ of full scale; precision $<0.01$ inch; pressure range $0-5$ psi; each sensor was ranged specific to its application. 
Table 4. Functionality of flow measurement technologies with respect to the Gainesville site and pertinent to any underdrained LID system. Data herein is based upon the author's technical review.

\begin{tabular}{|c|c|c|c|c|c|c|c|}
\hline Electromagnetic meters & $\mathrm{N}$ & $Y$ & $\mathrm{~N}$ & $Y$ & $\mathrm{~N}$ & Y & $Y$ \\
\hline Transit meters & $\mathrm{N}$ & $\mathrm{N}$ & $\mathrm{N}$ & & & $Y$ & $Y$ \\
\hline Doppler meters & $\mathrm{N}^{*}$ & & $\mathrm{~N}$ & & & $\mathrm{Y}$ & $Y$ \\
\hline Rotameters & $\mathrm{N}$ & & $\mathrm{N}$ & & & $\mathrm{N}^{\#}$ & $Y$ \\
\hline $\begin{array}{l}\text { Turbine/impeller/propell } \\
\text { er meters }\end{array}$ & $\mathrm{N}$ & $\mathrm{N}$ & $\mathrm{N}$ & & & $Y$ & $Y$ \\
\hline $\begin{array}{l}\text { Positive displacement } \\
\text { meters }\end{array}$ & $\mathrm{N}$ & & & & & & $Y$ \\
\hline Weirs & $Y$ & $\mathrm{Y}^{\wedge}$ & $\mathrm{N}$ & $Y$ & $Y$ & $\mathrm{~N}$ & $\mathrm{~N}$ \\
\hline Flumes & $Y$ & $\mathrm{Y}^{\wedge}$ & $\mathrm{N}$ & $\mathrm{N}^{\oplus}$ & $Y$ & $\mathrm{~N}$ & $\mathrm{~N}$ \\
\hline $\begin{array}{l}\text { Depth Sensor: } \\
\text { Ultrasonic }\end{array}$ & $Y$ & $\mathrm{~N}$ & $Y$ & $Y$ & & Y & $\mathrm{N}$ \\
\hline $\begin{array}{l}\text { Depth Sensor: } \\
\text { Pressure }\end{array}$ & $Y$ & $Y$ & $Y$ & $Y$ & $Y$ & $Y$ & $\mathrm{~N}$ \\
\hline Depth Sensor: Bubbler & $Y$ & $Y$ & $\mathrm{~N}$ & $\mathrm{~N}$ & $Y$ & $Y$ & $\mathrm{~N}$ \\
\hline $\begin{array}{l}\text { Marsh McBirney Flo- } \\
\text { Dar }\end{array}$ & $\mathrm{Y}$ & $Y$ & $\mathrm{~N}$ & $\mathrm{~N}^{\oplus}$ & & $\mathrm{Y}$ & $\mathrm{Y}$ \\
\hline $\begin{array}{l}\text { American Sigma } 950 \\
\text { Area Velocity Sensor }\end{array}$ & $Y$ & $Y$ & $\mathrm{~N}$ & $\mathrm{~N}^{\mathrm{e}}$ & $\mathrm{N}^{+}$ & $Y$ & $Y$ \\
\hline DataGator & Y & $Y$ & $\mathrm{~N}$ & $\mathrm{~N}^{\oplus}$ & & $\mathrm{N}$ & $Y$ \\
\hline Custom Ccmbination & $Y$ & $Y$ & $\mathrm{~N}$ & $\mathrm{~N}$ & $Y$ & $\mathrm{Y}$ & $Y$ \\
\hline Trap System & $Y$ & $Y$ & $\mathrm{~N}$ & $Y$ & $\mathrm{~N}$ & $\mathrm{~N}^{\circ}$ & $Y$ \\
\hline U System & Y & $Y$ & $\mathrm{~N}$ & $Y$ & $\mathrm{~N}$ & $\mathrm{~N}^{0}$ & $Y$ \\
\hline
\end{tabular}

* NOTAT WSSI PIPE SIZES

\# REQUIRES VERTICAL/UPWARD FLOW

A INSTALLEDAT THE END OF THE PPE

@ YES IF AT SELECTED SITES ONLY (EG. ONA TRIAL/EDUCATIONAL BASIS)

+ MINIMUM DEPTH READING IS 0.12 INCHES

- CONCERN FOR BACKWATER EFFECTS HIGH FLOWS. 
Table 5. Existing pipe diameters and slopes at stilling well monitoring locations in Gainesville and their expected maximum flow rates for a 1-yr, 2-hr storm event as compared to full pipe flow rates. Peak flowrates are based upon the author's rational method calculations.

\begin{tabular}{|c|c|c|c|c|c|c|c|}
\hline \multirow[b]{2}{*}{ ID } & \multirow[b]{2}{*}{$\begin{array}{c}\text { Slope } \\
(\%)\end{array}$} & \multirow[b]{2}{*}{$\begin{array}{c}\text { Diameter } \\
\text { (in) }\end{array}$} & \multicolumn{2}{|c|}{ 1-yr 2-hr Storm Flow } & \multicolumn{2}{|c|}{ Full Pipe Flow } & \multirow[b]{2}{*}{$\begin{array}{l}\text { Equivalent Storm } \\
\text { Frequency }\end{array}$} \\
\hline & & & $Q$ (cfs) & Q (gpm) & $Q$ (cfs) & Q (gpm) & \\
\hline DP4 & 2.9 & 4 & 0.04 & 19 & 0.47 & 209 & $\sim 100-y r, 5-\min$ \\
\hline C3 & 3.3 & 8 & 0.48 & 215 & 2.54 & 1139 & $\sim 100-y \mathrm{r}, 30-\mathrm{min}$ \\
\hline GR & 0.5 & 6 & 0.03 & 14 & 0.59 & 264 & $<100-y r, 5-\min$ \\
\hline RG & 3.7 & 6 & 0.21 & 93 & 1.58 & 709 & $<100-y r, 5-\min$ \\
\hline
\end{tabular}

*C3 IS THE EMERGENCY OUTFLOW FROM THE CISTERN. THIS MAXIMUM FLOWRATE IS BASED ON THE DIFFERENCE BETWEEN THE MAX INFLOW TO THE CISTERN AND THE MAX OUTFLOW

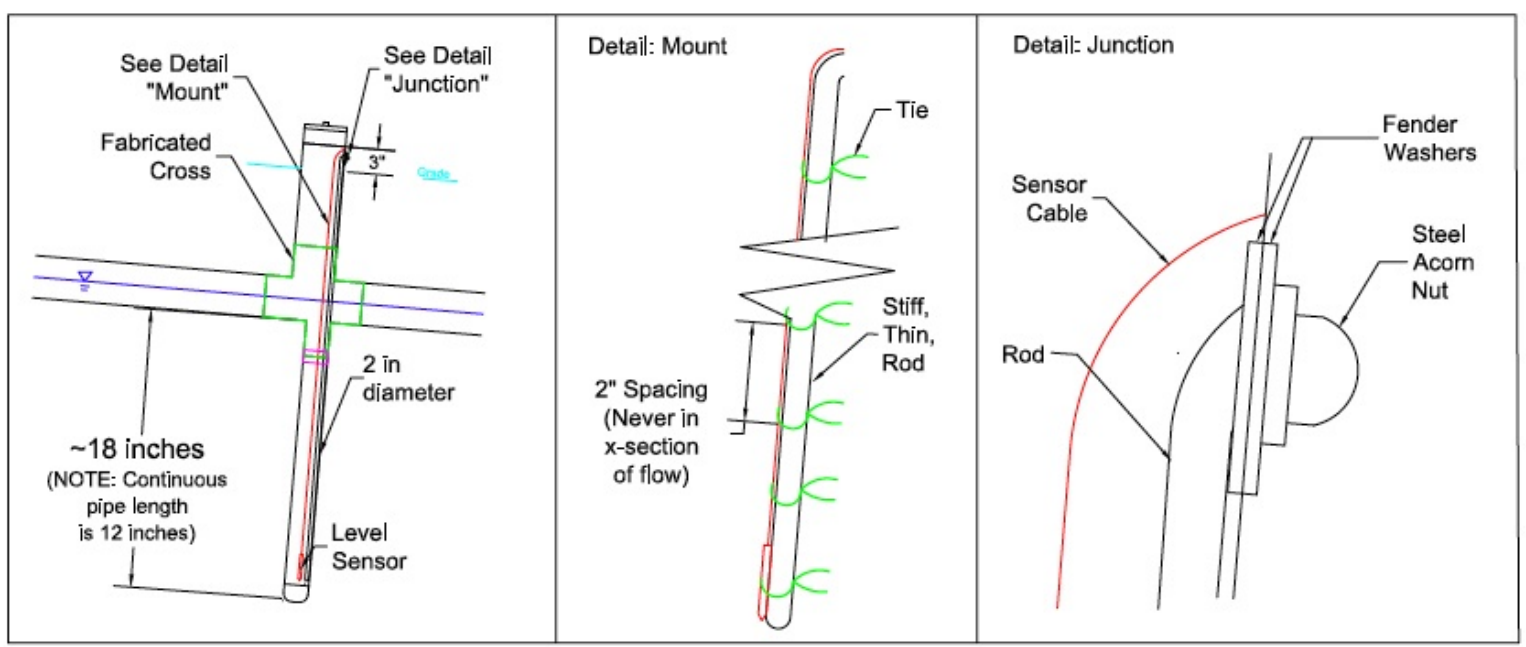

Figure 7. Stilling well and level sensor mounting design for depth-outflow measurement in PVC underdrains at the Gainesville site.

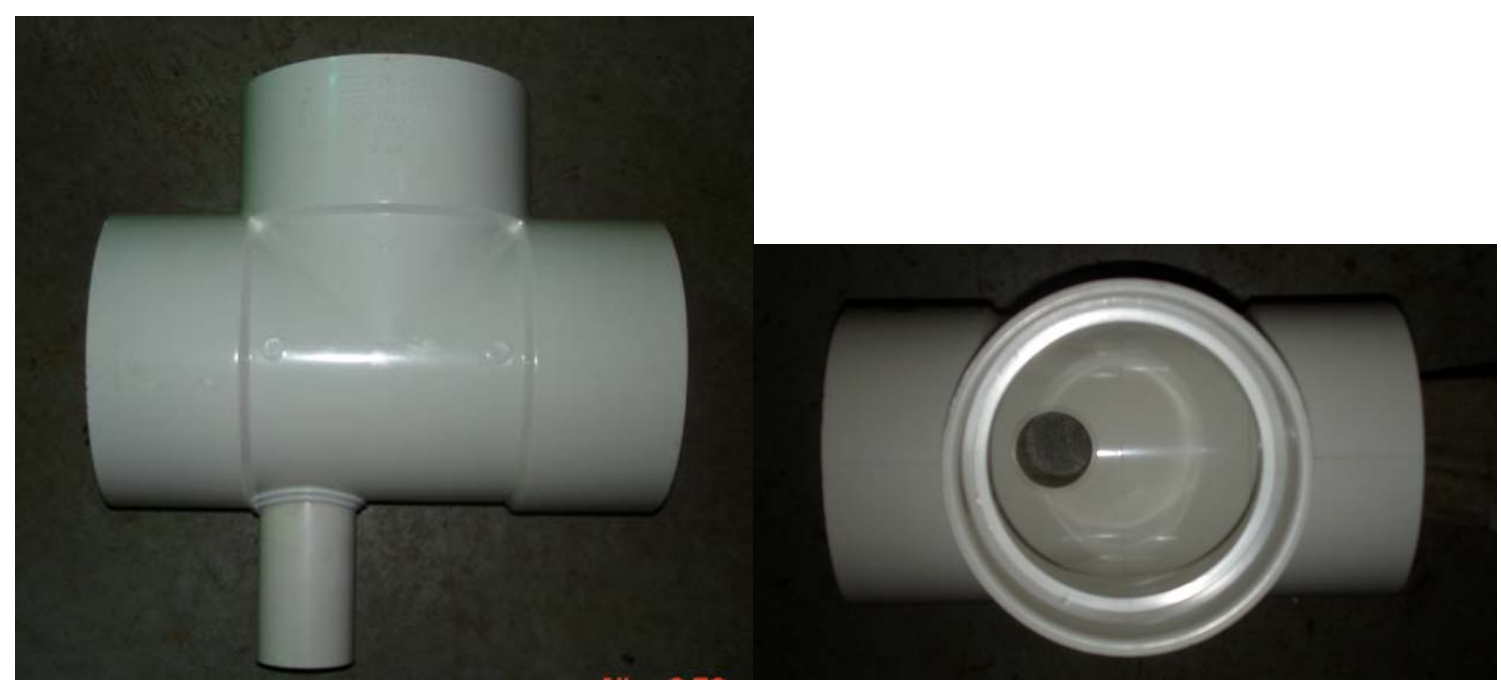

Figure 8. Photo of the fabricated PVC fitting ( 8 " size) used for stilling well installation in existing pipe at the Gainesville site (profile - left, aerial - right). 


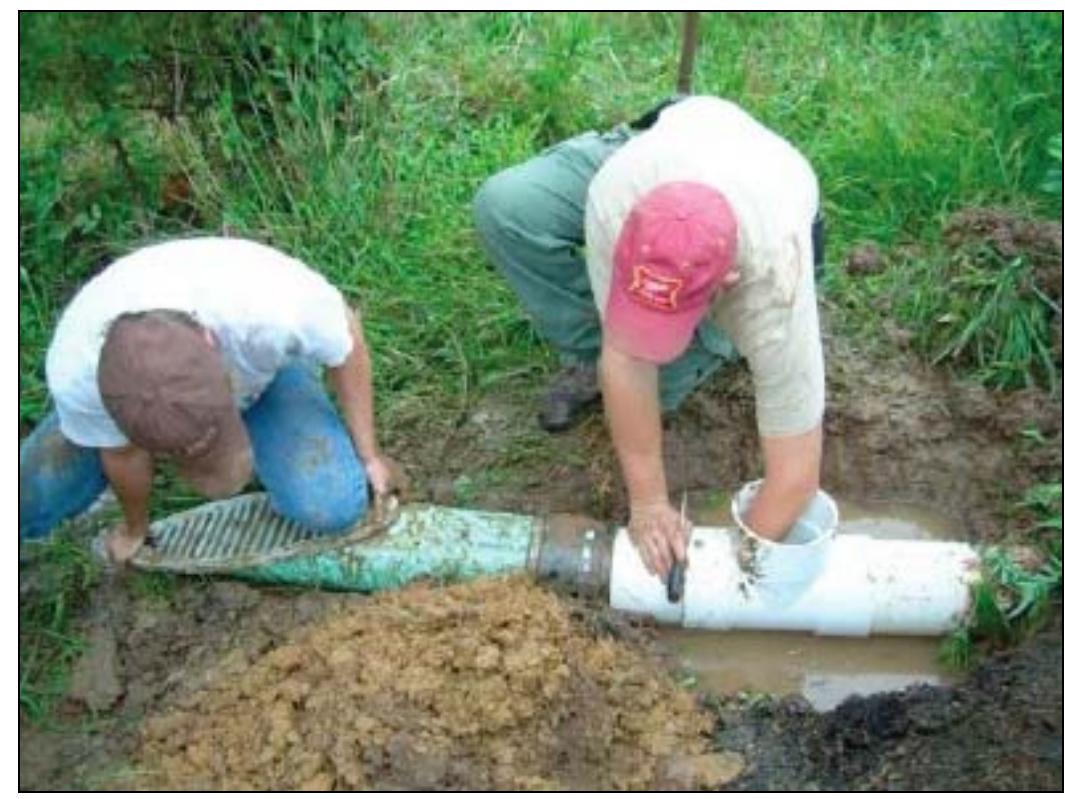

Figure 9. Installation of fabricated fitting and stilling well at monitoring location DP4 towards the north end of the site. Photo taken September 27, 2006, (Copyright 2006, Wetland Studies and Solutions, Inc.).

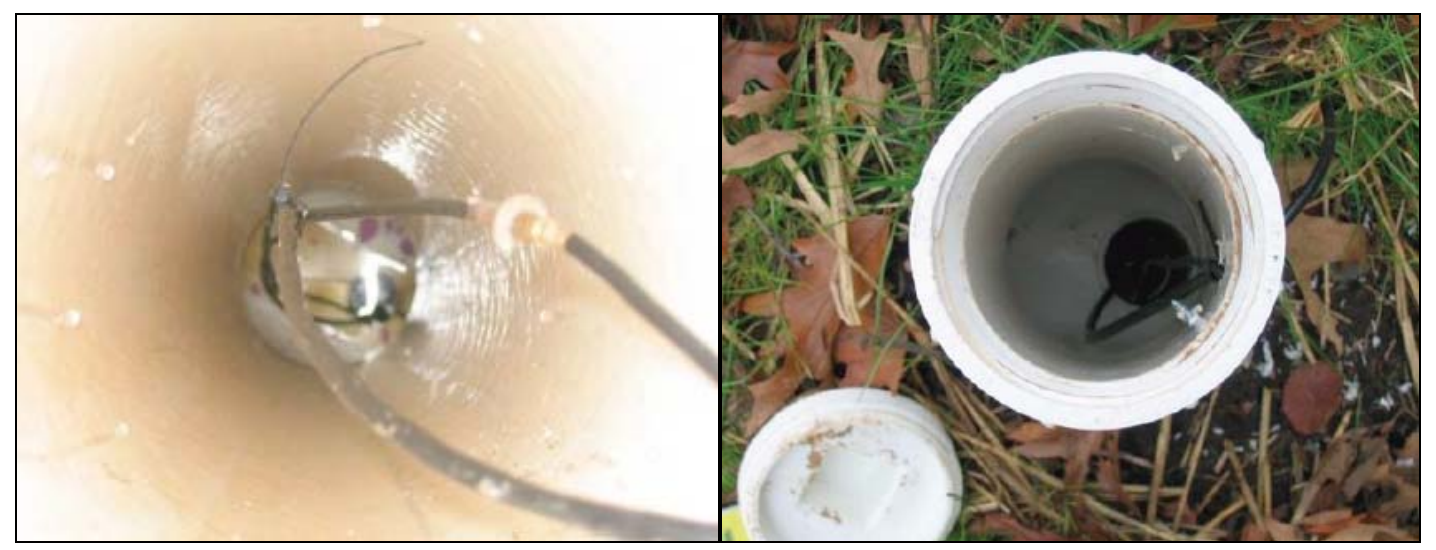

Figure 10. Installation of Model 8000 level sensor into stilling well (two locations pictured here). Sensor is mounted on semi-flexible cable extending to the top access point of the PVC design. Photos taken in November 2006, (Copyright 2006, Wetland Studies and Solutions, Inc.). 


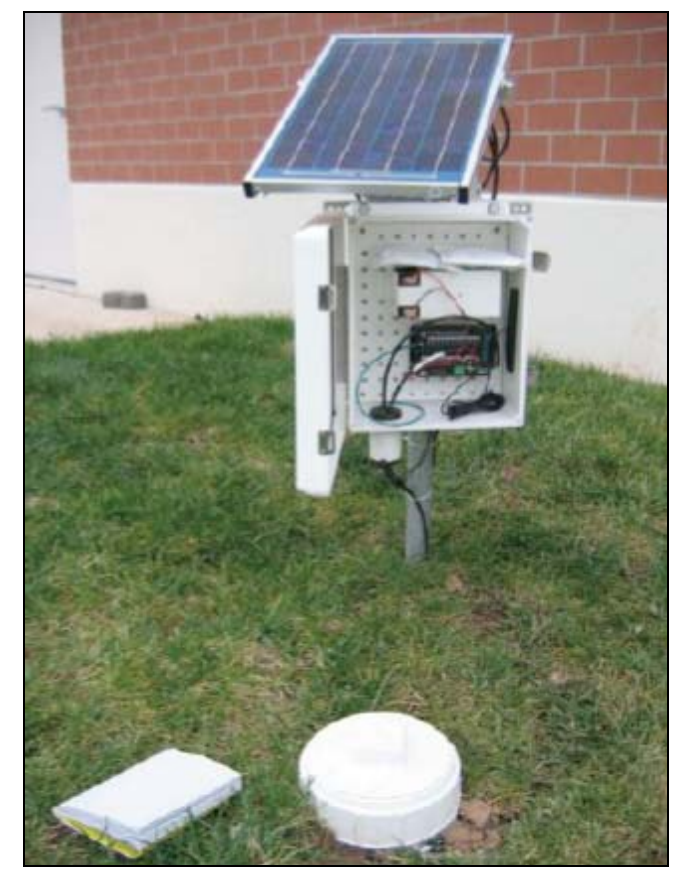

Figure 11. Power and communication equipment set-up using the CR206 datalogger by Campbell Scientific, Inc. from Logan, Utah. Photo taken in November 2006, (Copyright 2006, Wetland Studies and Solutions, Inc.).

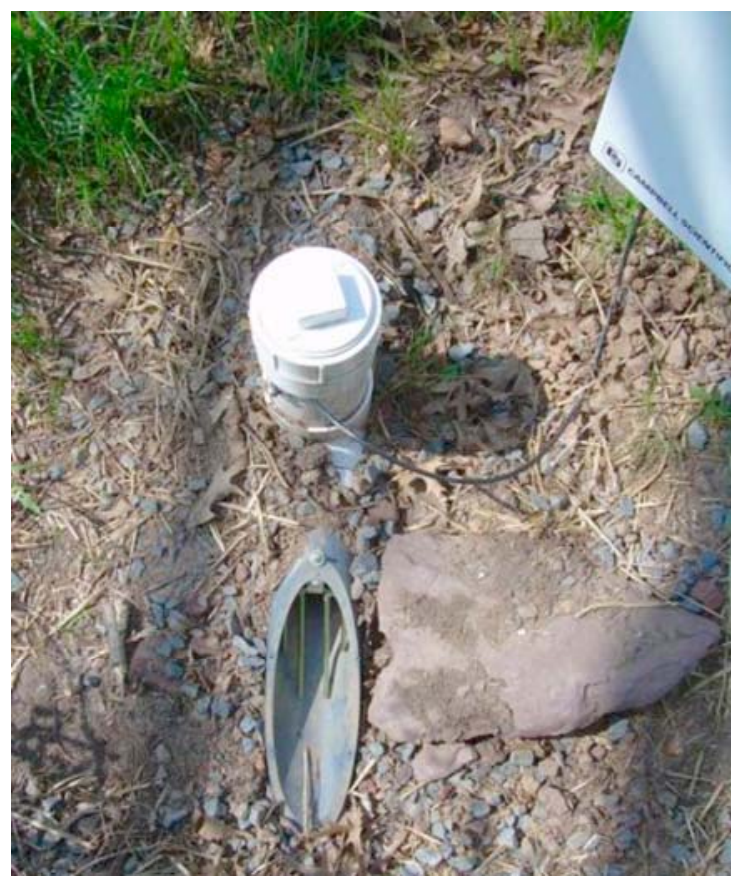

Figure 12. Grate replaced at DP3 (and DP4) in Spring 2007, Rat Guards ${ }^{\mathrm{TM}}$ by AgriDrain Coorporation models RG06 and RG04, respectively. Photo taken April 2007, (Copyright 2007, Wetland Studies and Solutions, Inc.). 


\subsubsection{All Other Monitoring Locations (DP2, ORI, CIS, C2, LIR, GIR, BS)}

Monitoring locations ORI and DP2 use the Model 8000 level sensor to obtain depth measurements. The sensor in the manhole at ORI measures a depth that is converted to a volume of storage for the upstream underground detention. This depth is also used to obtain a flow measurement based on hydrologic routing through the 1.625-inch orifice. Original routing calculations based on water surface elevation were made by Urban Engineering \& Associates, Inc. (Urban Engineering 2004). A subset of these values was used to establish a continuous rating curve from which outflow can be calculated based on depth (Figure 13). The stream height measured at DP2 is compared to the elevation of the orifice to determine when reverse and/or zero flow conditions are occurring at the orifice. In this manner, when backwater effects occur, the datalogger is programmed to terminate use of the rating curve and, rather, default to a zero flow reading from the orifice. Calculations could resume by the user based on the headwater and tailwater depth measurements using an outlet-control culvert model. Survey work indicates that the elevation of DP2 is 1.24 -feet lower than the sensor at ORI.

Monitoring location CIS also utilizes the Model 8000 level sensor. It is secured at the bottom of the cistern, along a stiff rod, and accessed through the air vent. This level measurement may be converted to a volume of storage based on the known geometry of the cistern.

Flow at monitoring point $\mathrm{C} 2$, though suited for a stilling well measurement application, is measured using a turbine meter made by Seametrics (TX101). The Seametrics AO55 blind analog transmitter converts current to voltage, and the equation for the calculation of flow in gallons per minute (Equation 4) is based on a maximum flowrate set as 
$350 \mathrm{gpm}$. This site is suited for a turbine meter because the pipe was installed with an upward elbow just before the exfiltration HDPE pipe that is buried along an upper edge of the rain garden. The elbow creates constant full pipe flow. The turbine meter is installed at least 6 feet upstream of the elbow between two reducing couples (4- to 3-inch diameter) to constrict flow and further ensure full pipe flow (see Figure 14).

Flow through the landscape irrigation and green roof irrigation lines (LIR and GIR, respectively) are measured with Data Industrial six-bladed impeller meters (IR228PV and IR250BR, respectively).

Flow from the bioswale is measured with a 30 -degree $\mathrm{V}$-notch weir and a typical head-discharge relationship (White 1999) (see Equation 5 and Figure 15).

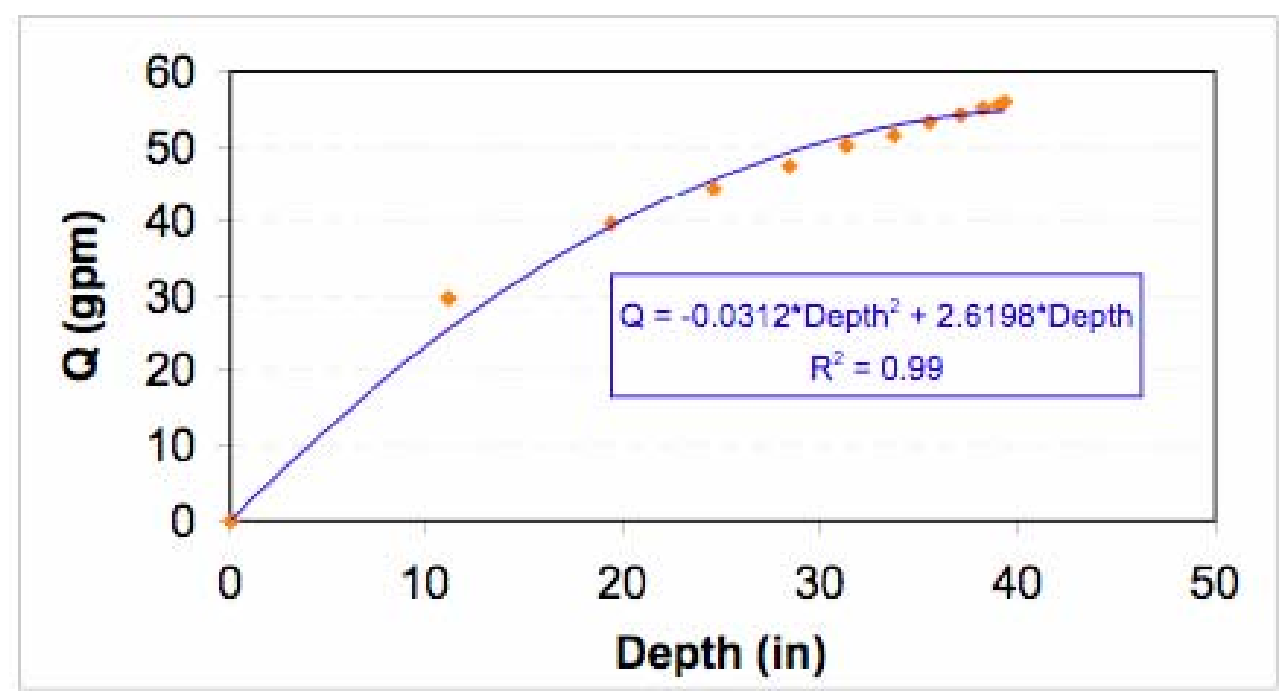

Figure 13. Rating curve established for monitoring location ORI based on hydrologic routing calculations by Urban Engineering \& Associates, Inc. (2004).

$$
Q=0.125(\text { Voltage }-500)
$$

Q - Flow rate in gallons per minute (gpm);

Voltage - Sensor output after conversion from milli-amps (mV). 


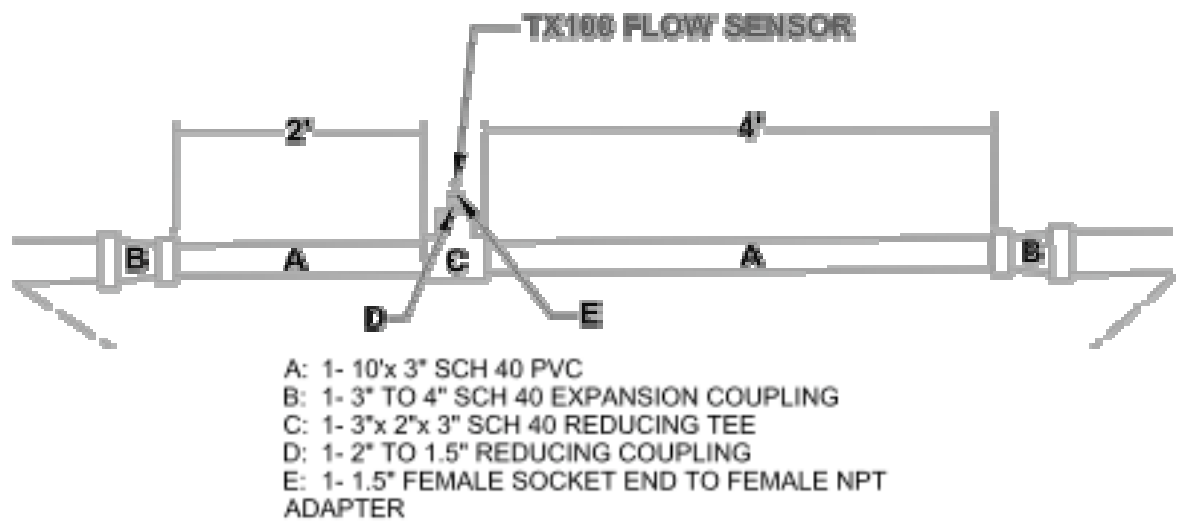

Figure 14. Seametrics TX101 turbine meter installation specifications as prepared by Wetland Studies and Solutions, Inc. Flow is from right to left.

$$
Q=0.7171 \cdot \tan \left(\frac{\theta}{2}\right) \sqrt{g}(H)^{\frac{5}{2}}
$$

Q - Flow rate in gallons per minute (gpm);

$\theta \quad$ - Degree of $\mathrm{V}$-notch;

H - Measured head above weir (inches).

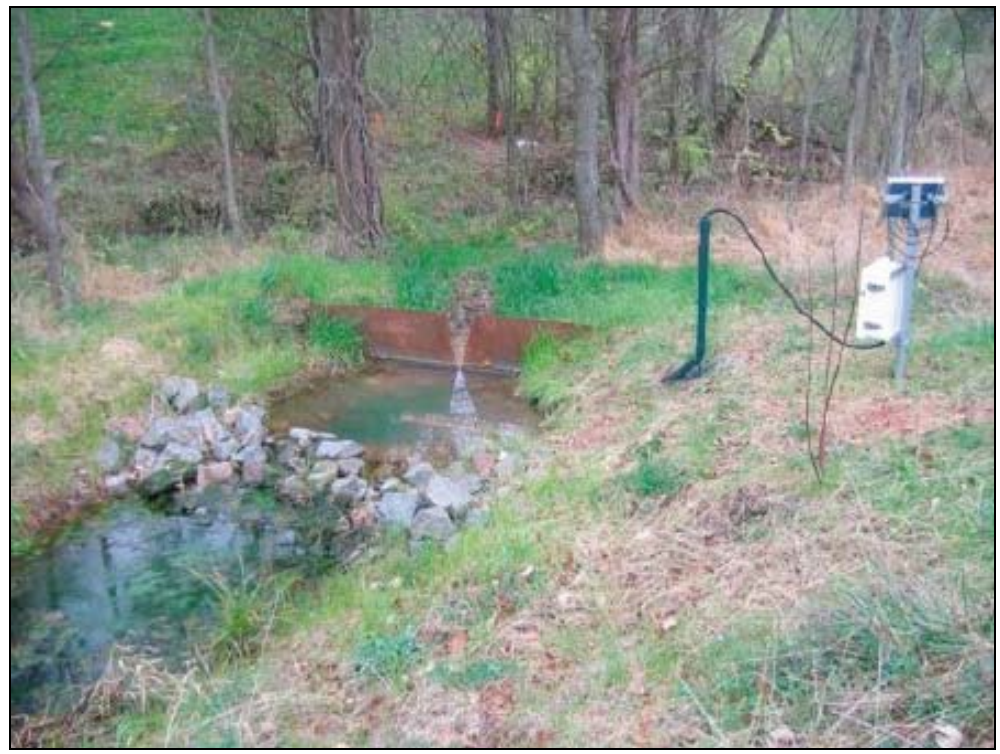

Figure 15. Thirty-degree V-notch weir and Model 8000 depth sensor installation with power and communication hookup. Photo taken in November 2006, (Copyright 2006, Wetland Studies and Solutions, Inc.). 


\section{Underdrain Measurement System Sensitivity Analysis and Calibration}

The measurement system installed at the Gainesville site for the underdrain pipes was evaluated with regard to the application of Manning's equation for the depth-outflow model. The sensitivity of Manning's equation to specific model parameters was evaluated. The design of the laboratory tests was based, in part, on the sensitivity results. Additional practical considerations for the underdrain measurement system are considered at the close of this chapter.

\subsection{Sensitivity of the Underdrain Hydrologic Measurement System}

The accuracy of Manning's equation was evaluated to determine the relative impact of parameter uncertainty on runoff calculations. Data from a single storm event (more frequent than the 1-yr, 2-hr) at measurement site DP4 was used to evaluate the sensitivity of Manning's equation calculations to parameter uncertainty. The relative sensitivity of Manning's equation to uncertainty in parameter values could be determined by calculating a single outflow value for a range of possible parameter values. However, the absolute effects of parameter-variability on outflow vary with the magnitude of the other parameters. During an actual storm event, the magnitude of the depth of flow is not constant. By using an actual runoff event, the following analysis (in addition to illustrating the relative sensitivity of Manning's equation to parameter uncertainty) is an example of the possible cumulative errors in total outflow volume and percent retention that may result throughout the full range (temporal and spatial) of depths occurring at a measurement point.

The relative effects of the following parameters were determined: zero-flow depth, pipe slope $(S)$, and Manning's $n$. Zero-flow depth refers to the sensor reading when the stilling well is full to the invert of the pipe. The depth of flow in the pipe during a storm event is the 
sensor reading less the zero-flow depth. Pipe slope data was available only from the site plans; measurements during construction were not recorded on the as-built drawings, so slope is considered uncertain and evaluated here. Manning's $n$ is a coefficient representing relative channel roughness. Typical values for various pipe materials and natural channels are available from the literature (e.g., Wurbs and James 2002). But it is considered variable because it has the potential to reflect an altered depth-outflow relationship due to a potentially significant change in the flow profile across the stilling well (due to the 2 -inch diameter stilling well or the interface between the cross and the existing pipe, see Figure 8). The magnitude of the deviation of each parameter was determined based upon expected precision attained without further investigation.

Results are shown in Figure 16, Figure 17, and Figure 18. Slope variability has a relatively minor effect on total outflow volume compared to both Manning's $n$ and the zeroflow depth. As a result, slope variability was not addressed further. If in situ pipe slopes (up to 5 feet below grade) can be measured with greater accuracy than the variability already existing in the construction plans, then it could improve the accuracy of the discharge calculations. 
Overwhelmingly the most important parameter is the zero-flow depth. This is a significant concern in the effectiveness of this measurement system and the practicality of its future use. Data suggest that in a relatively small storm event at measurement point DP4 (e.g., 0.65 inches, averaging $0.04 \mathrm{in} / \mathrm{hr}$ over $17 \mathrm{hrs}$ ), a deviation of $+/-0.065$ inches from the true zero-flow depth can overestimate cumulative volume calculations by $65 \%$ (if the true value is 0.065 inches lower) or underestimate by $45 \%$ (if the true value is 0.065 inches higher). Therefore, an exacting measurement method is required to determine the zero-flow depth to the precision of about half of the range mentioned above, e.g., $+/-0.03$ inches.

The calibration of Manning's $n$ is addressed below.

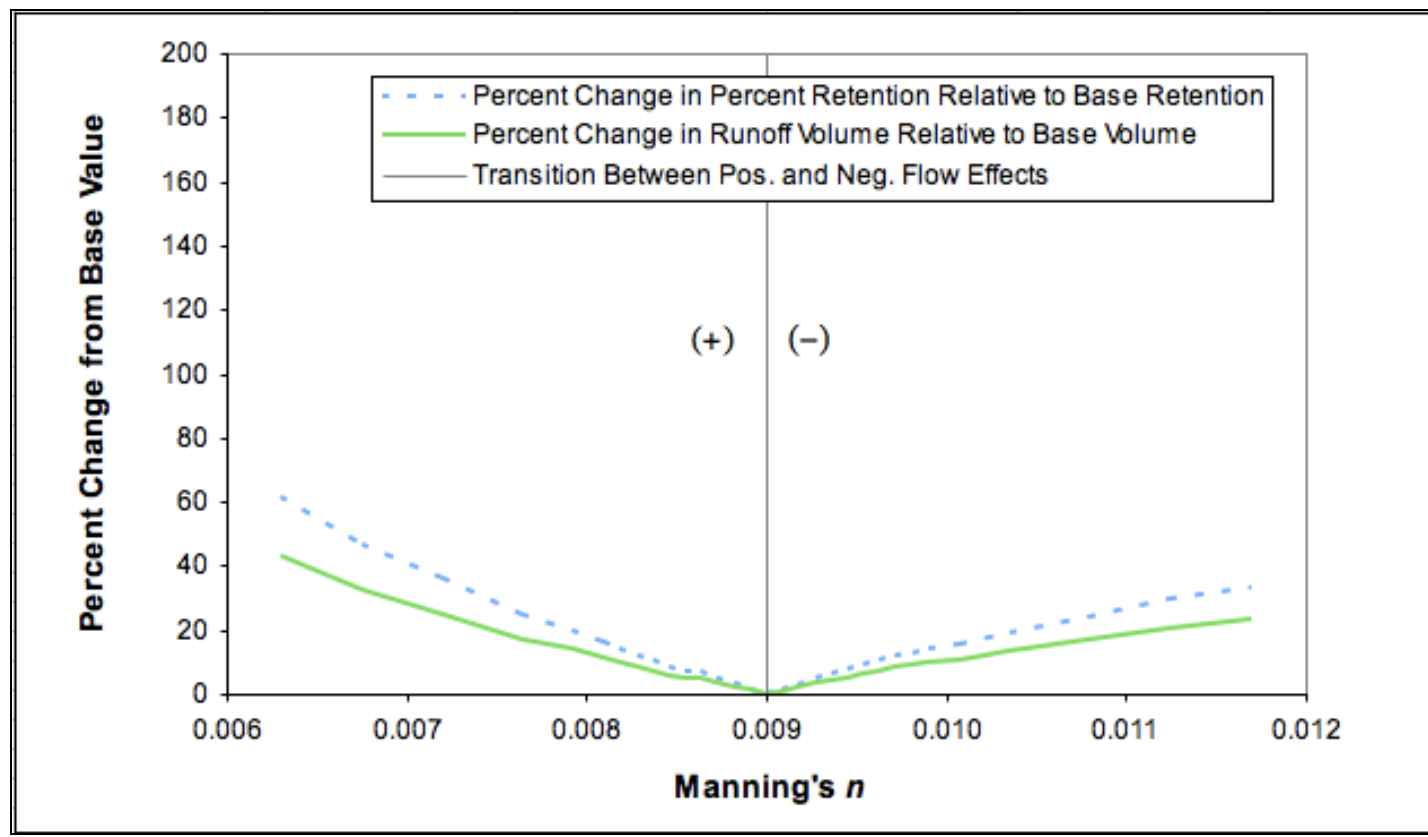

Figure 16. Determination of the cumulative runoff effects of varying Manning's $n$ (originally $0.009)$ for a $17-\mathrm{hr}, 0.65$-inch storm event $(0.04 \mathrm{in} / \mathrm{hr})$ at measurement point DP4. Storm frequency exceeds the 1-yr, 2-hr storm event for the region. The baseline divides the opposing effects to the flow: over- $(+)$ and under-estimates (-). 


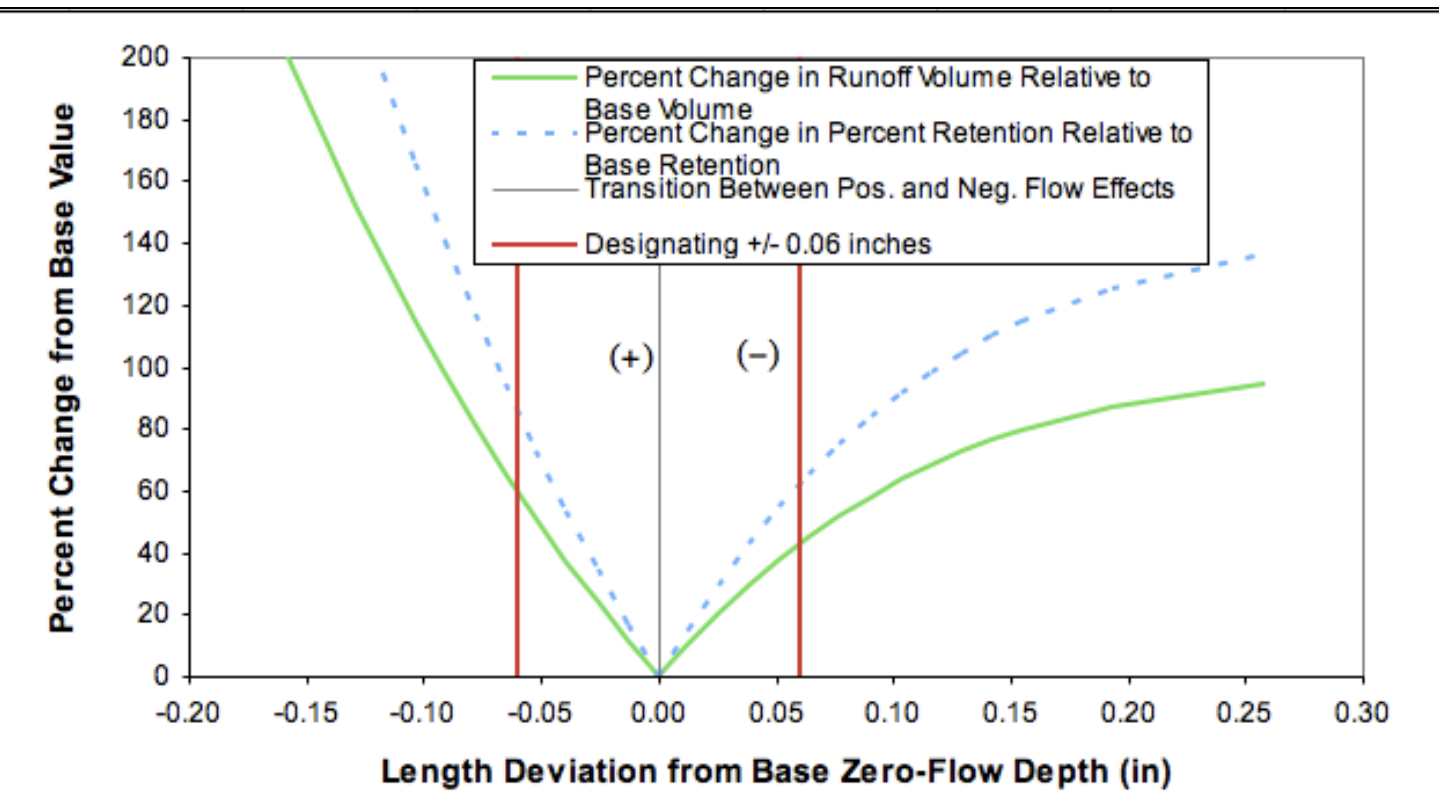

Figure 17. Determination of the cumulative runoff effects of varying the zero-flow depth (originally $12.93 \mathrm{in}$ ) from a $17-\mathrm{hr}, 0.65$-inch storm event $(0.04 \mathrm{in} / \mathrm{hr})$ at measurement point DP4. Storm frequency exceeds the 1-yr, $2-\mathrm{hr}$ storm event for the region. The baseline divides the opposing effects to the flow: over- $(+)$ and under-estimates (-).

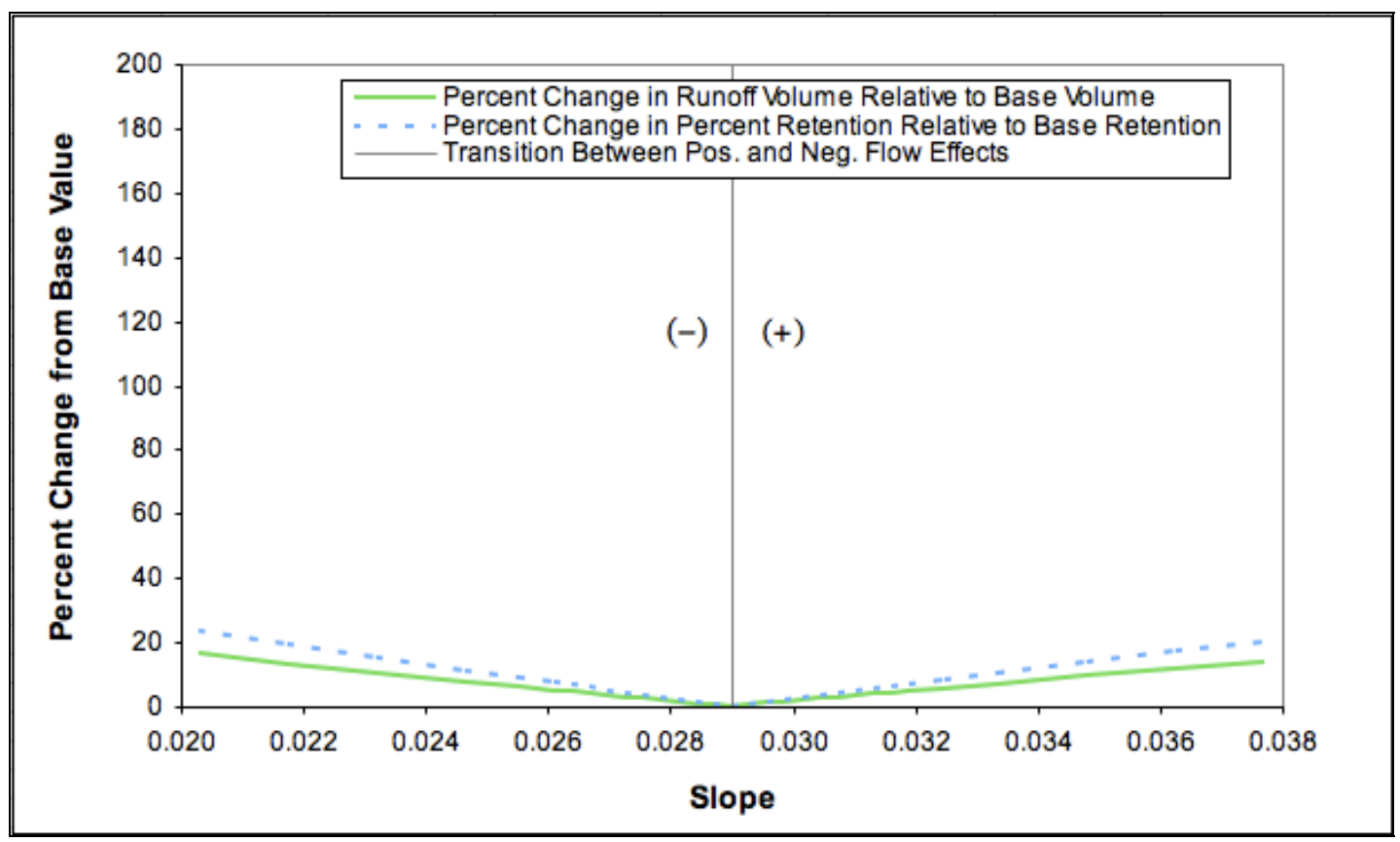

Figure 18. Determination of the cumulative runoff effects of varying the pipe slope (originally $0.029 \mathrm{ft} / \mathrm{ft})$ from a $17-\mathrm{hr}, 0.65$-inch storm event $(0.04 \mathrm{in} / \mathrm{hr})$ at measurement point $\mathrm{DP} 4$. Storm frequency exceeds the 1-yr, 2-hr storm event for the region. The baseline divides the opposing effects to the flow: over- $(+)$ and under-estimates $(-)$. 


\subsection{Calibration of Manning's $n$}

Manning's equation has a substantial history of use in smooth pipe applications (Wurbs and James 2002; Liu 1972). However, a varied flow regime is exhibited at the interface between the stilling well, cross fitting, and existing pipe, potentially creating a depth-outflow relationship that diverges from Manning's equation with a coefficient of 0.009 (Wurbs and James 2002). Manning's $n$ arguably has a physical basis related to channel roughness. Yen (1992) states that, “... any theoretical basis that can be assigned to [Weisbach friction factor] $f$ can also be assigned to $n$." On this premise, an increase in Manning's $n$ is a reasonable representation of increased channel roughness. Liu (1973) takes it a step further by suggesting Manning's $n$ can account for minor losses: "It is possible that in practice some minor losses are not considered separately but rather simply lumped into the equation of uniform flow [Manning's equation]. When this happens, a roughness coefficient larger than the theoretical one must be used." Liu published this statement in his closure to a discussion of Liu (1972), Manning's Coefficient for Smooth Pipes. Goswami (1973) had provoked Liu's statement by noting that in hydraulically-smooth sanitary sewer design, a “very commonly" used value of Manning's $n$ is 0.013 based upon the Great Lakes-Upper Mississippi River Board of State Sanitary Engineers (Health Education Service 1971). It is noted that 0.013 is higher than the range for Lucite (a.k.a. plexiglass, closest to PVC in the extensive set of tables) from 0.008 to 0.010 , as cited by Sturm (2001) from Chow (1959). If Manning's equation can accurately describe the stage-discharge relationship in PVC and across a stilling well, it may be extrapolated to other field sites with different slopes, pipe diameters, and flow rates.

Laboratory tests were conducted to test the applicability of Manning's equation to the field site. Measuring Manning's $n$ for a particular application based on laboratory or field 
depth-outflow data in a variety of channel-types has been done previously: e.g., Wong and Zhou (2002), Ramesh et al. (2000), Ding et al. (2004), and Esfandiari and Naheshwari (1998).

\subsubsection{Laboratory Methods}

The laboratory configuration replicated the stilling well measurement system as it exists in the field. Pressurized source water was first received in a 100-gallon reservoir to still the water and ensure gravity flow through the PVC measurement system. The PVC configuration was modeled after measurement site DP4 where 4-inch diameter PVC pipe has a slope of 0.029 . Duplicate stilling well fittings made by the same manufacturer (and at the same time) as the field fittings were used in the laboratory. Flow rates were measured gravimetrically, while depth measurements were recorded with the Rosemount 3051S_CD differential pressure transducer (Emerson Process Management) connected to the base of the stilling well. This instrument has an accuracy rating of $0.055 \%$ of $\operatorname{span}(<0.36 \mathrm{~mm}$ or 0.014 inches, in this application) comparable to that of the Model 8000 transducer in the field (See Section 3.3.3.1 and Footnote 2). Measurements were also taken at a constant flow rate for the range of slopes exhibited in the field.

Depth measurements from the pressure transducer were applied to Manning's equation to generate flow rates. Modeled flow rates were fit to the laboratory flow rates (measured gravimetrically) by adjusting Manning's $n$ until the sum of the squares of the difference (SSD) between the Manning's model estimate and the laboratory data is minimized. The fitness (SSD) and the $n$-values from data taken at constant slope were compared to that of data taken at variable slopes in order to test applicability across the range of slopes.

As a control, laboratory tests were then performed on the same pipe, range of flow, and slope but without the stilling well. The water surface profile was measured at multiple 
points along the length of pipe to confirm the presence of uniform flow (an assumption for Manning's equation). Water surface profile measurements were taken with a fixed caliper. Surface wave amplitudes were measured with a needle attached to an adjustable-height ruler. Data was also collected on a 6-inch diameter PVC pipe to check variability with pipe diameter. Re-calibration of Manning's $n$ was performed on control experiments and then compared to results with the stilling well to identify significant differences.

\subsubsection{Results and Discussion}

\subsubsection{Stilling Well and Water Surface Profile Tests}

Initial data from the 4-inch diameter laboratory tests with the stilling well indicate a calibrated Manning's $n$ of 0.0107 (at a slope of 0.029 ) and 0.0105 (at variable slopes). Results are shown in Figure 19. The minor variation in Manning's $n$ between the variable flow (constant slope) and variable slope data is considered acceptable to the degree that data are consistent with the Manning's equation assumption that $n$-values are constant with slope.

The slopes occurring in the field and laboratory result in supercritical flow at all flow rates. Calculations confirmed that critical slopes for the full range of flow rates exhibited in the field, and replicated in the lab, are lower than all pipe slopes in the field). This indicates that: 1) there is no flow transition between subcritical and supercritical flow that would complicate extrapolation of a laboratory-calibrated depth-outflow model; and 2) the water surface profile is dependent on upstream conditions. In the laboratory, the upstream conditions include a set of fittings to convey the flow from the reservoir through an orifice and expansions to the desired pipe size.

Measured water surface profiles are illustrated in Figure 20 and Figure 21. These observations indicate that uniform flow was only achieved at low-flow depths below 0.85 
and 0.56 inches for the 4 - and 6-inch diameter pipes, respectively. Therefore, the pipe length upstream of the fittings was not sufficiently long to achieve uniform flow at all flow rates.

Non-uniform flow may also be due to inadequate stilling of the source water in the upstream reservoir before entering the orifice. The presence of either condition is magnified at higher, more turbulent flow rates. It is, therefore, reasonable that the water surface profile measurements reveal uniform flow only at low flows. Data only from uniform flow measurements were used in the calibration of Manning's $n$.

The presence of uniform flow was crosschecked by modeling the laboratory set-up using the Hydrologic Engineering Center's River Analysis System (HEC-RAS) (Brunner 2006). The results confirm that uniform flow was achieved in the 6 -inch diameter pipe at a depth at or below 0.60 inches (see Figure 22). Model results fit the surface profile measurements sufficiently.

Caliper measurements of the water surface profile were potentially gauging only the crest of surface waves at high flow rates. At the lowest flow rates (in 4- and 6-inch diameter pipes), surface waves measured less than $0.5 \mathrm{~mm}$ in amplitude and could not be accounted for with the needle-nosed measurement device. Wave amplitudes at the highest flow rates at which uniform flow was achieved are reported in Table 6. Comparison with the water surface profile data at the same flow rate illustrate that wave amplitude is $2 \%$ or less of the entire flow depth measured. If the wave height did introduce a systemic bias at the higher depths of flow, it is considered negligible. However the bias may not have been systemic at all, in which case variability in the water surface profile measurements (based on the 95\% confidence interval) already accounts for the wave amplitudes.

Water surface profile data (without the stilling well) under only uniform flow conditions (in the 4- and 6-inch diameter pipes) was fit to Manning's equation by adjusting 
Manning's $n$. Manning's $n$ was estimated to be 0.0122 and 0.0121 for the 4 - and 6 -inch diameter pipes, respectively. These results agree with a fundamental Manning's equation assumption that Manning's $n$ does not vary with pipe diameter. These data also suggest consistency in laboratory methods.

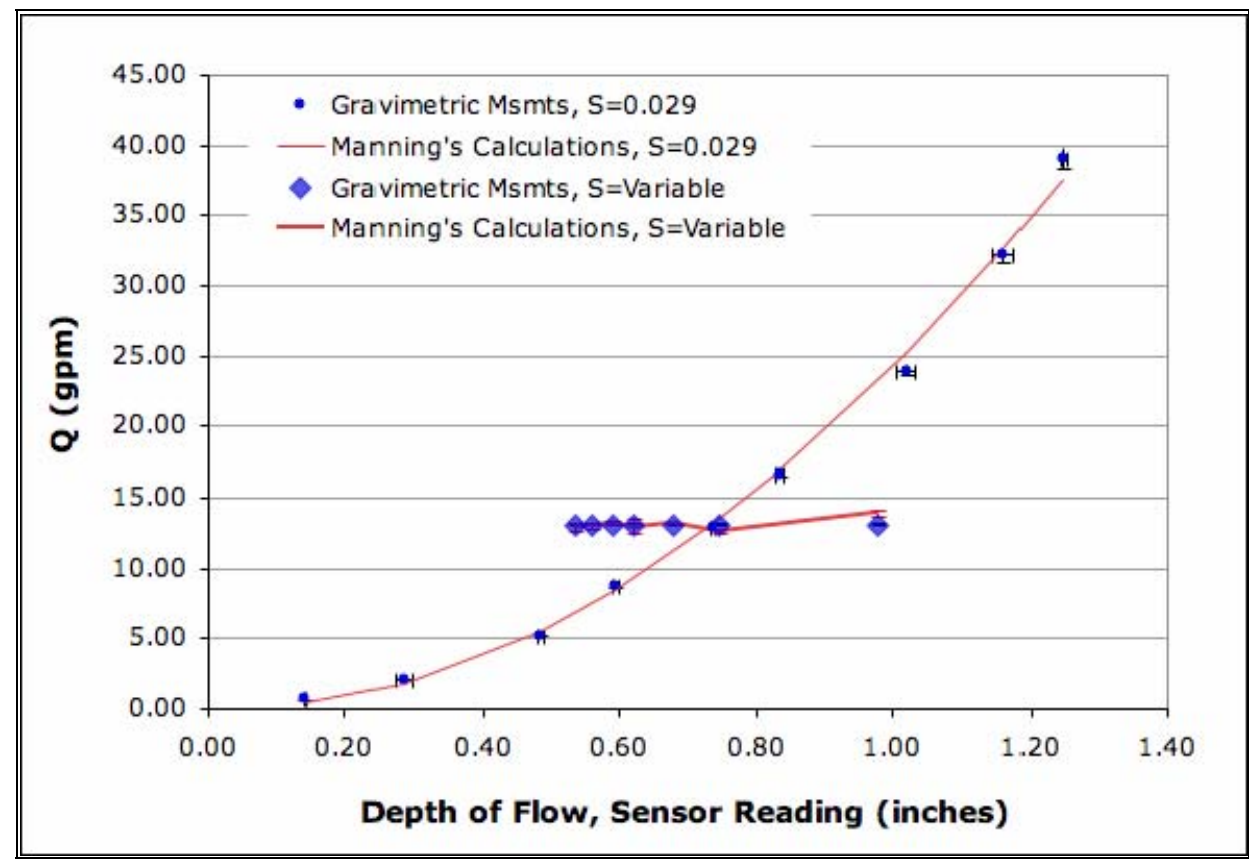

Figure 19. Laboratory data from 4-inch diameter set-up simulating stilling well measurement system at the Gainesville site. Data illustrated in red represents fitted Manning's equation solutions. At constant slope $(S=0.029)$, Manning's $n=0.0107(\mathrm{SSD}=4.92)$; when $S=$ Variable, $n=0.0105(\mathrm{SSD}=0.91)$. 


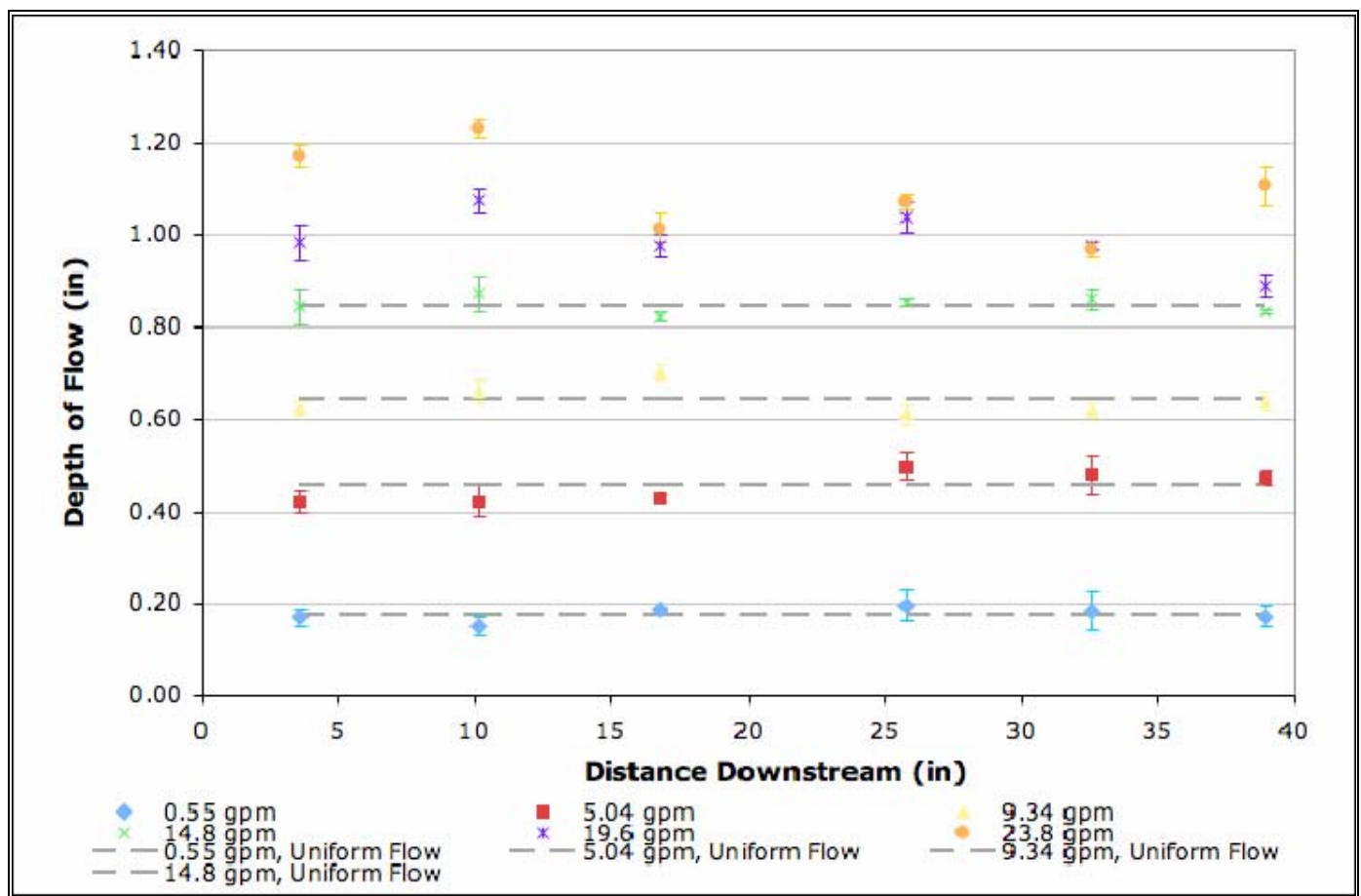

Figure 20. Water surface profiles measured in the laboratory with 4-inch diameter PVC. Upstream to downstream is represented from left to right. Error bars represent $\mathbf{9 5 \%}$ confidence intervals.

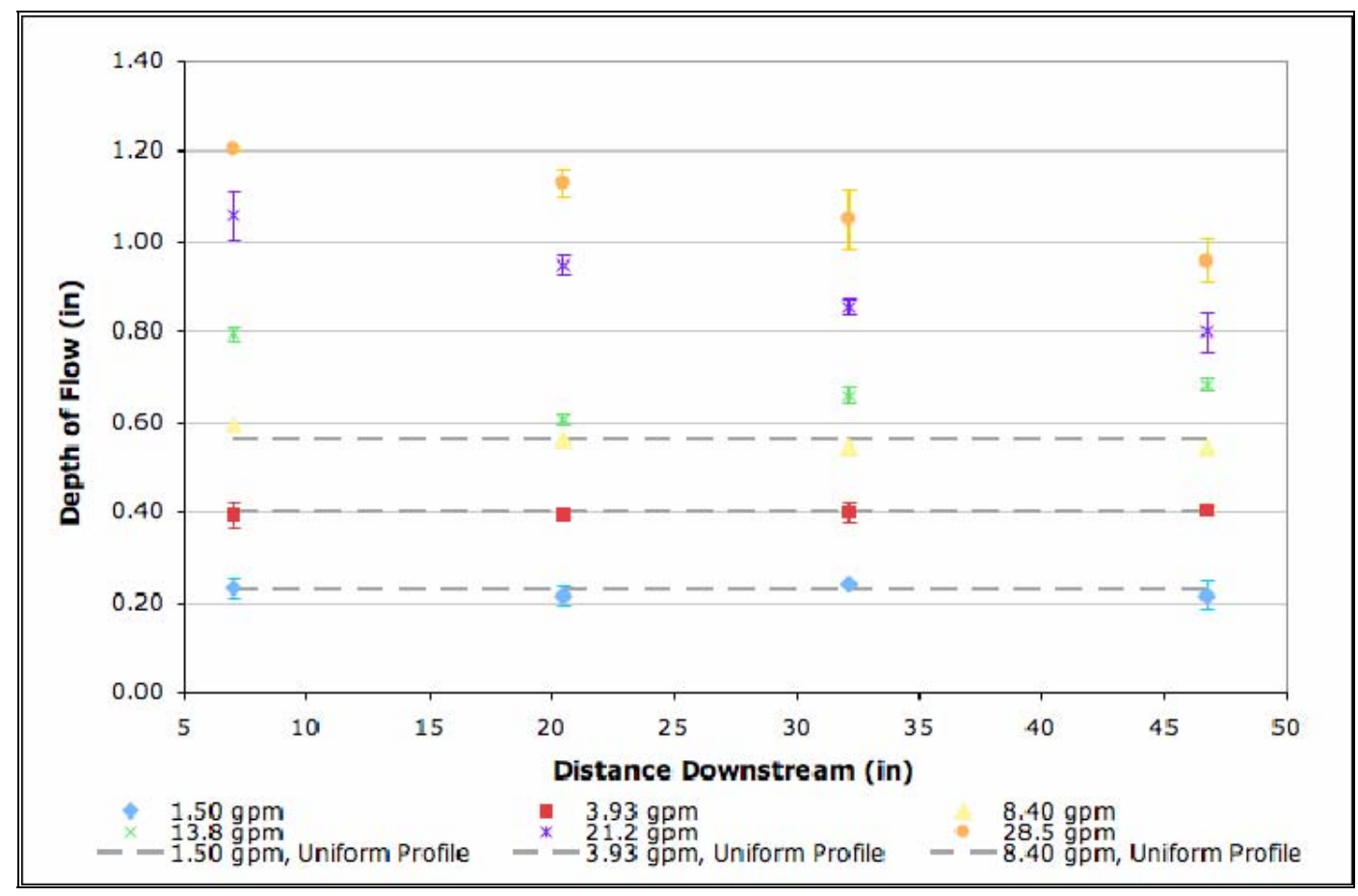

Figure 21. Water surface profiles measured in the laboratory with 6-inch diameter PVC. Upstream to downstream is represented from left to right. Error bars represent $\mathbf{9 5 \%}$ confidence intervals. 


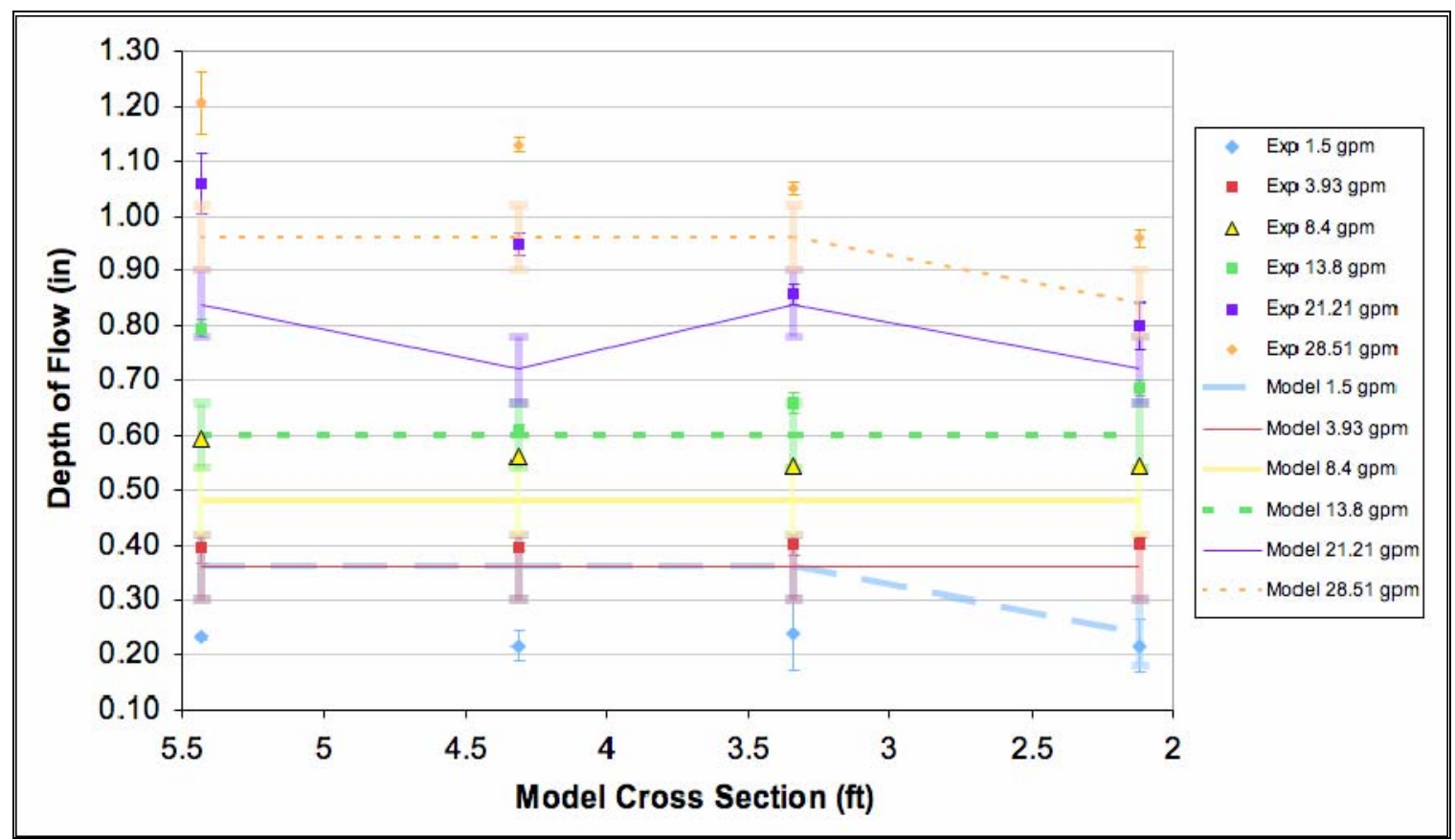

Figure 22. Water surface profile experimental data for the 6-inch diameter data and HECRAS model results. Narrow error bars on experimental (exp) data represent $95 \%$ confidence intervals; wide error bars on model data reflect automated rounding within HEC-RAS modeling software.

Table 6. Wave amplitude during supercritical, uniform flow water surface profile measurements.

\begin{tabular}{|c|c|c|}
\hline & \multicolumn{2}{|l|}{ Diameter } \\
\hline & 4-inch & 6-inch \\
\hline \multicolumn{3}{|l|}{ Wave Amplitude Data } \\
\hline Avg. Wave Amplitude, in ( $\mathrm{mm})$ & $0.016(0.40)$ & $0.026(0.65)$ \\
\hline \multicolumn{3}{|l|}{$95 \%$ confidence interval } \\
\hline Minimum & $0.012(0.31)$ & $0.011(0.27)$ \\
\hline Maximum & $0.019(0.49)$ & $0.041(1.0)$ \\
\hline \multicolumn{3}{|l|}{ Water Surface Profile Data } \\
\hline Avg Depth of Flow, in & 0.85 & 0.56 \\
\hline Percent wave is of total depth & 1.4 & 2.0 \\
\hline \multicolumn{3}{|l|}{$95 \%$ confidence interval } \\
\hline Minimum & 0.798 & 0.525 \\
\hline Maximum & 0.902 & 0.595 \\
\hline
\end{tabular}




\subsubsection{Re-Calibration of Manning's $n$ Under Uniform Flow}

\section{Conditions}

Manning's $n$ for the stilling well data in the 4-inch diameter pipe at only uniform flows (as determined by the profiles) was recalibrated to find a Manning's $n$ of 0.0108 ( $n$ is 0.0107 when non-uniform flow conditions are included). At the 4-inch size, only a 13\% difference in Manning's $n$ (from 0.0121 to 0.0108 , control and stilling well, respectively) was observed between the control (pipe only, no fittings) and the stilling-well configuration. The trend appears to be that the stilling well actually reduces Manning's $n$, an effect opposite to the hydraulic law that fittings cause energy losses. Data from both experiments are plotted together with their respective fitted Manning's equation curves in Figure 23. Error based on replicate measurements ( $95 \%$ confidence intervals) as well as sensor accuracy is illustrated in error bars. Overlap occurs between error bars of one data set and the Manning's curve of the other, and visa versa. In particular, with exception to the deepest measurement, the stillingwell curve would shift upwards towards the data without the stilling well (having an equal, if not greater, Manning's $n$ ). From these laboratory tests, Manning's $n$ varies, but the variations are not statistically significant over the range of conditions measured.

Manning's $n$ was again recalibrated to fit the combined 4-inch diameter data due to their statistical similarity. The overall fitted Manning's $n$ is $0.0113^{3}$.

\footnotetext{
${ }^{3}$ The author notes that a 6-inch diameter stilling-well field duplicate was also laboratory tested. Only two data points were left for Manning's $n$ re-calibration after data was limited to uniform flow conditions ( $<0.56$ inches). Manning's $n$ for these two data points ranged from 0.0162 to 0.0172 within the range of error. These values are considerably high and inconsistent with both literature values and other laboratory results. The event of an outlier within a set of only two data points completely alters the results. An outlier cannot be distinguished within a set of two data points, and, therefore, both data were disregarded.
} 
Manning's equation is a valuable model for practical application because it requires only one parameter to be estimated. It is important to point out that if the assumption holds that Manning's $n$ accounts for variable slopes, it should also account for variable pipe diameters (as expressed in the hydraulic radius). While the water surface profile data was consistent with this assumption, it is helpful at this point to return to the consideration of variability across pipe diameters. Figure 24 illustrates a Manning's equation curve of the 4inch diameter, laboratory-calibrated $n$-value of 0.0113 plotted against the 6 -inch pipe diameter data (uniform flow conditions only). A Manning's $n$ of 0.0113 from the 4 -inch data is well within the error of that experiment. The two 8-inch diameter monitoring points should also exhibit a Manning's $n$ of approximately 0.011 .

It is a reasonable assumption that if little to no effects of the stilling well exist in the 4-inch diameter pipe size, then the 6- and 8-inch diameter pipes will experience no effects. Effects of the same fittings and roughness are reduced with increasing pipe size (Wurbs and James 2002). 


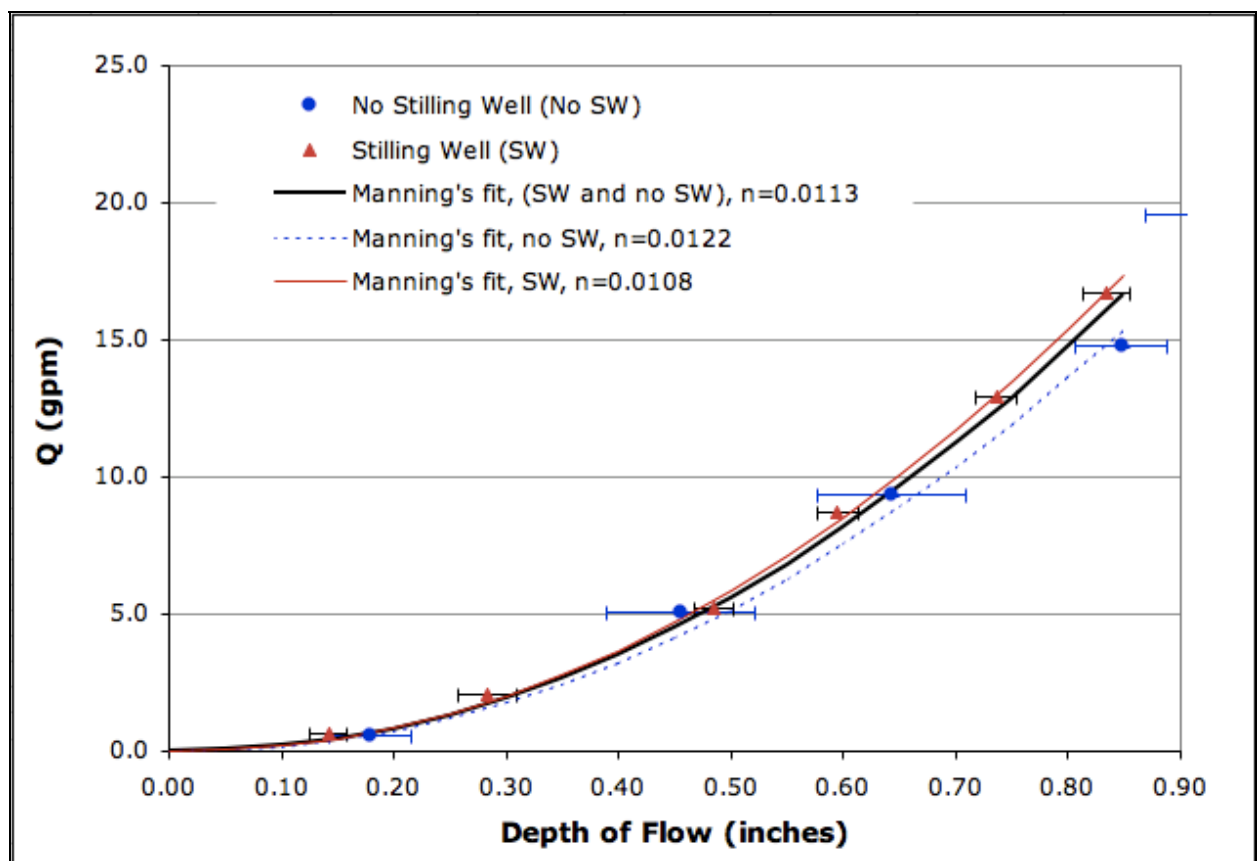

Figure 23. Laboratory data for the 4-inch diameter pipe size comparing depth-outflow data under uniform flow with and without the presence of the stilling well (SW). Error bars represent a 95\% confidence replicate caliper measurements and reported accuracy of pressure transducer.

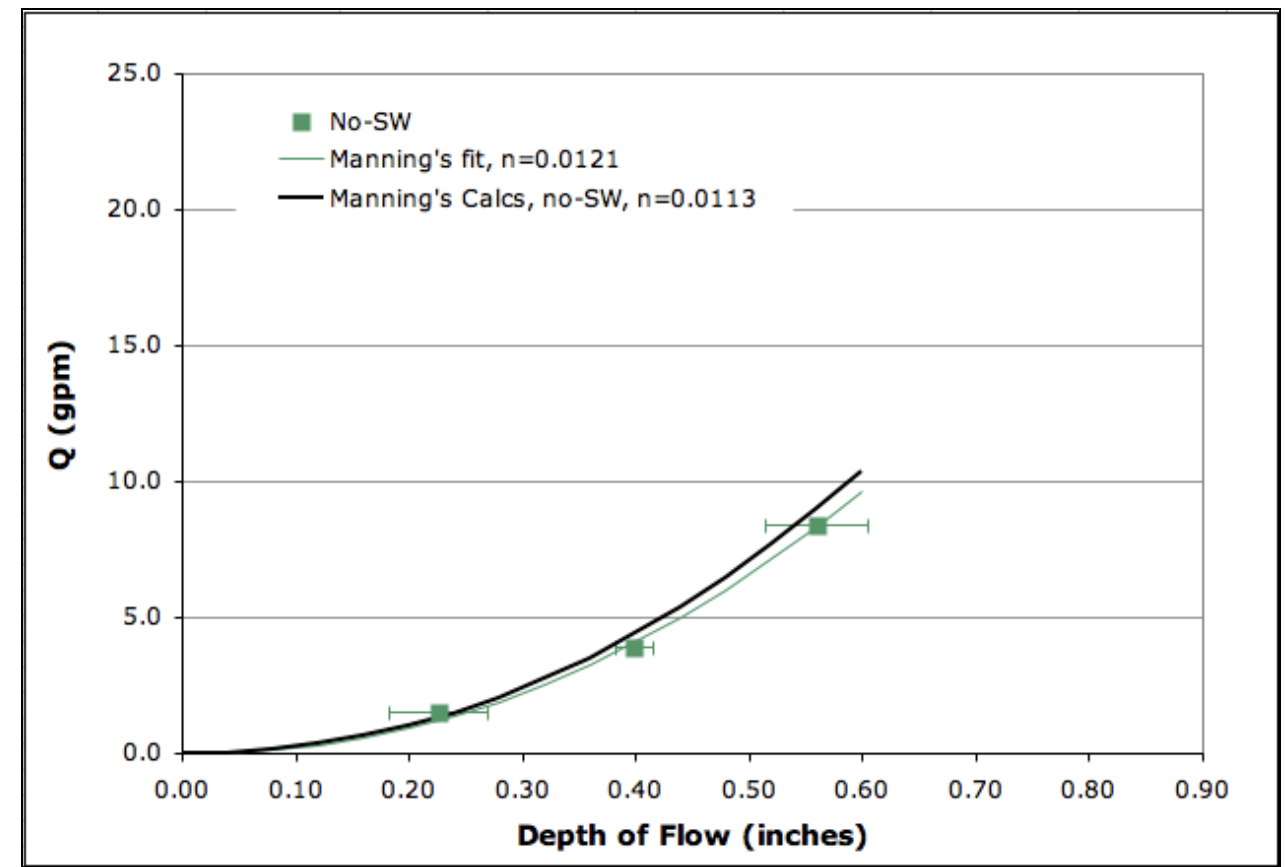

Figure 24. Laboratory data for the 6-inch diameter pipe size comparing depth-outflow data under uniform flow with and without the presence of the stilling well (SW). Error bars represent $95 \%$ confidence. 
There remains a consideration of whether to use the range of Manning's $n$ values determined from the laboratory or to use the literature value of Manning's $n$. The relative impact on the data evaluation is found by referring to Figure 16. Assuming Manning's $n$ as estimated in the lab-replication of the field site is valid $(n=0.0113)$, the runoff volume (using the same 0.65 -inch storm event at DP4) decreases by $16.7 \%$ and the retention increases $24 \%$.

There is substantial value in this laboratory set-up because it is a replicate, full-scale model. It is a strong argument for varying from the textbook value.

In addition, Liu (1972) explains that, "when the maximum height of roughness elements in a pipe is smaller than the thickness of the viscous sublayer..., further decrease of roughness of the pipe does not decrease the flow resistance." An $n$-value of 0.0113 is within Liu's range of 0.005 to 0.012 for smooth pipes and 13\% greater than Chow's (1959) upper value of 0.010. Bishop and Jeppson (1975) and Neale and Price (1964) designate a range of 0.009 to 0.011 for Manning's $n$ for PVC with smooth inner walls (as cited in LMNO 2000).

Finally, there is literature available that sets a precedent for using experimentally determined Manning's $n$, and, in some cases, others have found and used Manning's $n$ values that differ from the literature. Ding et al. (2004) notes the uncertainty of empirical parameters due to the complex physical processes that they are made to represent thereby suggesting the inherent need to adjust Manning's $n$ for individual applications. Musleh and Cruise (2004) experimentally calibrated Manning's $n$ and found $n$-values within the wide range of expressed literature values. The overall uncertainty of the data was found to range from 10 to 30\% (mostly < 20\%). Wong and Zhou (2002) found experimentally determined Manning's $n$ outside of the literature values. The authors chose to apply the Manning's $n$ from flow experiments because they fit the observed field hydrograph better than those 
simulated with the literature value of Manning's $n$. Esfandiari and Naheshwari (1998) also used laboratory tests to determine Manning's $n$. Esfandiari and Naheshwari (1998) applied the experimentally determined values without published comment on literature values.

\subsubsection{Conclusions}

Laboratory results indicate that Manning's $n$ does not vary with the addition of the stilling well, and the $n$-value of 0.011 is acceptable for all slopes and pipe sizes experienced in the field. It is possible that a laboratory with automated leveling and flow control capabilities would be able to find an effect of the stilling well on the stage-discharge relationship as compared to undisturbed open channel flow. However, based on the laboratory findings, it is apparent that any variability in the effect of the stage-discharge relationship is small. And of course the magnitude of the effects of Manning's $n$ is much lower than the effects of the zero-flow depth (see Figure 16 and Figure 17).

An $n$-value of 0.011 is considered valid for the field-data assuming uniform flow. The maximum flowrate achieved in the lab under uniform flow was $17 \mathrm{gpm}$ (due to the laboratory-specific set-up). Thus far, field data has conclusively exhibited flow rates of at least $80 \mathrm{gpm}$ for a storm event more frequent than the regional 1-yr, 2-hr. The validity of the laboratory-generated $n$-values would need to be assumed for the higher flow rates. Unlike the laboratory that accepted source water from a pressurized system, underdrain pipes in the field accept water through gravity fed infiltration into perforated high-density polyethylene pipe, and upstream lengths, in general, are many times longer than that experienced in the laboratory.

The laboratory work also illustrates that it is imperative that fittings are tight and all elements are flush with the invert of the pipe. Small disturbances to the flow regime can occur with gaps or penetration of the flow path. The intersection between the stilling well 
and the pipe invert may need to be smoothed upon fabrication. Based on visual laboratory observations, without smoothed interfaces the tee fitting housing the stilling well may impact the flow regime more than the 2-inch diameter stilling well itself.

Modeling the flow regime experienced across the measurement system using HECRAS was effective. It is recommended as an option for determining the presence of uniform or non-uniform flow under a range of conditions experienced at the Gainesville site and other applicable underdrained field sites.

\subsection{Additional Practical Considerations of the Measurement System}

Pressure transducers are highly affordable and, in general, the industry considers them a very dependable measurement device in terms of both accuracy and durability. The communication system for transferring the sensor readings to a central PC became the largest component $(60 \%)$ of the $\$ 25,000$ budget.

Curtis Hinman of Washington State University has found that conditions in the waterproof Campbell Scientific, Inc. equipment enclosures which house the open-air end of the cable from the transducer may have an unstable pressure that varies from constant atmospheric pressure (Hinman 2007). If this occurs on the WSSI site, it introduces inconsistencies in the differential pressure reading, and, therefore, the level readings. The magnitude of any hypothetical drop if it were to occur at the Gainesville site is unknown. For the sake of evaluation, consider a drop in atmospheric pressure of $0.8 \mathrm{~mm} \mathrm{Hg}$, as experienced in a December 25, 2006 storm event recorded by the National Oceanic and Atmospheric Administration (NOAA) at the Manassas, VA, atmospheric gauging station (03710, 10 miles from Gainesville) (NOAA 2007). At a conversion rate of $13.6 \mathrm{~mm}$ water per $1 \mathrm{~mm} \mathrm{Hg}$, that is a difference of 0.429 inches of water $(10.9 \mathrm{~mm})$. 
The measurement system is ideal for top access at grade, which is a major advantage in the design. Installation is efficient and non-complex. Careful consideration does need to be paid to minimizing the chance for air bubbles to enter the nose of the probe when lowered vertically into a full stilling well.

It may be necessary to clean out the stilling wells periodically due to sediment accumulation. However, water is filtered through fine mesh filter fabric before it reaches any of the stilling well monitoring points. It might be considered an annual concern where vacuuming would be a good precaution.

In this measurement system any depth reading will be interpreted as a flow even if the water is stationary or flowing in reverse due to backwater effects. At locations where backwater effects are anticipated, downstream conditions can be monitored to enable flow estimation from two readings (and are set up to do so in one case, DP2 and ORI). The situation may require a sensor that indicates forward, backward, or possibly zero flow. Sensors may be available that indicate one of those three flow regimes; however, to date the small pipe diameter and open channel flow conditions preclude direct measurement of the flowrate.

Excess electrical charge from the solar panels during the daytime will impact the reading of the Model 8000 sensor if a resistor is not used to prevent the battery from overcharging. This was determined early on in the installation of the Gainesville system and resistors have been installed. Results in Chapter 5 suggest there may be some lowermagnitude solar-induced peaks still lingering at selected monitoring locations. 


\section{Performance of the Underdrained LID Network}

The flow monitoring system was designed to be automated, collecting field data at strategic locations across the Gainesville LID site (in most cases depth measurements) and outputting outflow hydrographs. It is intended for researchers to use the data to evaluate the hydrologic characteristics of each LID feature within individual subwatersheds and to evaluate the unique effects of LID features implemented in series through a compact network of underdrain pipes and conveyances. Hydrologic characteristics of interest include: percent volume retention, delay time of peak outflow, percent peak outflow reduction, and equivalent rational method C-values and NRCS curve numbers (see Equations 6 through 8 and Equations 1 and 2, respectively).

$$
R=\left(1-\frac{O}{I}\right) * 100
$$

R - Percent volume retention;

O - Outflow volume;

I $\quad$ - Inflow volume.

$$
T=T_{Q_{P}}-T_{0}
$$

T - Time to peak outflow;

$T_{Q_{P}} \quad$ - Time at peak outflow;

$T_{0} \quad$ - Time at start of rainfall. 


$$
\begin{gathered}
Q_{P, R}=\left(1-\frac{Q_{P, L}}{Q_{P, C}}\right) * 100 \\
Q_{P, \mathrm{R}} \quad-\text { Percent peak outflow reduction; } \\
Q_{\mathrm{P}, \mathrm{L}} \quad-\text { Peak outflow from LID site; } \\
Q_{\mathrm{P}, \mathrm{C}} \quad \text { - Peak outflow from comparable conventional site. }
\end{gathered}
$$

The NRCS Curve Number method accounts for three qualitative variations in antecedent moisture conditions (Wurbs and James 2002). Antecedent moisture conditions that are "dry but not to wilting point" (Condition I) and those where "heavy rainfall or light rainfall with low temperatures have occurred within the last 5 days saturating the soil" (Condition III) require mathematical adjustment of the curve number generated based on "average conditions" (Condition I, see Equation 2) (Wurbs and James 2002). Antecedent moisture conditions have been accounted for in the curve number analysis.

The rational method utilizes the peak storm intensity over the duration of the time of concentration of the watershed (Wurbs and James 2002). Urban Engineering \& Associates assumed a time of concentration of 5 minutes for the watershed discharging to the stream at the southeastern end of the site at measurement point ORI (Urban Engineering 2004). Precipitation data is collected at 6-minute intervals. Therefore, the time of concentration for each monitoring point is assumed to be 6 minutes.

Data from the Gainesville site is particularly valuable due to the nature of the LID site design. The 3.87-acre site maximizes the use of space for LID stormwater management controls including bioretention, bioswales, porous pavement, green roof, cistern, native vegetation, and orifice-controlled underground detention. Many of the LID features are interconnected through underground PVC pipes such that they treat the stormwater in 
series. Data on the effectiveness of a compact system like this inform designers as to the applicability of retrofit, underdrained LID systems on traditionally compact urban sites.

Data evaluated herein represent preliminary findings after five months of

troubleshooting monitoring system communication, electronics, and datalogger

programming. For reference throughout the analysis below, subcatchment characteristics related to each monitoring point are presented in Table 7 . Slope data used for each stillingwell-gaged watershed was based on the plan sets except for a recent field measurement of monitoring point DP3. Pipe slope and diameter used in Manning's equation calculations as well as the pipe length used to generate the slope data are illustrated in Table 8. To reduce the systematic variability of the one-minute data intervals, results shown here have been centrally averaged between adjacent data points. 
Table 7. Subcatchment characteristics with respect to monitoring points. Data were generated with AutoCAD files created by Wetland Studies and Solutions, Inc.

\begin{tabular}{|c|c|c|}
\hline Subcatchment & Subcatchment Feature & Area \\
\hline \multirow[t]{5}{*}{ DP3 } & Total $\left(\mathrm{ft}^{2}\right)$ & 28,470 \\
\hline & Impervious pavement & $63 \%$ \\
\hline & Permeable pavement (Pavers and GravelPave2) & $19 \%$ \\
\hline & Grass & $9 \%$ \\
\hline & Native vegetation & $8 \%$ \\
\hline \multirow[t]{3}{*}{ DP4 } & Total $\left(\mathrm{ft}^{2}\right)$ & 4,390 \\
\hline & Permeable pavement (Pavers) & $52 \%$ \\
\hline & Native Vegetation & $48 \%$ \\
\hline \multirow[t]{4}{*}{ BS } & Total $\left(\mathrm{ft}^{2}\right)$ & 25,790 \\
\hline & Impervious pavement & $59 \%$ \\
\hline & Permeable pavement (Pavers) & $2 \%$ \\
\hline & Native vegetation & $40 \%$ \\
\hline \multirow[t]{4}{*}{ RG } & (excluding roof areas) & 17,710 \\
\hline & Impervious pavement & $42 \%$ \\
\hline & Grass & $50 \%$ \\
\hline & Native vegetation & $9 \%$ \\
\hline \multirow[t]{3}{*}{$\mathbf{C 2}$} & Total $\left(\mathrm{ft}^{2}\right)$ & 32,450 \\
\hline & Reflective roof (impervious) & $87 \%$ \\
\hline & Green roof & $13 \%$ \\
\hline \multirow[t]{4}{*}{ ORI } & Total $\left(\mathrm{ft}^{2}\right)$ & 24,660 \\
\hline & Impervious pavement & $9 \%$ \\
\hline & Permeable pavement (GravelPave2) & $82 \%$ \\
\hline & Grass & $9 \%$ \\
\hline \multirow[t]{3}{*}{ DP1/ORI } & Total $\left(\mathrm{ft}^{2}\right)$ & 15,050 \\
\hline & Impervious pavement & $91 \%$ \\
\hline & Permeable pavement (Gravel) & $9 \%$ \\
\hline \multirow{2}{*}{ Site-wide } & Total asphalt $\left(\mathrm{ft}^{2}\right)$ & $55,900(38 \%)$ \\
\hline & Total impervious $\left(\mathrm{ft}^{2}\right)$ & $59,980(41 \%)$ \\
\hline
\end{tabular}

Table 8. Slope and diameter data generated for the calculation of flow from depth data provided at each stilling-well-gaged measurement point, and the pipe length used for generation of the slope data.

\begin{tabular}{|c|c|c|c|}
\hline Location & $\begin{array}{l}\text { Diameter } \\
\text { (in) }\end{array}$ & $\begin{array}{c}\text { Pipe } \\
\text { Length (ft) }\end{array}$ & Slope (ft/ft) \\
\hline DP3 & 6.05 & $\bar{N} / \mathrm{A}$ & $0.0001^{\star}$ \\
\hline DP4 & 4 & 94 & 0.029 \\
\hline C3 & 7.94 & 154 & 0.032 \\
\hline RG & 6.05 & 48 & 0.037 \\
\hline GR & 6.05 & NA & $0.005^{\star}$ \\
\hline
\end{tabular}




\subsection{Identification of the Zero-Flow Depth}

As indicated in Section 4.1, the zero-flow depth is the most sensitive parameter in the calculation of outflow and in hydrograph interpretation based on depth measurements. The user can calibrate the zero-flow depth with each storm event. In general, sensor readings between rainfall events output the zero-flow depth sufficiently long for identification of its value to the precision required (about +/- 0.03 inches). At the end of any runoff event, when the zero-flow depth stabilizes, evaporation is not likely to occur for several hours due to ambient moisture in the system. This event-based calibration technique is especially meaningful because it negates any interference that would alter the absolute depth readings (in particular, long-term sensor drift or induced pressure in the enclosures that house the sensor air tubing). An example of this zero-flow depth determination technique is illustrated in Figure 25. Recall that Figure 17 suggests that the requisite precision for identification of the zero-flow depth is around +/- 0.03 inches; data such as this allow identification well within that range of precision.

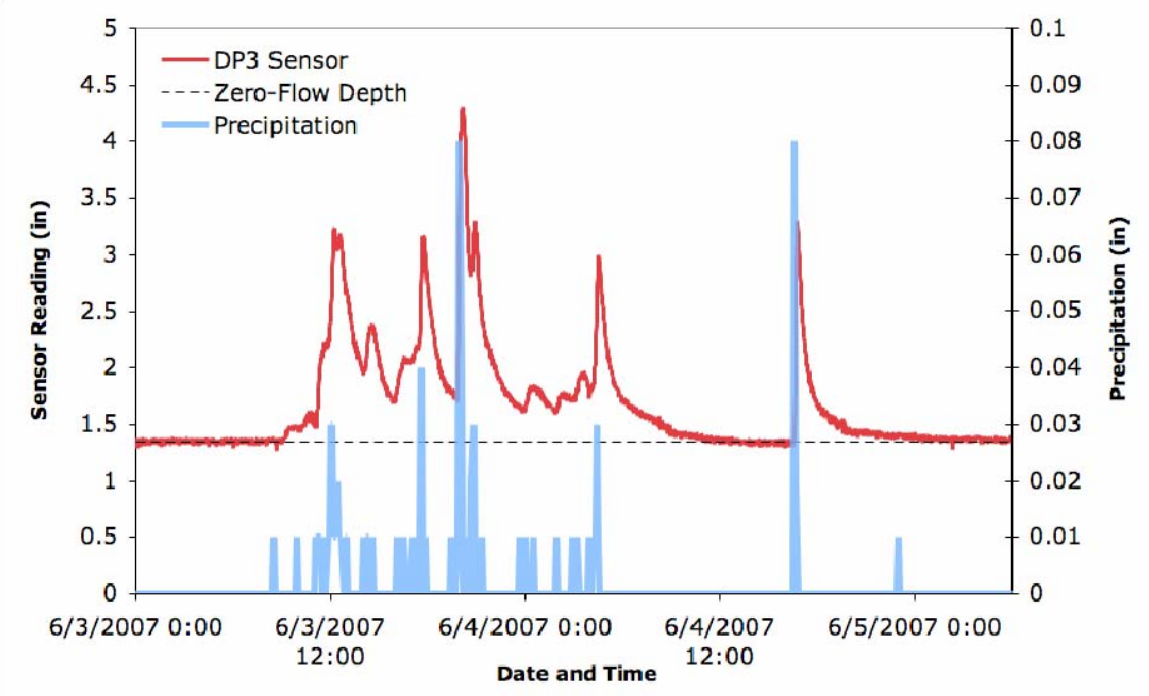

Figure 25. Zero-flow depth determination of 1.34 inches from sensor depth readings at measurement point DP3, already offset by approximately 16 inches for the stilling well. Precipitation began 3 June 2007 and resulted in 0.8 inches of rain. 


\subsection{Results and Discussion}

\subsubsection{Monitoring Point DP4 - Northeast Outfall}

The DP4-gaged watershed is approximately half porous pavement and half native vegetation (see Table 7 for proportions, see Figure 2 and Figure 3 for schematics). It is expected to have relatively high retention because every surface is permeable. Results from two mid-May storm events are shown in Figure 26 and Figure 27. The higher intensity storm leads to notably lower percent retention. The 18 May storm event (Figure 27) illustrates clearly the responsiveness of the outflow to intra-event rainfall pulses. Delayed runoff is likely the result of the system reaching its saturation threshold. This could be a volume-based response within the pervious pavement LID device (concrete pavers) or the native vegetation. Each of the peaks may be related to threshold responses where water fills void spaces and flushes once saturation connects those filled voids.

Data from three storm events on 28 June, 29 June, and 5 July are plotted in Figure 28 , along with cistern depth measurements. This figure illustrates the influence of the irrigation water being pumped from the cistern into drip irrigation lines on the DP4 watershed (see watershed schematic in Figure 3). The water level in the cistern drops in response to it being pumped. During the pumping periods, DP4 is receiving an excess of irrigation water such that runoff is generated. Based on the zero-flow depth identified therein, it is evident that irrigation water and rainfall are both contributing to runoff on 28 June and 5 July. As a result, rainfall and irrigation water could not be distinguished, and the data was not used to determine percent retention of rainfall on the DP4 watershed. Data from the 29 June rainfall event is plotted in Figure 29.

Results from the three storm events analyzed are shown in Table 9. The depth of rainfall before the release of runoff is similar for each storm event except for the very small 
rain event on 29 June. The antecedent dry condition and depth of rainfall before runoff occurs appears to be directly proportional to each other. Excessively wet conditions at the start of the small (0.03-inch) 29 June rainfall event, which immediately followed the 0.4-in (0.22 in/hr) rain event (plus irrigation) on 28 June, is a likely cause of the rapid runoff and lower percent retention from the 29 June storm event. The additional retention exhibited in the 18 May data is likely the result of drier conditions prior to the storm event.

The lower intensity ( $0.06 \mathrm{in} / \mathrm{hr}$ ) rain event on 18 May delayed the peak runoff by 5 hours. This is 23 times longer than the higher intensity ( $0.90 \mathrm{in} / \mathrm{hr})$ rain event on 16 May that delayed the peak runoff by 0.22 hours. It might be expected that the volume of rain from the 16 May storm event would have 23 times the amount of precipitation. However, the 16 May rain event received only 1.6 times the amount of precipitation as that from the 18 May rain event (0.27 inches compared to 0.17 inches on 18 May).

Curve numbers presented here were not adjusted for antecedent moisture conditions because conditions were considered average. Curve numbers are different for each storm event where, theoretically, they should be the same. In addition, curve numbers appear high when compared to the literature. Fennessey and Hawkins (2001) indicate that the CN parameter "relies implicity on the assumptions of extreme runoff events" where, "during non-extreme runoff events in humid regions, the underlying assumptions are almost never valid.” In order for runoff to be generated from the high frequency (low intensity) storm events that have been analyzed here, curve number values must be high. It is possible that these low intensity storm events in the humid region of Gainesville are outside of the calibrated range of the NRCS CN model.

It is also possible that the DP4 watershed $\left(4390 \mathrm{ft}^{2}, 0.10 \mathrm{ac}\right)$ is smaller than watershed sizes for which the empirical CN model has been calibrated. The model was 
developed for runoff from agricultural watersheds, but historical literature does not indicate what watershed sizes were originally used for calibration (Fennessey and Hawkins 2001). Only a few papers have been published suggesting from what watersheds the original data may have come (Fennessey and Hawkins 2001). Agricultural watersheds used for model calibration are likely to have been larger than the less than 1-ac watersheds analyzed at the Gainesville site.

The C-values are very low. The actual time of concentration may be shorter or longer than the design value of 5 minutes. It is possible that the rational method model is insufficient for predicting peak flow rates because vertical downward flow through porous pavement features conveys and concentrates the flow differently than sloped sheet flow for which the model is used.

Data extending before and after the May events shown here was not available because data output was programmed to record only readings above a user-specified offset. It is possible that data interpretation was inhibited by the lack of surrounding data points that inform the presence of irrigation or illustrate more extensively the stabilization of sensor readings at the zero-flow depth. The 29 June event has a clearly identifiable zero-flow depth that is not affected by irrigation as evidenced in Figure 28. Figure 29 is a hydrograph of the 29 June event. Each of the three outflow hydrographs evaluated at DP4 show increasing runoff peak delay time with increasing storm duration. Additionally, if the actual pipe slope in the field is different than the 0.029-slope drawn in the plan sets, results will be altered to the extent previously illustrated in Figure 18. 


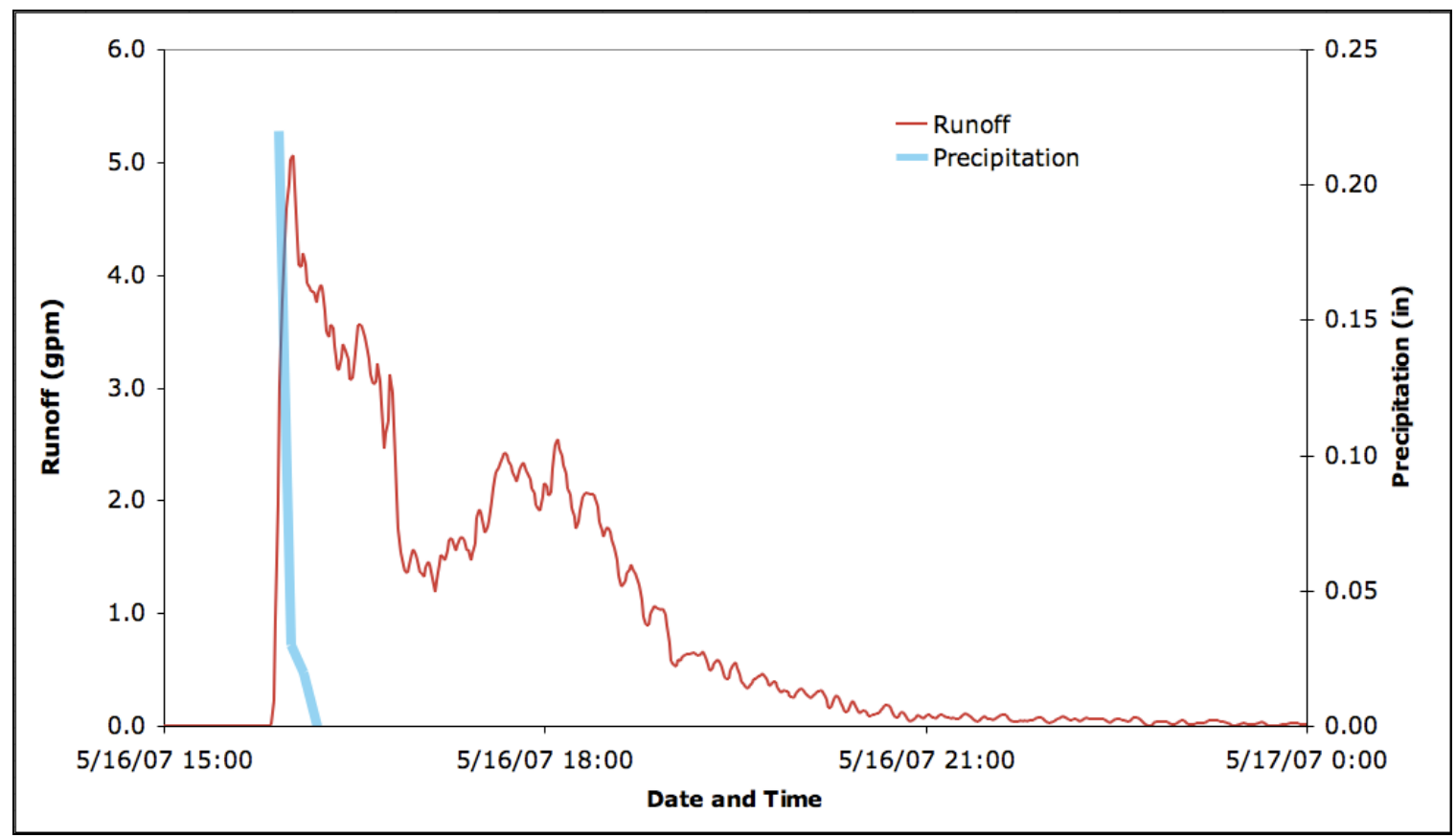

Figure 26. Runoff hydrograph generated from data recorded at measurement point DP4 (porous concrete pavers and native vegetation) for precipitation beginning 16 May 2007.

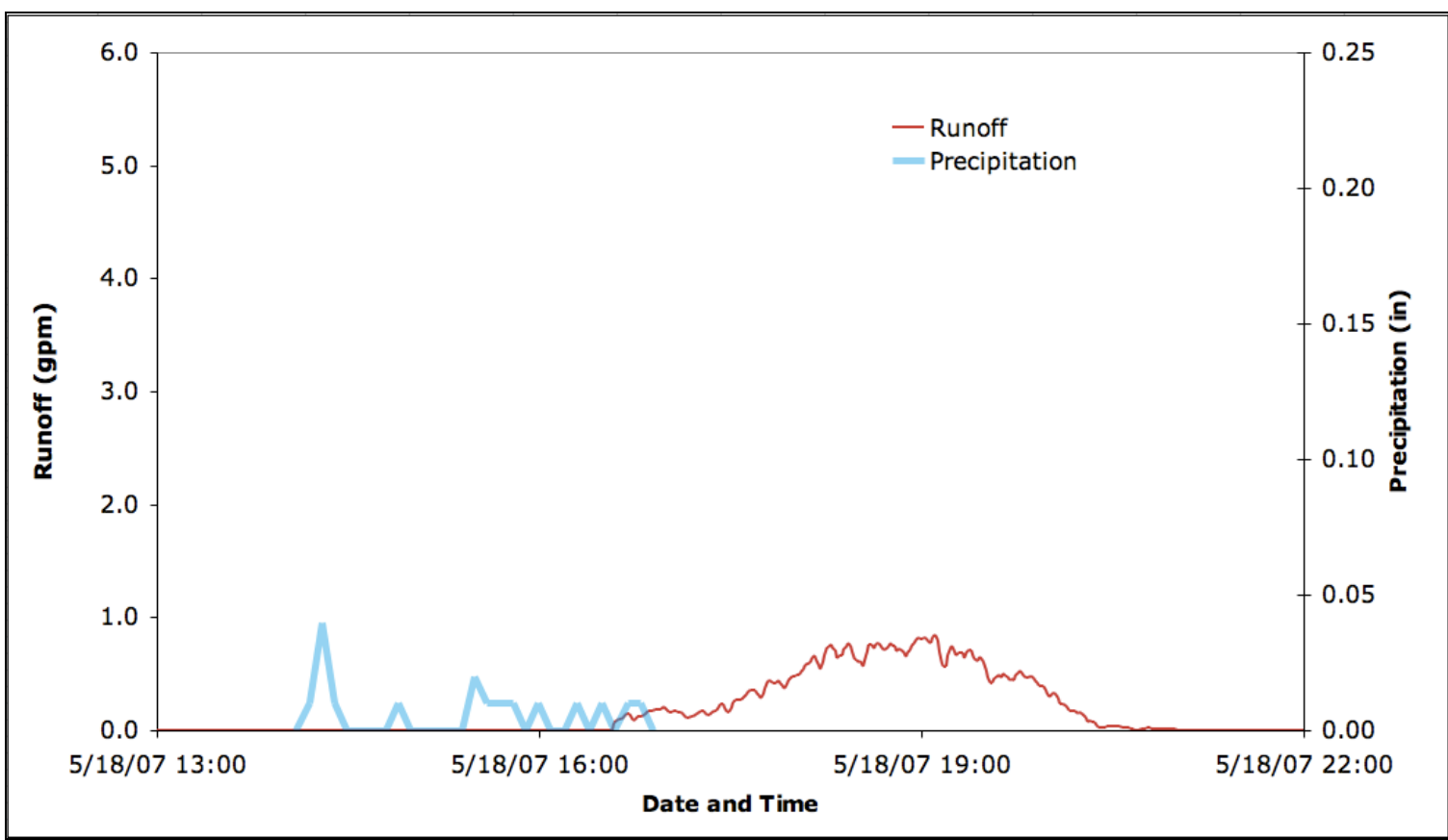

Figure 27. Runoff hydrograph generated by data recorded at measurement point DP4 (porous pavement and native vegetation) for precipitation beginning 18 May 2007. 


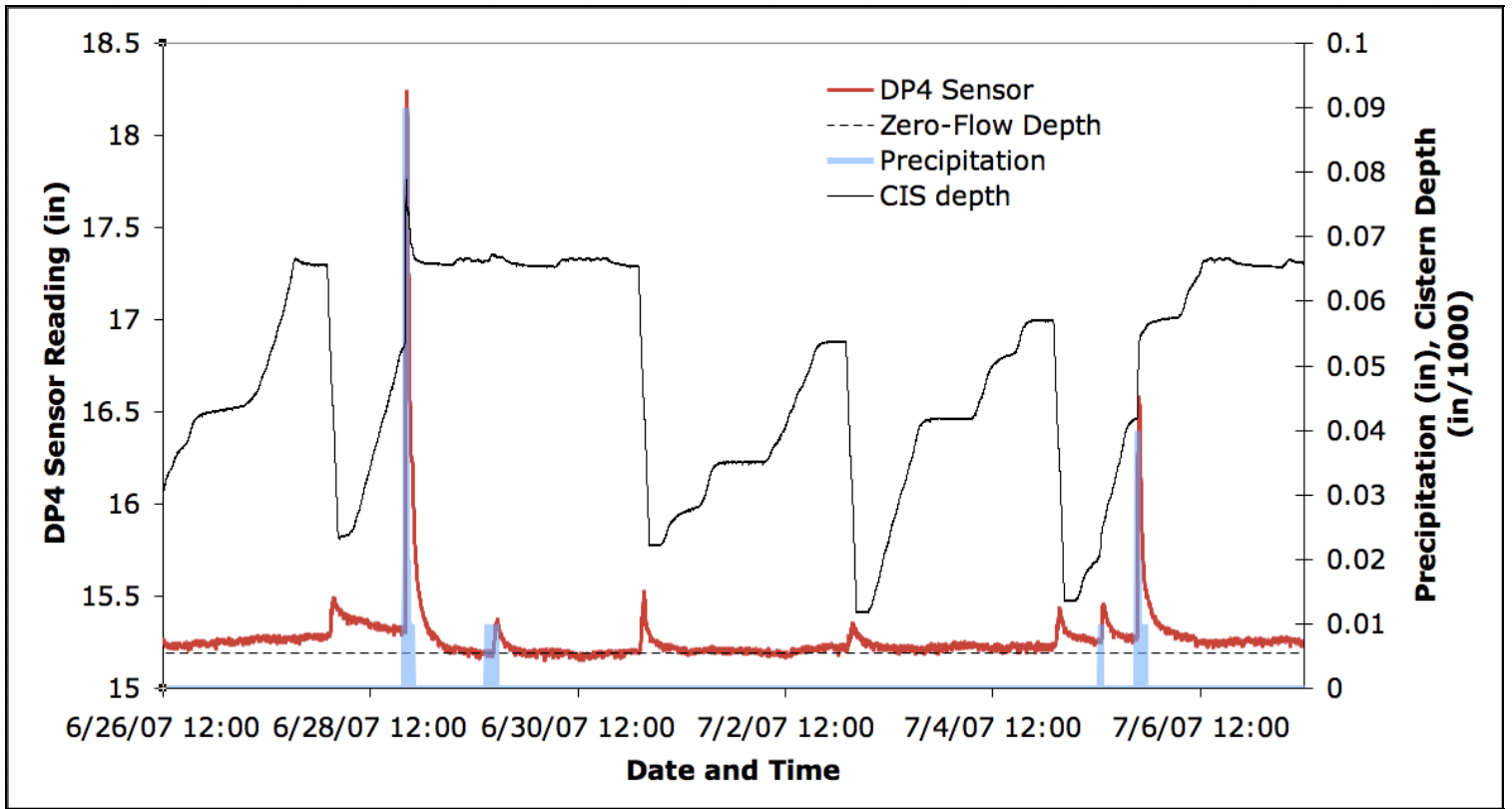

Figure 28. Runoff hydrograph generated from data recorded at measurement point DP4 (porous pavement and native vegetation) illustrating responses to both precipitation and cistern irrigation.

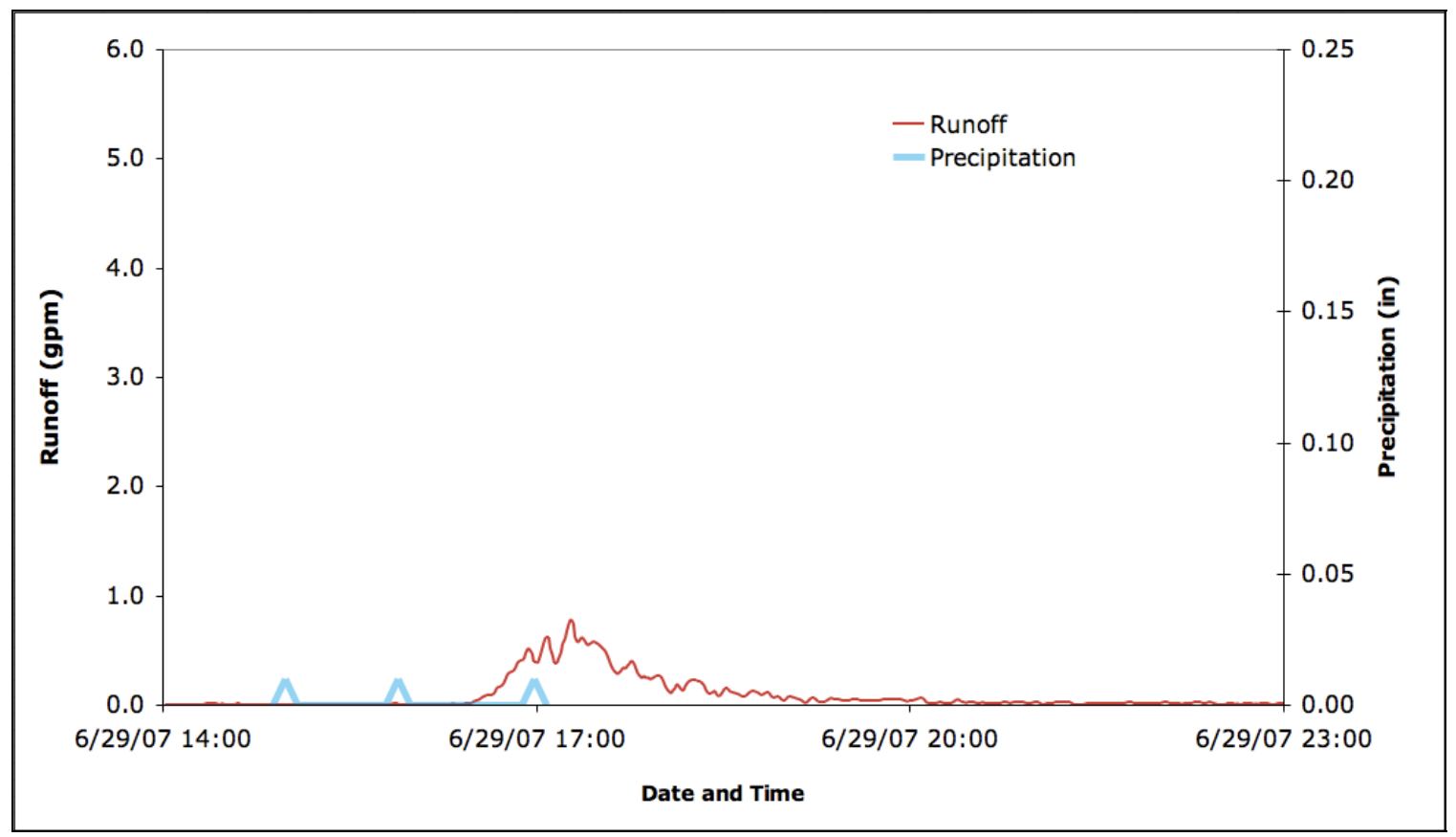

Figure 29. Runoff hydrograph generated from data recorded at measurement point DP4 (porous pavement and native vegetation) for precipitation event beginning 29 June 2007. 
Table 9. Hydrologic characteristics of precipitation and DP4 subwatershed. Ranges are generated by adjusting the zero-flow depth by $+/-0.03$ inches.

\begin{tabular}{|c|c|c|c|}
\hline Hydrologic Characteristics & 16-May & 18-May & 29-Jun \\
\hline \multicolumn{4}{|l|}{ Precipitation } \\
\hline Total Depth (in) & 0.27 & 0.17 & 0.03 \\
\hline Duration (hrs) & 0.3 & 2.7 & 2.1 \\
\hline Intensity (in/hr) & 0.90 & 0.06 & 0.01 \\
\hline Storm Frequency & 1-yr, 2-hr & $>1-y r, 2-h r$ & $>1-y r, 2-h r$ \\
\hline Antecedent Dry (d) & 4.45 & 1.92 & 0.72 \\
\hline \multicolumn{4}{|l|}{ DP4 - Northeast Outfall } \\
\hline \multicolumn{4}{|l|}{ RUNOFF QUANTITIES } \\
\hline Rainfall Volume (gal) & 739 & 465 & 82 \\
\hline Runoff Volume (gal) & 469 & 99 & 49 \\
\hline Runoff Retention & $37 \%$ & $79 \%$ & $41 \%$ \\
\hline Range & $20-50 \%$ & $68-86 \%$ & $N^{*} A^{\star}-69 \%$ \\
\hline Peak Outflow (gpm) & 5.1 & 0.85 & 0.78 \\
\hline Range & $4.4-5.7$ & $0.61-1.1$ & $N^{*} A^{*}-1.1$ \\
\hline \multicolumn{4}{|l|}{ RUNOFF TIMING } \\
\hline Precip. Depth at Start of Runoff (in) & 0.22 & 0.15 & 0.02 \\
\hline Peak Delay (hrs) & 0.22 & 5.0 & 2.4 \\
\hline Duration (hrs) & 6.8 & 4.5 & 9.7 \\
\hline \multicolumn{4}{|l|}{ RUNOFF PARAMETERS } \\
\hline Curve Number & 99 & 97 & 100 \\
\hline Range & $98-99$ & $97-98$ & $N^{*} A^{*}-100$ \\
\hline C - Value & 0.05 & 0.05 & 0.17 \\
\hline Range & $0.04-0.06$ & $0.03-0.06$ & $N^{*} A^{*}-0.24$ \\
\hline
\end{tabular}

\subsubsection{Monitoring Point DP3 - West Outfall}

Monitoring point DP3 records data from a very large subwatershed with 63\%

impervious pavement, the majority of which is asphalt (see Table 7). The subwatershed includes two types of porous pavements, Gravelpave 2 and concrete pavers, which together account for $19 \%$ of the area (see Figure 2 and Figure 3 for schematics). It has only a small strip of native vegetation ( $8 \%$ of the subwatershed), and, as expected, it does not exhibit flow due to irrigation on that parcel (unlike the subwatershed monitored at DP4). This watershed is expected to have a low percent reduction in runoff due to the high percent of impervious surface.

Specific hydrographs from the four storm events analyzed here are shown in Figure 30, Figure 31, Figure 32, and Figure 33. The previous Figure 25 illustrates the sensor's high stability between storm events for the identification of the zero-flow depth. Because of the 
stability of the zero-flow depth in the DP3 hydrographs, data ranges based upon a varied zero-flow depth are not reported in results in Table 10. Variability from the findings is more likely due to unknown field conditions.

Recent field measurements of the slope at measurement point DP3 (on 13 July 2007) found a slightly negative slope of 0.014 using an 8.4-inch run of pipe. Algae collect in the outlet of this discharge point. The slope in the plan sets for the pipe at DP3 was a steep 0.089, an unexpectedly large variation from the actual slope in the field resulting in a significant discrepancy in calculated flow rates (see Figure 18). For the purposes of reporting the results at this time (and because the as-built slope measurement was taken from only a short length of pipe), a slope of practically 0 (0.0001) is assumed for all data from monitoring point DP3. Backwater effects could be calculated more specifically through modeling using HEC-RAS or culvert equations as found in Sturm (2001).

The curve number calculated from the 4-June storm event was adjusted for antecedent moisture conditions to Condition III, occurring after rain that was considered recent and heavy enough to create saturated conditions. Curve numbers are 86 and higher, which is characteristic of land-uses such as streets and roads (Wurbs and James 2002). Due to the $63 \%$ impervious asphalt, this is not unreasonable. C-values are again very low.

Table 10 illustrates high retention within subwatershed DP3 (87\% and higher). As shown in Figure 34, water bypasses the DP3 measurement point between the parking abutment (placed to help remedy the erosion caused by flow across this bypass point) and the curb. The image also shows that inflow entering the Gravelpave2 porous pavement away from the bypass is captured efficiently. The quantity bypassing the DP3 measurement point is unknown but appears significant. Figure 35 gives an idea of the depth of flow at this bypass point. 
High runoff retention was not expected in this subcatchment. Runoff retention will be substantially decreased once bypass flows are taken into account, and curve numbers will increase. It remains possible that the curve number model is not applicable to this small (0.65-acre) site.

Precipitation depths at the time that runoff begins are similar across all storm events, and all storm intensities were equally similar, though total precipitation depths varied from 0.04 to 0.8 inches. These data suggest that storm intensities are the greatest factor on the timing of the peak runoff.

Table 10. Hydrologic characteristics of precipitation and DP3 subwatershed.

\begin{tabular}{|c|c|c|c|c|}
\hline Hydrologic Characte ristics & 5-May & 12-May & 3-Jun & 4-Jun \\
\hline \multicolumn{5}{|l|}{ Precipitation } \\
\hline Total Depth (in) & 0.04 & 0.23 & 0.80 & 0.11 \\
\hline Duration (hrs) & 1.0 & 8.8 & 20 & 6.5 \\
\hline Intensity (in/hr) & 0.04 & 0.03 & 0.04 & 0.02 \\
\hline Storm Frequency & $>1-\mathrm{yr}, 2-\mathrm{hr}$ & $>1-\mathrm{yr}, 2-\mathrm{hr}$ & $>1-\mathrm{yr}, 2-\mathrm{hr}$ & $>1-\mathrm{yr}, 2-\mathrm{hr}$ \\
\hline Antecedent Dry (d) & 9.3 & 7.2 & 16 & 0.50 \\
\hline \multicolumn{5}{|l|}{ DP3 - West Outfall } \\
\hline \multicolumn{5}{|l|}{ RUNOFF QUANTITIES } \\
\hline Rainfall Volume (gal) & 710 & 4082 & 14199 & 1951 \\
\hline Runoff Volume (gal) & 50 & 431 & 1802 & 164 \\
\hline Runoff Retention & $93 \%$ & $89 \%$ & $87 \%$ & $92 \%$ \\
\hline Peak Outflow (gpm) & 0.8 & 6.6 & 14 & 6.7 \\
\hline \multicolumn{5}{|l|}{ RUNOFF TIMING } \\
\hline Precip. Depth at Start of Runoff (in) & 0.02 & 0.03 & 0.02 & 0.08 \\
\hline Peak Delay (hrs) & 0.67 & 3.6 & 12 & 0.27 \\
\hline Duration (hrs) & 4.4 & 11 & 22 & 2.9 \\
\hline \multicolumn{5}{|l|}{ RUNOFF PARAMETERS } \\
\hline Curve Number & 99 & 95 & 86 & 96 \\
\hline C - Value & 0.01 & 0.07 & 0.06 & 0.03 \\
\hline
\end{tabular}




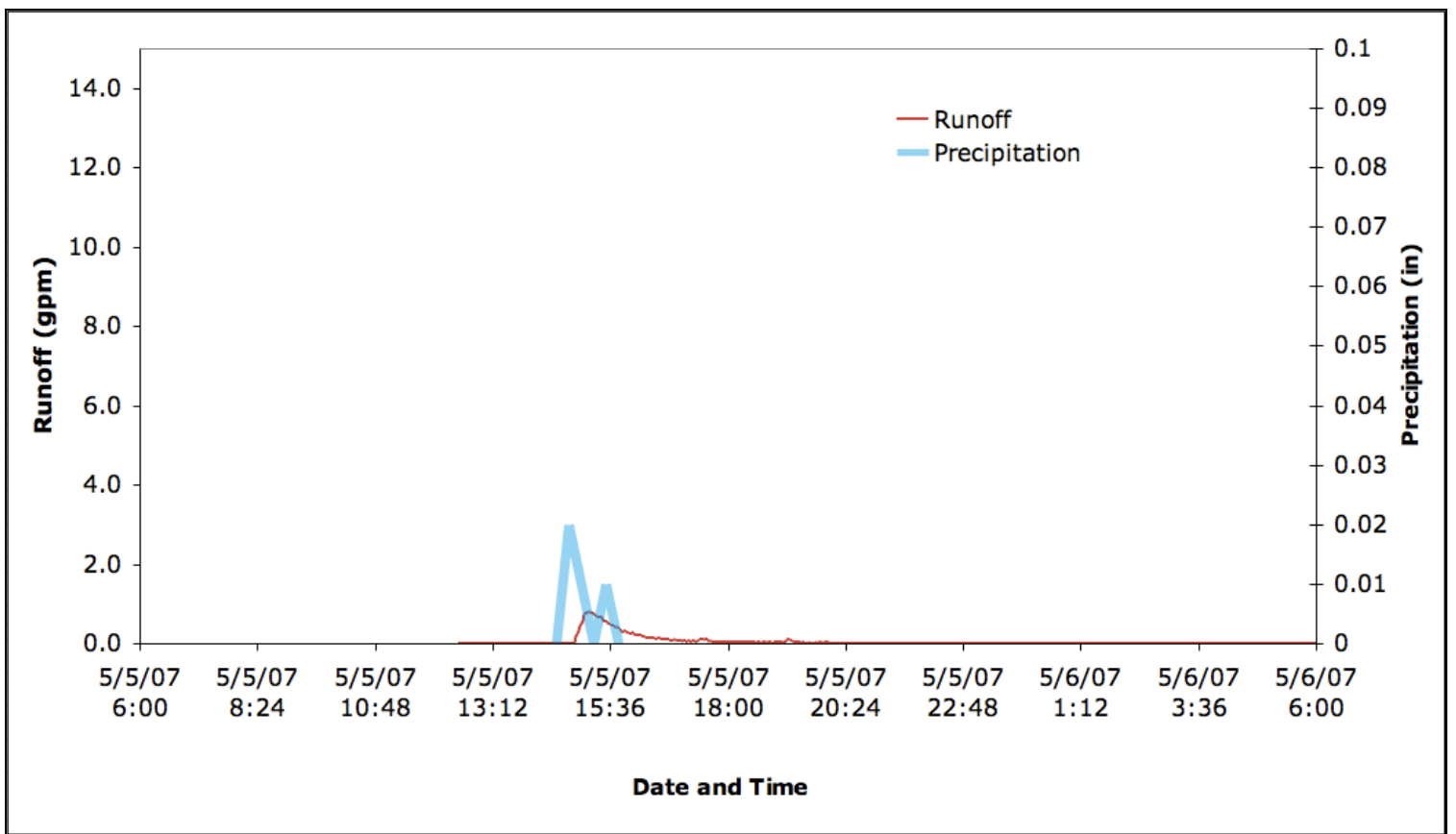

Figure 30. Runoff hydrograph generated from data recorded at measurement point DP3 (asphalt, porous pavement, native vegetation) from precipitation beginning 5 May 2007.

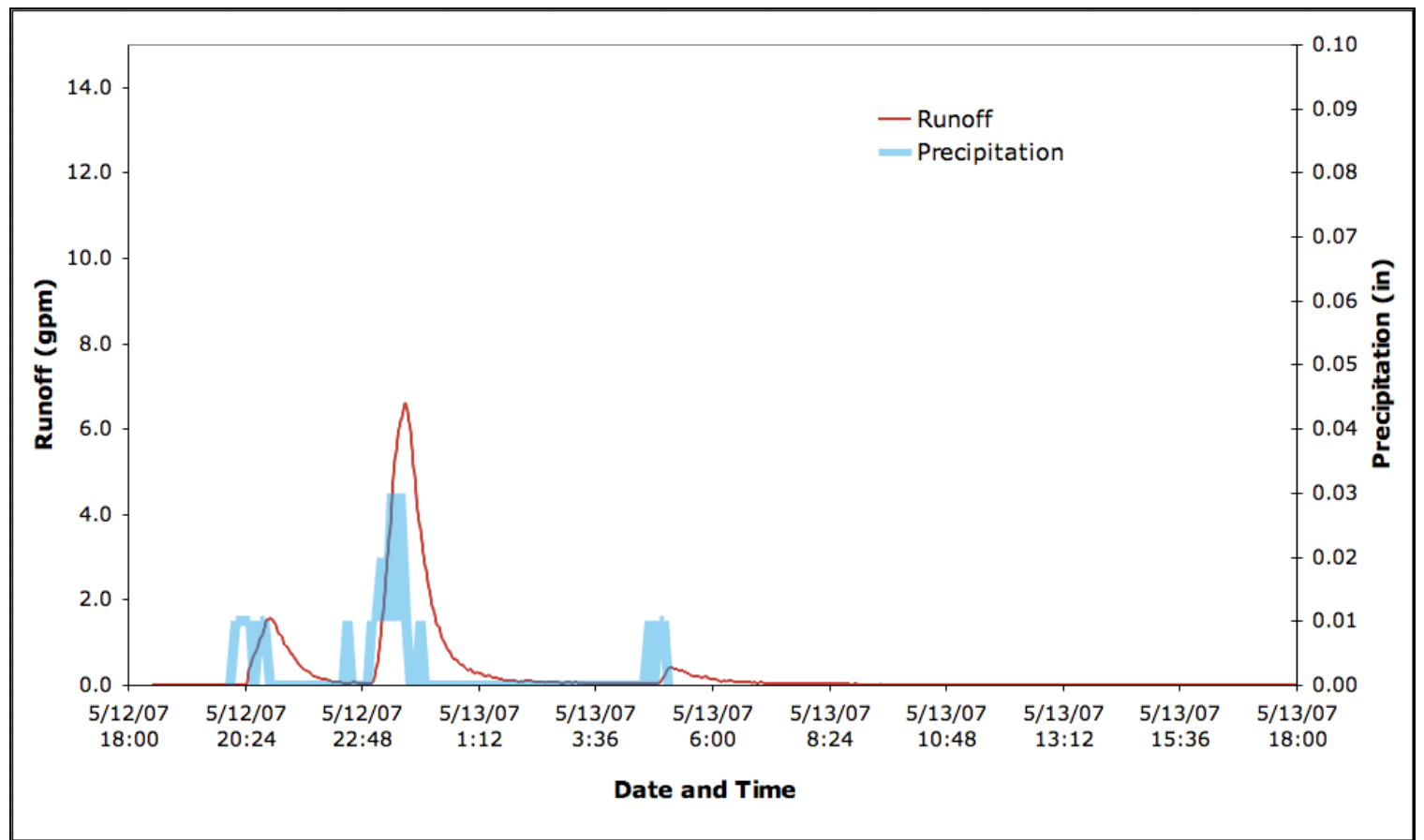

Figure 31. Runoff hydrograph generated from data recorded at measurement point DP3 (asphalt, porous pavement, native vegetation) from precipitation beginning 12 May 2007. 


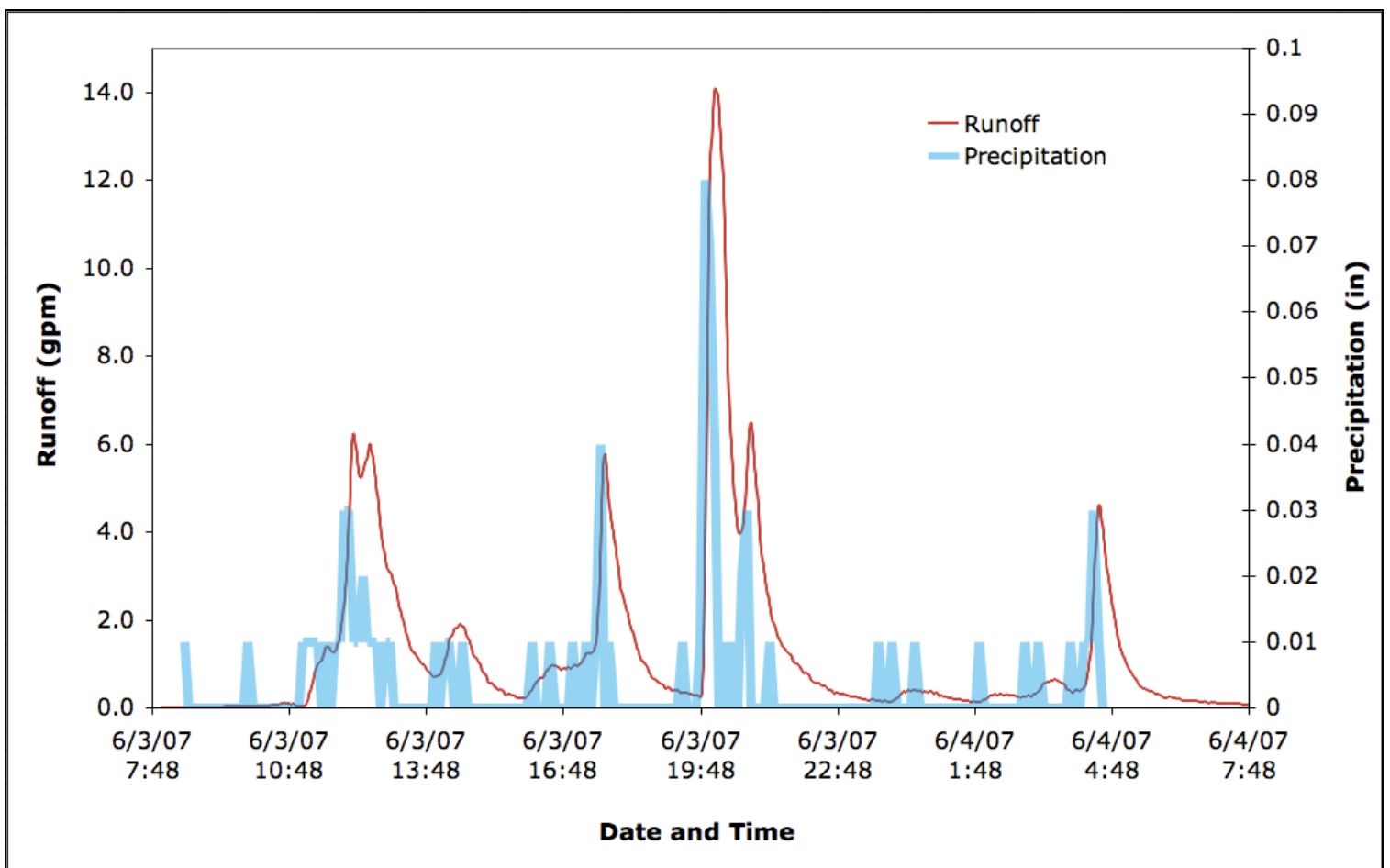

Figure 32. Runoff hydrograph generated from data recorded at measurement point DP3 (asphalt, porous pavement, native vegetation) from precipitation beginning 3 June 2007.

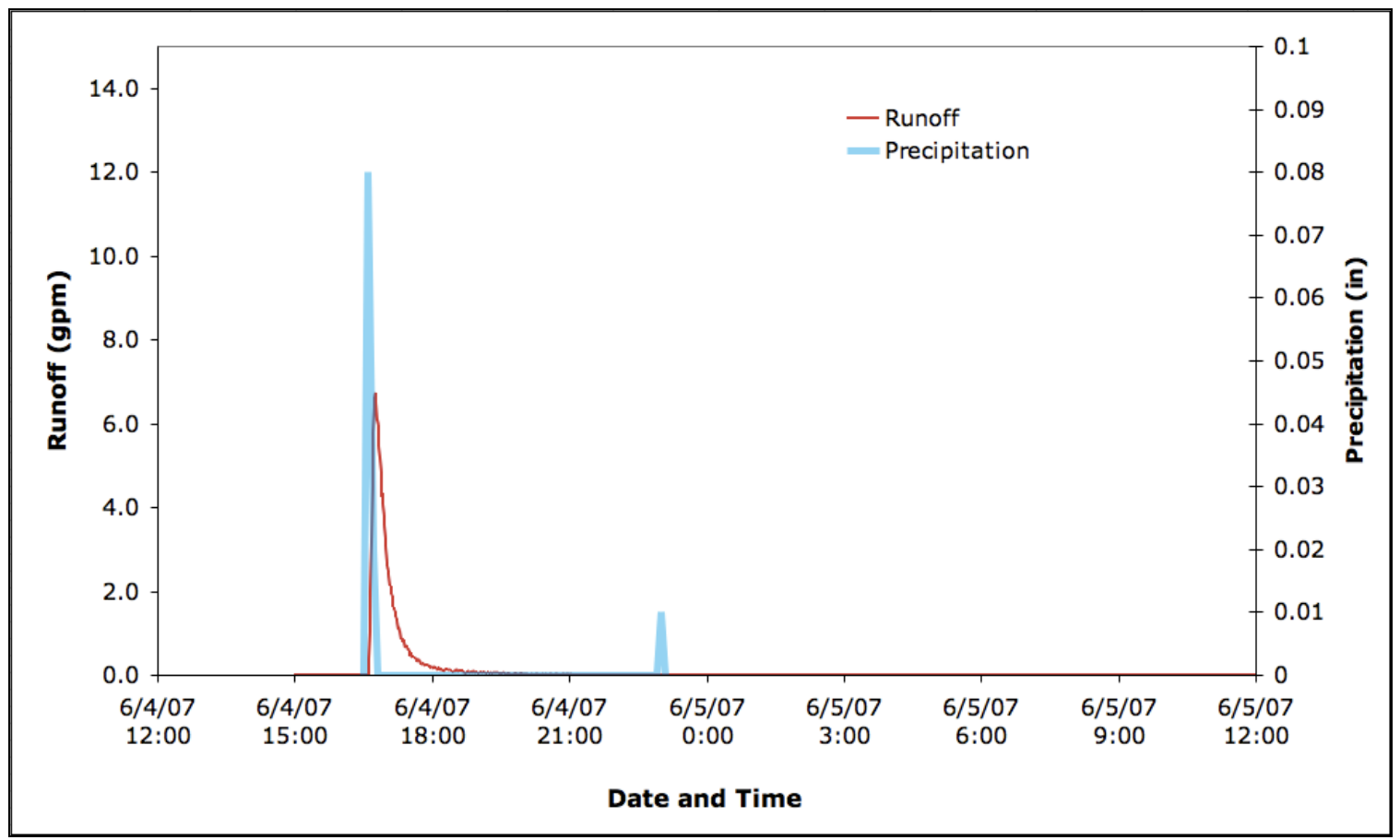

Figure 33. Runoff hydrograph generated from data recorded at measurement point DP3 (asphalt, porous pavement, native vegetation) from precipitation beginning 4 June 2007. 


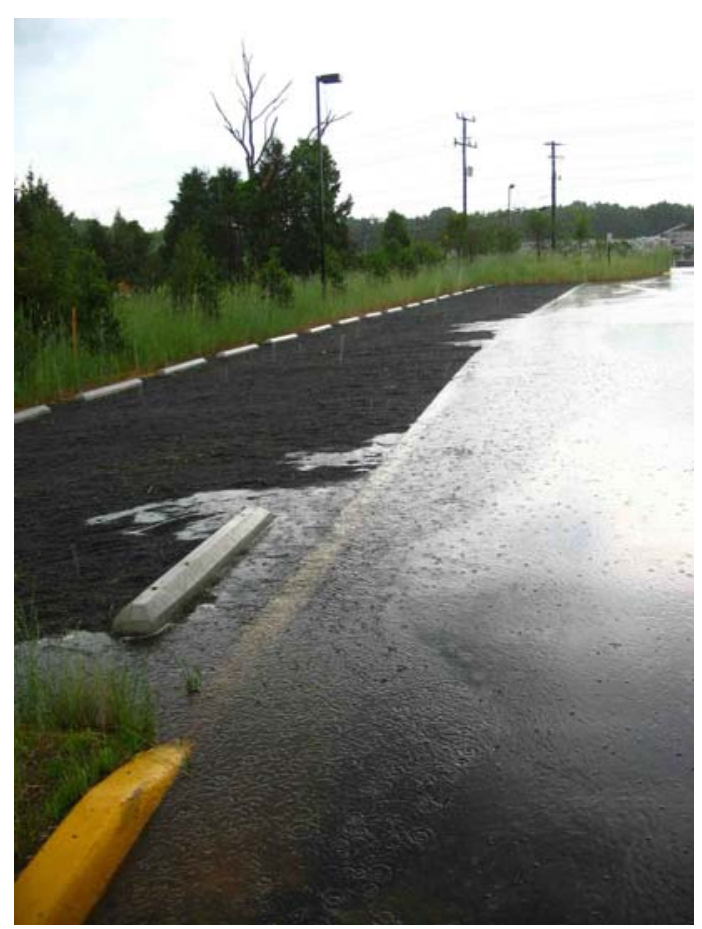

Figure 34. Runoff across watershed monitored at measurement point DP3, illustrating the high infiltration rate of Gravelpave2 porous pavement (left in photo) receiving runoff from the impervious asphalt (right in photo). The flow bypassing the DP3 monitoring point between the parking abutment and the orange curb is also evident, (Copyright 2006, Wetland Studies and Solutions, Inc.).

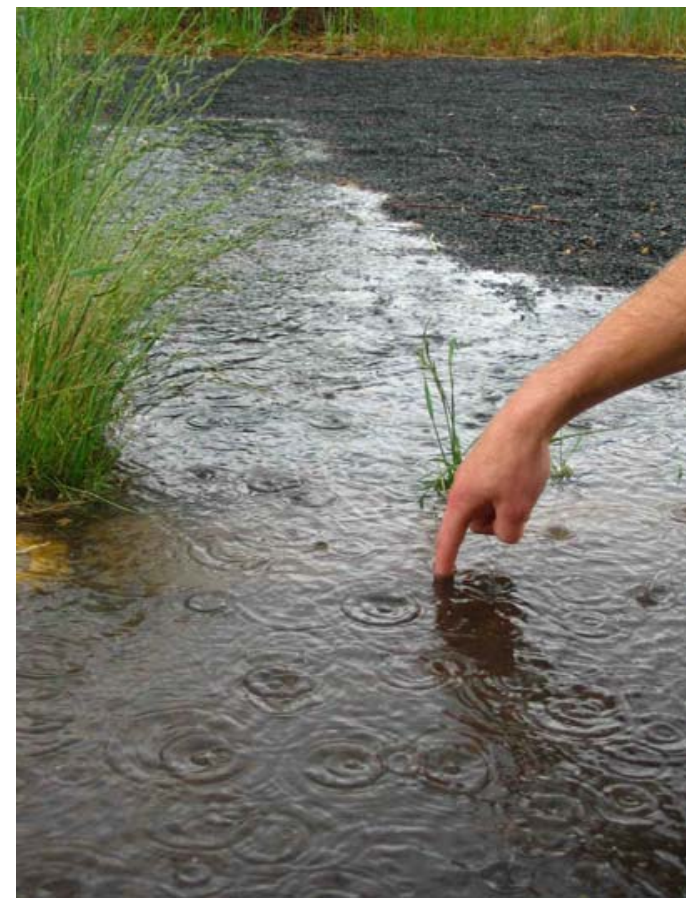

Figure 35. Characterization of flow depth and magnitude of runoff bypassing measurement point DP3, (Copyright 2006, Wetland Studies and Solutions, Inc.). 


\subsubsection{Comparison of Hydrograph Shapes from Porous Pavement Runoff (DP3) and Cistern Emergency Overflow (C3)}

Hydrographs from monitoring points DP3 and C3 (the emergency outflow from the cistern to the underground gravel bed detention, see Figure 2 and Figure 3 for schematics) illustrate that the emergency outflow from the cistern is extremely flashy, as expected (Figure 36 and Figure 37). Outflow at DP3 is released over a longer period of time and has a more curved runoff hydrograph shape. Since no additional storage is available once the cistern fills to the overflow level, the outflow hydrograph resembles that of a curb and gutter drainage system where flow is conveyed without porous land-use features. The porous pavement (and the small strip of native vegetation) in the DP3 subcatchment has the intended effect of delaying the peak outflow and reducing the flashiness of runoff.

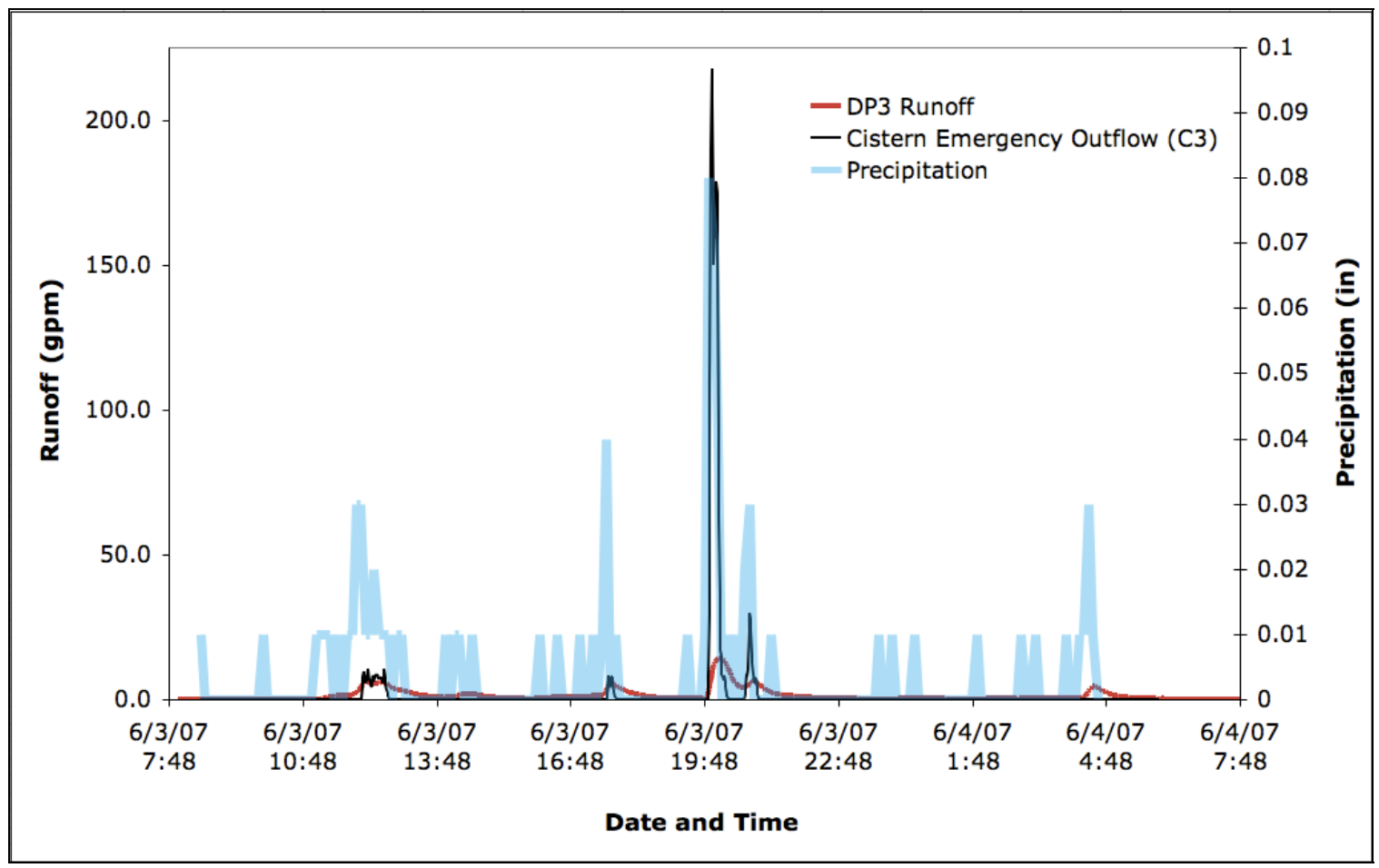

Figure 36. Runoff hydrographs generated from data recorded at monitoring points DP3 and C3 from precipitation beginning 3 June 2007. 


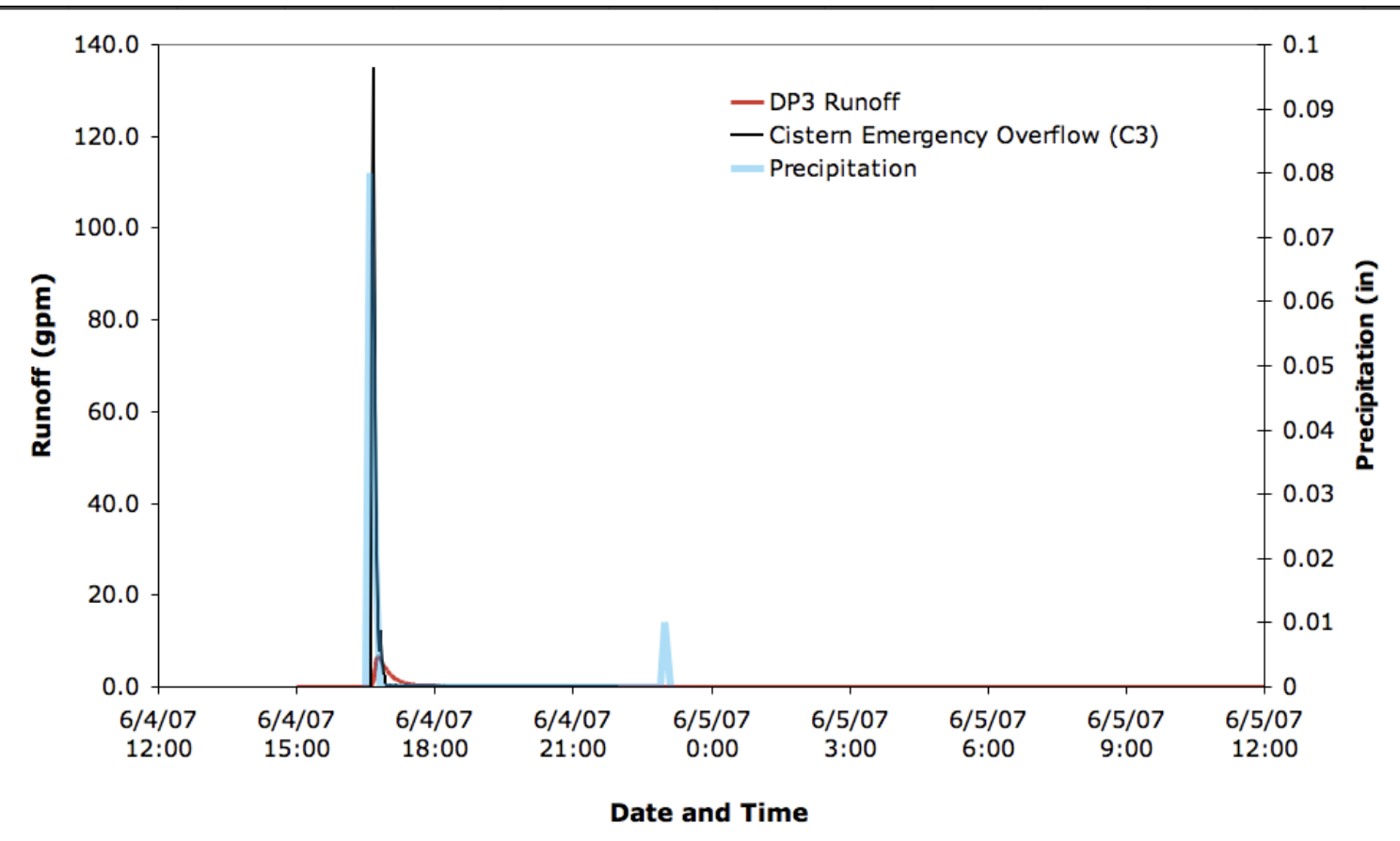

Figure 37. Runoff hydrographs generated from data recorded at monitoring points DP3 and C3 from precipitation beginning 4 June 2007.

\subsubsection{Monitoring Point GR - Green Roof Subwatershed}

Monitoring point GR was installed just below grade in a pipe that conveys flow from the six green roof drains to the cistern (see Figure 2 and Figure 3 for schematics). This data contributes to an understanding of the hydrologic characteristics of the green roof. Runoff hydrographs coming from the green roof illustrate that green roof irrigation generates runoff (see Figure 38).

The green roof irrigation system is automated. In Zone A (intensive and extensive regions) the system checks the moisture content of the growing medium every day at 6am, $12 \mathrm{pm}$, and $6 \mathrm{pm}$. If at any reading is below a moisture content of $25 \%$, the irrigation system is triggered, and city water runs through drip irrigation tubes for one hour. In Zone B (wetland regions) the system checks for a moisture content of $80 \%$ six times a day. Irrigation occurs for 5 minutes if the moisture content is less than $80 \%$ at any of those times. These 
routine irrigation events are evident in Figure 38 based upon flows measured at monitoring point GR.

The sensor in the cistern rises daily with each irrigation event. This is especially evident from 30 May to 3 June. On the 3 June and 4 June precipitation events, the green roof irrigation system has also been triggered. After these storm events, the cistern depth is again affected by the routine green roof irrigation, but at this point the cistern has reached its capacity just below the outlet to the rain garden (monitored at C2). The green roof irrigation runoff maintains the same trend, while cistern levels reflect only slight water level rises as water discharges through the rain garden outflow.

The invert of the outlet from the cistern to the rain garden is at a height of 65.5 inches based on the level to which the cistern depth recedes after it is filled with excess green roof irrigation water. Flow from the excess green roof irrigation water should theoretically be evident in measurements at monitoring point C2. However, the minimum flowrate measurable by the turbine meter at $\mathrm{C} 2$ is $5 \mathrm{gpm}$. The flow rate calculated from the rise of the cistern during a pre-June 3 event is $2.2 \mathrm{gpm}$, well below the minimum measurable flow rate of the turbine meter. Cistern activity before 1 June is likely due to a precipitation event on 27 May to 28 May, during which time the Gainesville rain gage was out of operation. The fall of the cistern depth on 29 May and 30 May is due to pumping of irrigation water from the cistern to the landscaping.

The long-term upward trend in the GR outflow data is a result of laboratory identified sensor drift over time resulting in significant differences only over long time periods. Laboratory results for one particular sensor illustrated about a 2-inch decline in sensor readings over a two-week time period. 
Automated green roof irrigation is in excess of approximately 1885 gallons on 1 June. This volume is equivalent to a depth of 0.83 inches of water across the $3,360-\mathrm{ft}^{2}$ green roof. This value may be lower in actuality due to daily solar-induced peaks in sensor readings as a result of lingering, post-troubleshooting effects of the electronic system. However, the increased magnitude of daily peak patterns from the pre- to the post- May 30 GR data implies that though solar peaks may be occurring, irrigation runoff is also occurring and to a greater magnitude (though differentiation has not taken place in the data presented here). Certainly field observation is required for verification of these findings.

Fortunately much of the irrigation runoff is stored in the cistern for later use in the landscape irrigation system. As noted previously, excess irrigation waters can even be conveyed to the rain garden when cistern levels are already high. Again, this results in additional beneficial use of the water, though it is not an intended feature of the green roof irrigation system.

It is evident that irrigation is taking place during the 3 June and 4 June storm events. However, the volume of flow off of the green roof, including the irrigation excess, can be calculated based on the data and two assumptions. The first assumption, based on field observation, is that the green roof drainage pipe that runs to the cistern was not installed with a $1 \%$ slope as the plans indicate. Rather, water ponds in the pipe at monitoring point GR. Since flow is conveyed towards the cistern during runoff events, it is assumed that the average slope over the total length of the pipe (45 feet of straight length) is sloped downward to the cistern, but it is extremely shallow. Data from the green roof reflect an assumed slope of 0.005 . The sensor readings do not exhibit any long periods of stability around a zero-flow depth. Results in Table 11 were found with a rough estimation of a zeroflow depth at 1.74 inches $+/-0.03$ inches. 
Results in Table 11 are used for the water balance established in Section 5.2.5.

Results from GR also emphasize the significance of the antecedent dry period. Though irrigation was actually maintaining moist conditions on the green roof prior to each storm event, antecedent moisture content was likely the greatest for the second storm event. The 3 June storm event resulted in a precipitation depth and volume of almost 8 times more than the 4 June storm event. However, the outflow from the 3 June storm event was many times less than from the 4 June event with respect to the hydrologic inputs.

Once flow from the reflective roof is contributing to the runoff (during storm events), flow from the roofs (reflective and green roofs) reaches the detectable limit of the monitored overflow to the rain garden nearly immediately (see C2 outflow hydrograph in Figure 38). It is evident that the large impervious reflective roof has an overwhelming impact on the system hydrology; since the green roof is only $11 \%$ of the total roof area and has modest detention capacity.

During large storm events (specifics unknown), it has been observed that the observation well above the fabricated stilling well fitting at GR fills with water. A pressurized system is generated in this case, likely due to the vertical drainage pipes that rapidly convey flow from the green roof to monitoring point GR. To date, the few data collected after system troubleshooting and between system down-time has not recorded a surcharge event. In this situation, Manning's equation is ineffective as a stage-discharge equation, and the level sensor readings can be used to relate the pressure head and orifice (pipe diameter) size and shape to the flowrate. 


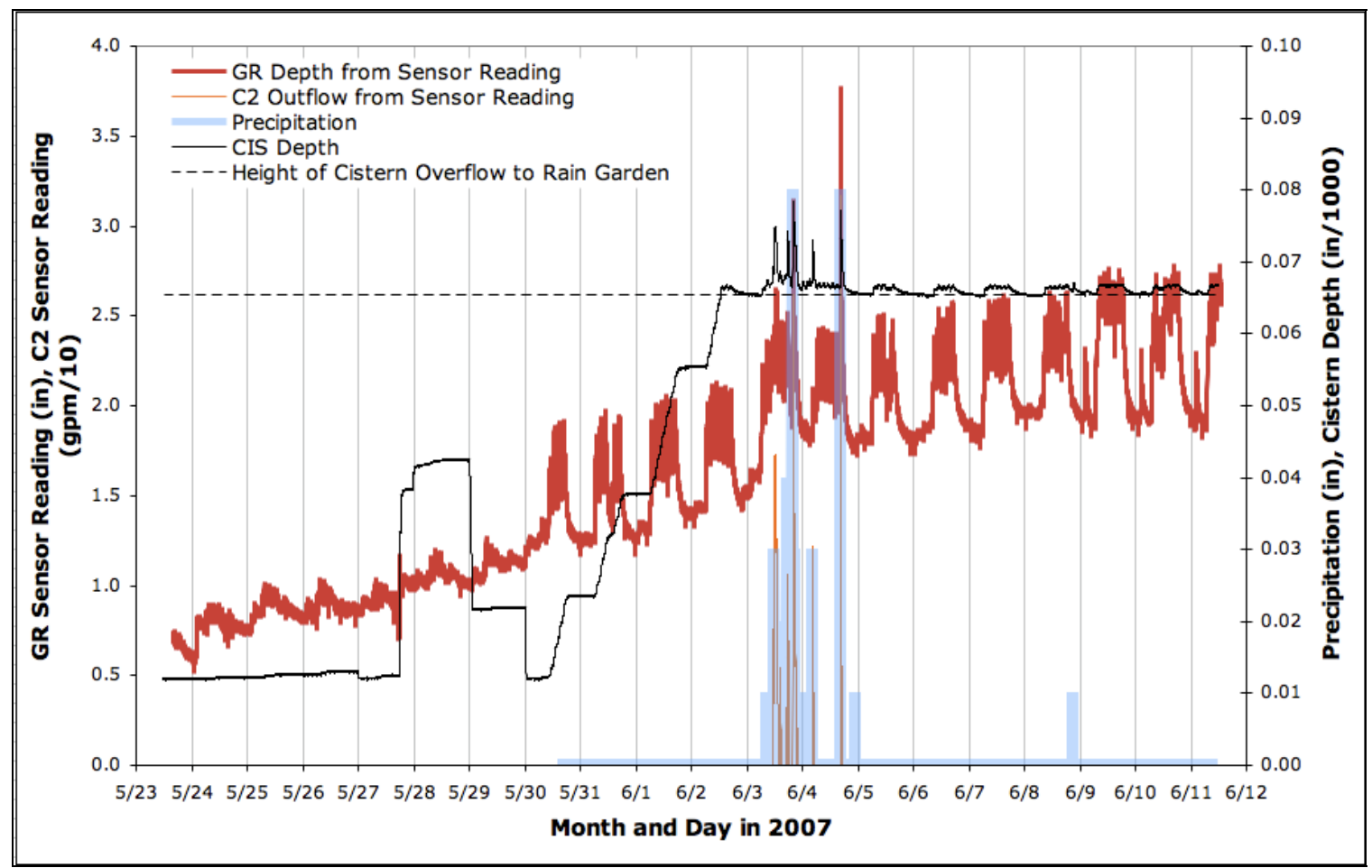

Figure 38. Sensor depth readings from monitoring point GR demonstrating the effects of excess green roof irrigation on cistern depth. Cistern overflow to the rain garden (monitoring point $\mathrm{C2}$ ) only breaches the minimum readable flow rate during a rain event, though the cistern is overflowing daily (approximately $2.2 \mathrm{gpm}$ ) from 6 June through 12 June.

Table 11. Hydrologic characteristics of precipitation and GR watershed including the effects of irrigation. Ranges are generated by adjusting the zero-flow depth by $+/-0.03$ inches.

\begin{tabular}{|r|r|r|}
\hline Hydrologic Characteristics & 3-Jun & 4-Jun \\
\hline Precipitation & & \\
Total Depth (in) & 0.80 & 0.11 \\
Duration (hrs) & 20 & 6.5 \\
Intensity (in/hr) & 0.04 & 0.02 \\
Storm Frequency & $>1-\mathrm{yr}, 2-\mathrm{hr}$ & $>1-\mathrm{yr}, 2-\mathrm{hr}$ \\
Antecedent Dry (d) & 16 & 0.50 \\
\hline GR & & \\
\hline RUNOFF QUANTTIES & & 249 \\
Rainfall Volume (gal) & 1810 & 1642 \\
Runoff Volume (gal) & 3859 & 1848 \\
Range & $3404-4355$ & $1456-13 \%$ \\
\hline Range & $188-241$ & $585-742$ \\
\hline Runoff Release (Incl. Irrigation)
\end{tabular}




\subsubsection{Cistern Water Balance for the 3 June Storm Event}

Data from the 3 June storm event (see Table 11 for storm characteristics) can be used to create a water balance related to the flow movement in and out of the cistern. Green roof inputs to the cistern are identified in Table 11. The reflective roof is assumed to have a NRCS runoff curve number of 98 (Wurbs and James 2002).

Outflow through the emergency overflow that flows directly to the underground detention flows through monitoring point C3. These flows can be determined by identifying the zero-flow depth as shown in Figure 39. Reduced zero-flow depth stability at this monitoring point is accounted for as leakage from the C3 stilling well as demonstrated in Figure 39.

Monitoring point C2 (cistern overflow to the rain garden) is monitored with a turbine meter. This turbine meter cannot measure flow rates below $5 \mathrm{gpm}$, and it is installed between two couples as shown previously in Figure 14. Inflow from the roofs and outflow through the emergency overflow, plus the condition of a full cistern (e.g., no available storage) at the beginning of the 3 June rain event, allow for the calculation of flow through C2 with Equation 9. The resulting water balance is illustrated in Table 12.

$$
\Delta S=I-O
$$

$\Delta S$ - Change in storage volume, equal to zero;

$I$ - Inflow volume to cistern from reflective and green roofs;

$\mathrm{O}-\quad$ Outflow volume from cistern through C3 (measured) and C2 (calculated).

This water balance demonstrates that flow through C2 is approximately 3.2 times that which the sensor is reading. This error is very high. It may be that turbulence from the upstream and downstream couples inhibits the free spinning of the turbine. A factor of 3.2 compared favorably with findings from flow calculations for low flows through C2: 
estimated flows from a conventional culvert equation (equation conditions of unsubmerged inlet, weir flow) for the 3 June storm event were compared to C2 measurements when the inlet was unsubmerged (based upon cistern depth measurements).

Another methodology for creating a water balance is to consider the change in cistern volume with respect to time. The validity of the differential cistern depth readings were tested in this way. Equation 10 expresses the known and unknown elements for the computation.

$$
\frac{d S}{d t}=I(t)-O(t)
$$

$$
\begin{aligned}
& \frac{d S}{d t}- \text { Change in storage with respect to time, calculated by with } \\
& \text { cistern depth measurements and cistern geometry; } \\
& I(t) \text { - Inflow rate to cistern from reflective and green roofs, calculated; } \\
& O(t) \text { - Outflow rate from cistern through C3 (measured) and C2 (measured } \\
& \text { and increased with } 3.2 \text { multiplier). }
\end{aligned}
$$

Data compared favorably. Inflow from the roofs was calculated to be 12797 gallons, which is only a 3.7\% difference from the previously determined value of 13281 gallons. Cistern data could be a good tool for modeling flow through the emergency outflow (C3) and to the rain garden (C2). Based upon the geometry of the cistern, the elevation and geometry of outlets, and the change in storage with time, the entire cistern water balance could be mathematically modeled. Measured data could be used for calibration, validation, and verification. It could decrease the number of necessary monitoring sites and instruments for this and other integrated LID sites.

Figure 40 (0.8-inch, 3 June rain event) represents the synchronized responses of interconnected LID components to rain events as reflected in the established water balance. Figure 40 also illustrates the LID system's sensitivity to isolated intra-event rainfall pulses. 


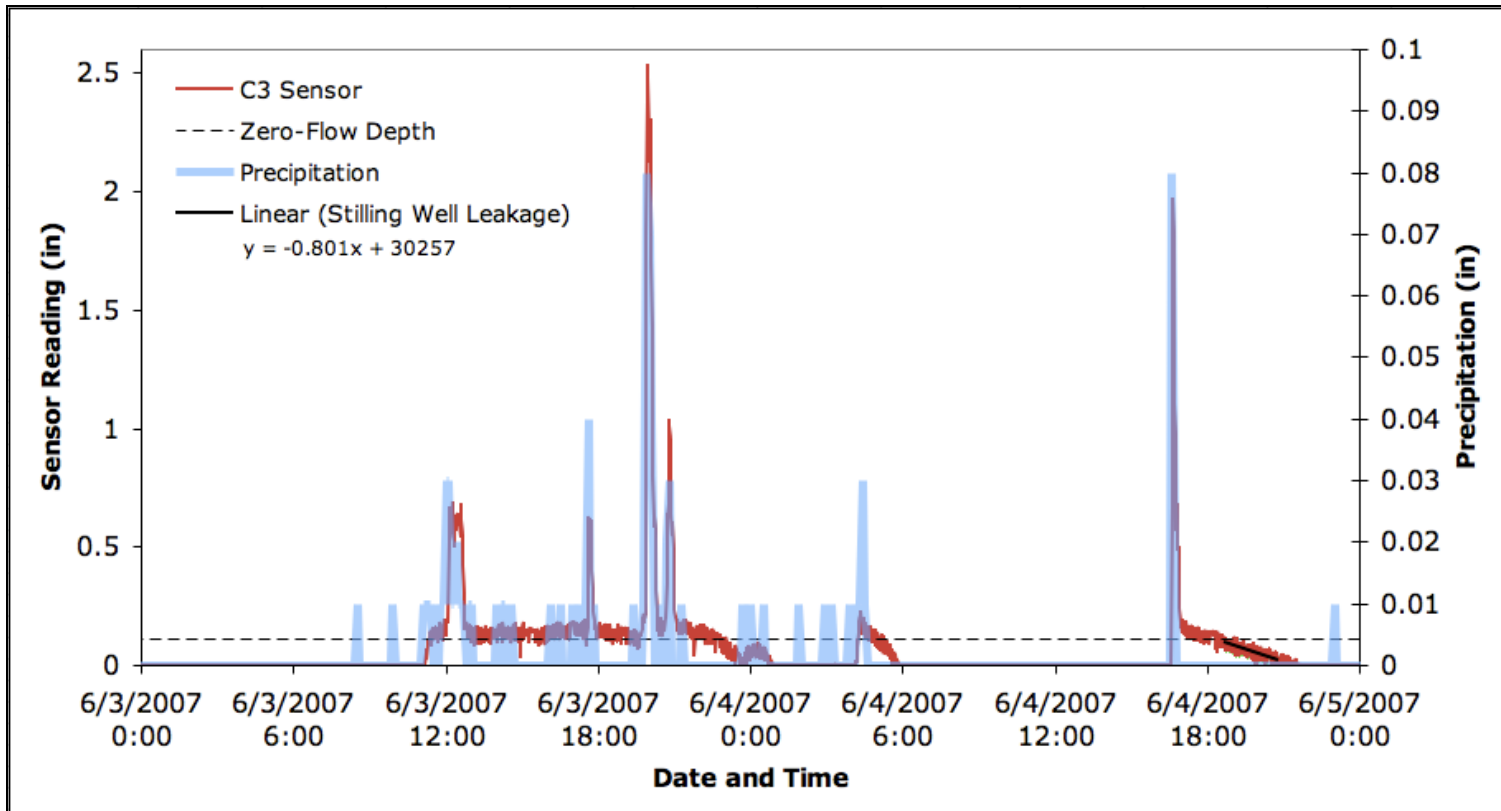

Figure 39. Determination of zero-flow depth (0.11 inches) for the cistern emergency overflow monitoring point (C3) from precipitation events beginning 3 June and 4 June. The trendline is used to demonstrate that data below the identified zero-flow depth represent a realistic leakage rate from the stilling well (7.6E-6 gpm or $2 \mathrm{in} / \mathrm{min})$.

Table 12. Cistern water balance for precipitation event beginning 3 June.

\begin{tabular}{|c|c|}
\hline Hydrologic Characte ristics & 3-Jun \\
\hline \multicolumn{2}{|l|}{ Precipitation } \\
\hline Total Depth (in) & 0.80 \\
\hline Duration (hrs) & 20.1 \\
\hline Intensity (in/hr) & 0.04 \\
\hline Storm Frequency & $>1-\mathrm{yr}, 2-\mathrm{hr}$ \\
\hline Antecedent Dry (d) & 15.65 \\
\hline \multicolumn{2}{|l|}{ Roofs } \\
\hline RR Runoff Volume (gal) & $\overline{9422}$ \\
\hline GR Runoff Volume (gal) & 3859 \\
\hline Total & 13281 \\
\hline \multicolumn{2}{|l|}{ C3 - Cistern Emergency Overflow } \\
\hline Runoff Volume (gal) & 2847 \\
\hline \multicolumn{2}{|l|}{ Cistern } \\
\hline Initial Available Storage (gal)* & 0 \\
\hline \multicolumn{2}{|l|}{ C2 - Cistern Overflow to Rain Garden } \\
\hline Volume of Runoff through C2 & 10434 \\
\hline \multicolumn{2}{|l|}{ FATE OF CISTERN INFLOW } \\
\hline $\begin{array}{l}\text { Flow through C2 } \\
\text { Flow through C3 }\end{array}$ & $\begin{array}{l}79 \% \\
21 \%\end{array}$ \\
\hline
\end{tabular}




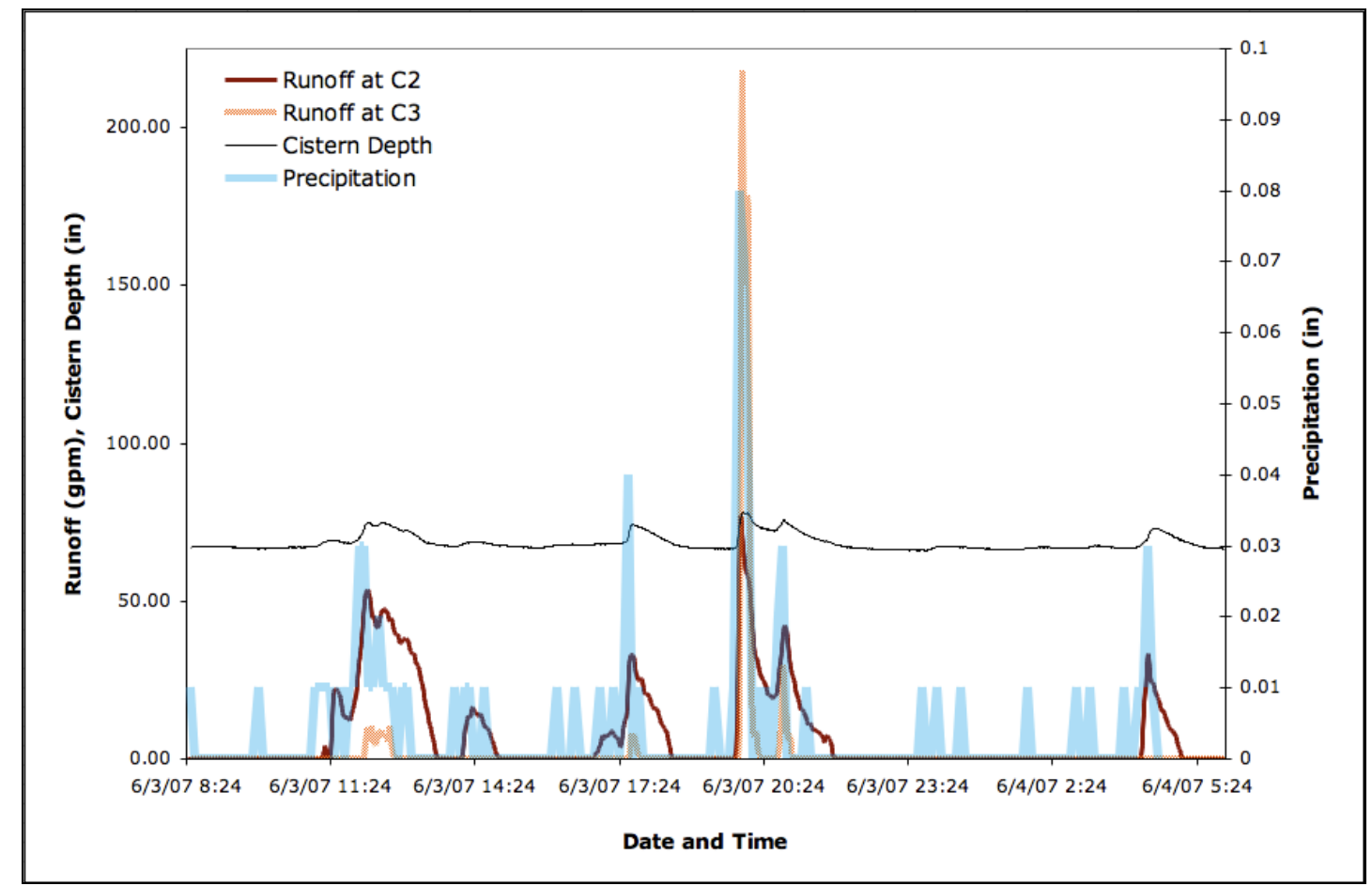

Figure 40. Outflow hydrographs and depth measurements generated from data recorded in the cistern (CIS) and at the cistern emergency outflow (C3) and for the outflow to the rain garden multiplied by a factor of 3.2 (C2) from precipitation beginning 3 June 2007.

\subsubsection{Monitoring Point C3 - Cistern Emergency Overflow}

The cistern was designed to capture the first half-inch of rainfall without overflowing into the emergency drain directly to the underground detention through monitoring point C3 (see Figure 2 and Figure 3 for schematics). Runoff from a 0.24-inch rain event (0.03 in/hr) on 26 April reached the emergency overflow (see Figure 41). For this rain event, it is unknown whether or not green roof irrigation was added to the cistern inflow. Certainly the 3 June event of only 0.11 inches breached the cistern emergency overflow outlet, yet contributions were made from the green roof irrigation excess in this case. If the cistern is overflowing more frequently than desired, it is likely due to small differences in drainage areas of the roofs as compared to the plan sets and design calculations or due to unanticipated volume of green roof irrigation excess. One-half inch of rainfall, at $0 \%$ 
retention, results in approximately 9,000 gallons of runoff based upon a combined roof area of $28,820 \mathrm{ft}^{2}$. The nominal volume of the cistern is 8,000 gallons.

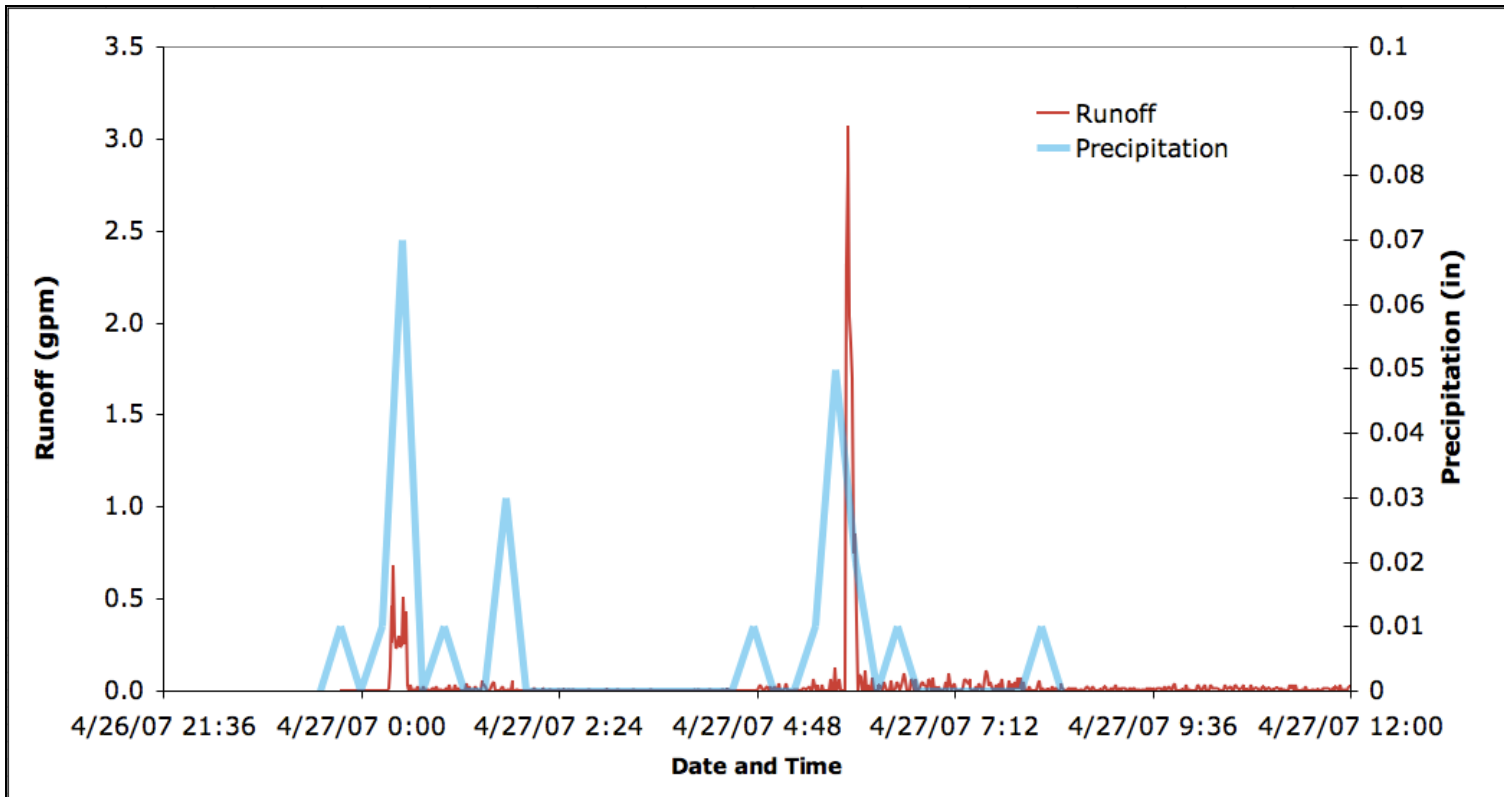

Figure 41. Outflow hydrograph from measurement point $\mathrm{C} 3$ from a rain event totaling 0.24 inches (average intensity $-0.03 \mathrm{in} / \mathrm{hr}$, duration $-8.75 \mathrm{hrs}$, antecedent dry conditions $-6.48 \mathrm{~d}$, frequency - > 1-yr 2-hr).

\subsubsection{Monitoring Point RG - Rain Garden}

The rain garden receives direct surface runoff as well as roof runoff after traveling through the cistern (see Figure 2 and Figure 3 for schematics).

Rain garden data is unavailable for the time period analyzed above. Sensor drift resulted in an excessively high field-calibrated zero-flow depth that was reflected in the data output of only zeros for all storm events. Figure 42 illustrates the differences in hydrograph shapes from an earlier storm event on 22 December 2006 (0.65-inch, 0.04 in/hr). The time at which this data was collected was during system troubleshooting, including electronics, datalogging, and calibration. Flow measurements are only rough estimates that may be influenced by a variety of possible errors later eliminated from the measurement system. 
Hydrographs shown in Figure 42 are to be used to compare qualitative runoff responses (hydrograph shapes) only.

The hydrographs provide strong evidence that the rain garden is the best performing site feature in terms of hydrologic detention of inflow. Peak outflow from the rain garden occurs noticeably later than peak outflow from the subcatchment consisting of $50 \%$ porous pavement and 50\% native vegetation watershed (measured at monitoring point DP4). Runoff peaks from the rain garden are especially more gradual than the steep runoff peaks found at C3, where rising cistern water levels rapidly discharge water through the emergency cistern overflow (C3) until the level drops.

The rain garden (RG) hydrographs in Figure 42 and Figure 43 illustrate that it has the greatest effect on delaying the peak outflow and dispersing the runoff across a greater length of time. Buhl (2007) modeled the Gainesville site using the Prince George’s County BMP module and likewise found the rain garden to be the most effective hydrologic component of the LID network in terms of percent retention and reduction of peak outflow.

Figure 43 also illustrates that the subwatershed DP4 (50\% native vegetation and 50\% concrete pavers) has a greater peak delay time than DP3. DP3 generates a more steep, rapidly rising hydrograph. Runoff from DP3 begins sooner than both runoff from the rain garden (RG) and DP4. 


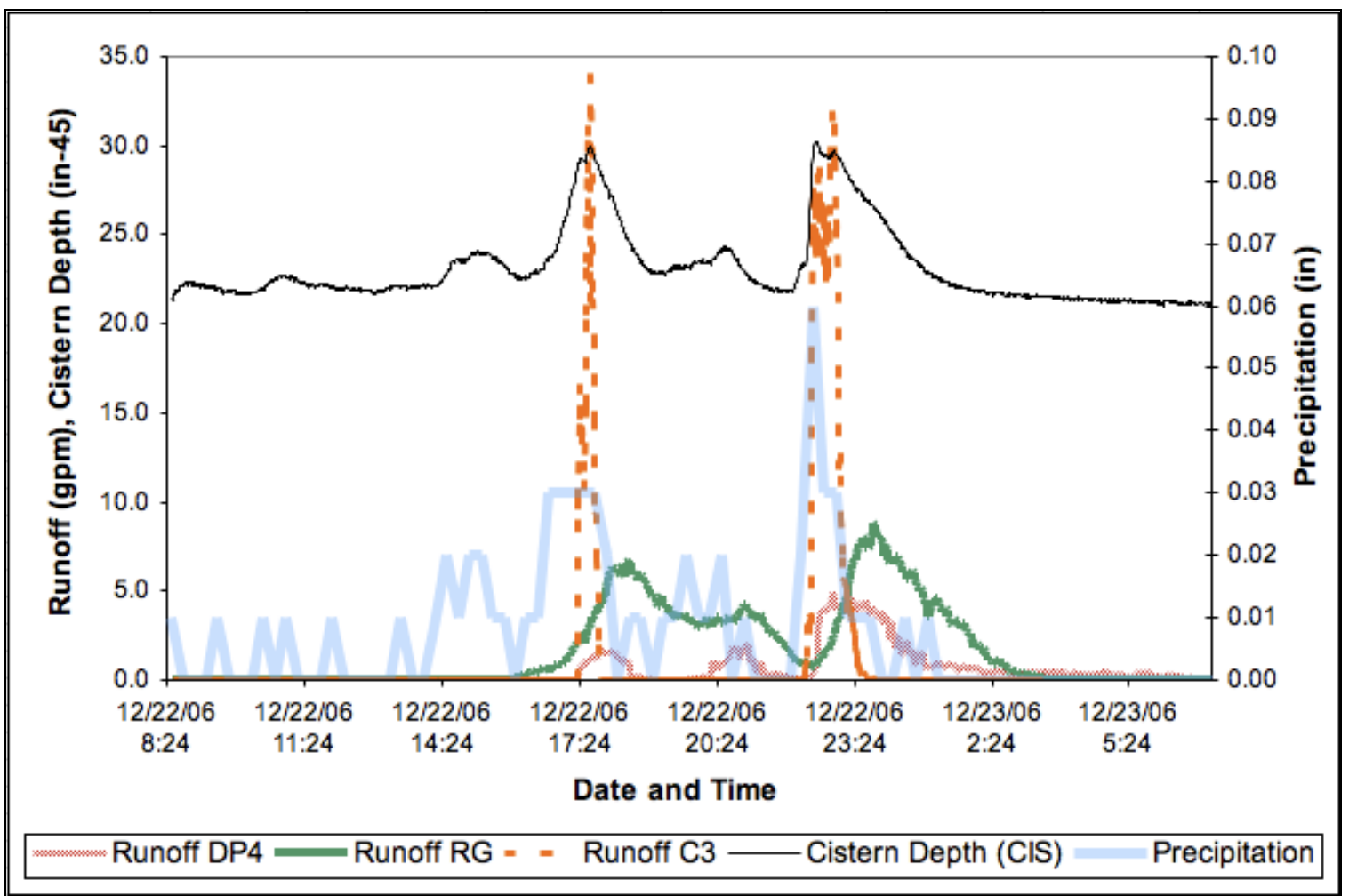

Figure 42. Comparison of hydrograph shapes generated from data recorded at monitoring points DP3, C3, RG, and CIS from precipitation beginning 22 December 2006.

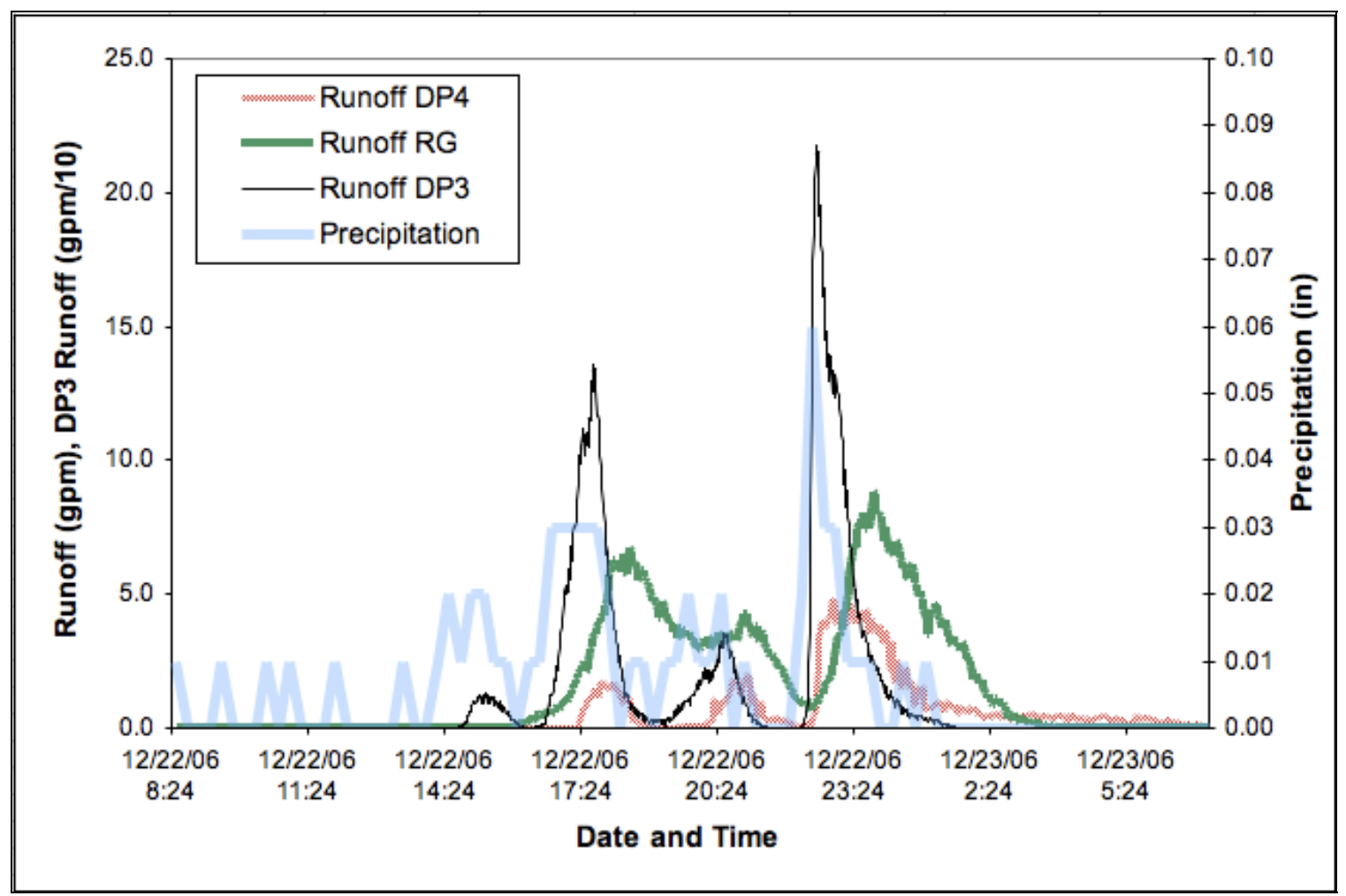

Figure 43. Comparison of hydrograph shapes generated from data recorded at monitoring points DP3, DP4, and RG from precipitation beginning 22 December 2006. 


\subsubsection{Monitoring Point BS - Subwatershed including Bioswale}

The bioswale accepts runoff mainly from impervious asphalt (see Figure 2 and Figure 3 for schematics). However, rock check dams provide significant storage of the runoff before it reaches the measurement point at the weir at the downstream end of the bioswale. The bioswale (267 linear feet) was designed to store the first half-inch of rainfall on the subwatershed, designated as the water quality volume. This volume equates to 5,270 gallons.

Data from monitoring point BS for the 3 June and 4 June events provided an estimate of the zero-flow depth (see Figure 44). The zero-flow value identified here was not as clear as some of the stilling well zero-flow depth data. The notch of the weir was designed to lie 6 inches above the channel bottom where the sensor rests. However, abrupt changes in slope of the depth data suggest a possible zero-flow depth of 5 inches. A 5-inch notchheight may either be due to installation or sensor drift. The two zero-flow depths are illustrated in Figure 44. Both have been evaluated, and results are summarized in Table 13. Hydrographs are based upon a 5-inch zero-flow depth.

The premise of measuring flow using water surface depth above the crest of a weir is that the critical depth is achieved as the water passes over the weir. The benefit of the measurement mechanism is that less precision is required in the zero-flow depth calibration. Changing the zero-flow depth by one inch (from 6 inches to 5 inches), has only a small effect on the cumulative hydrologic results. Recall that using Manning's equation requires precision down to about 0.06 inches for the zero-flow depth calibration. This is a clear advantage to the weir measurement system if it is amenable to field constraints.

The volume of runoff generated from the bioswale subwatershed on 3 June demonstrates retention (primarily storage due to clay soils) of the design water quality 
volume of 5,270 gallons plus additional storage. However, the 4 June storm event does not achieve that amount of storage. This is another example of the effects of interevent periods on runoff. The storage in the bioswale was already maximized when the 4 June storm event began. As a result, the 0.11 -inch storm event resulted in runoff. If conditions were dry prior to this storm event, runoff is unlikely to have occurred.

The outflow hydrograph from the bioswale (Figure 45) is characterized by rounded peaks and delay of the peak outflow. Figure 46 illustrates the superior effect the bioswale has on delaying the peak outflow and extending the outflow duration as compared to the DP3 subcatchment. The BS and DP3 subcatchments have comparable areas and percent impervious surface $(59 \%$ and $63 \%$, respectively). The result is a relatively direct comparison of porous pavement LID techniques and a bioswale vegetated with native plants. The hydrograph from the bioswale (particularly in Figure 46) has the classic shape where the runoff is slightly skewed to the right, and the hydrograph is gently curved rather than steep and pointed.

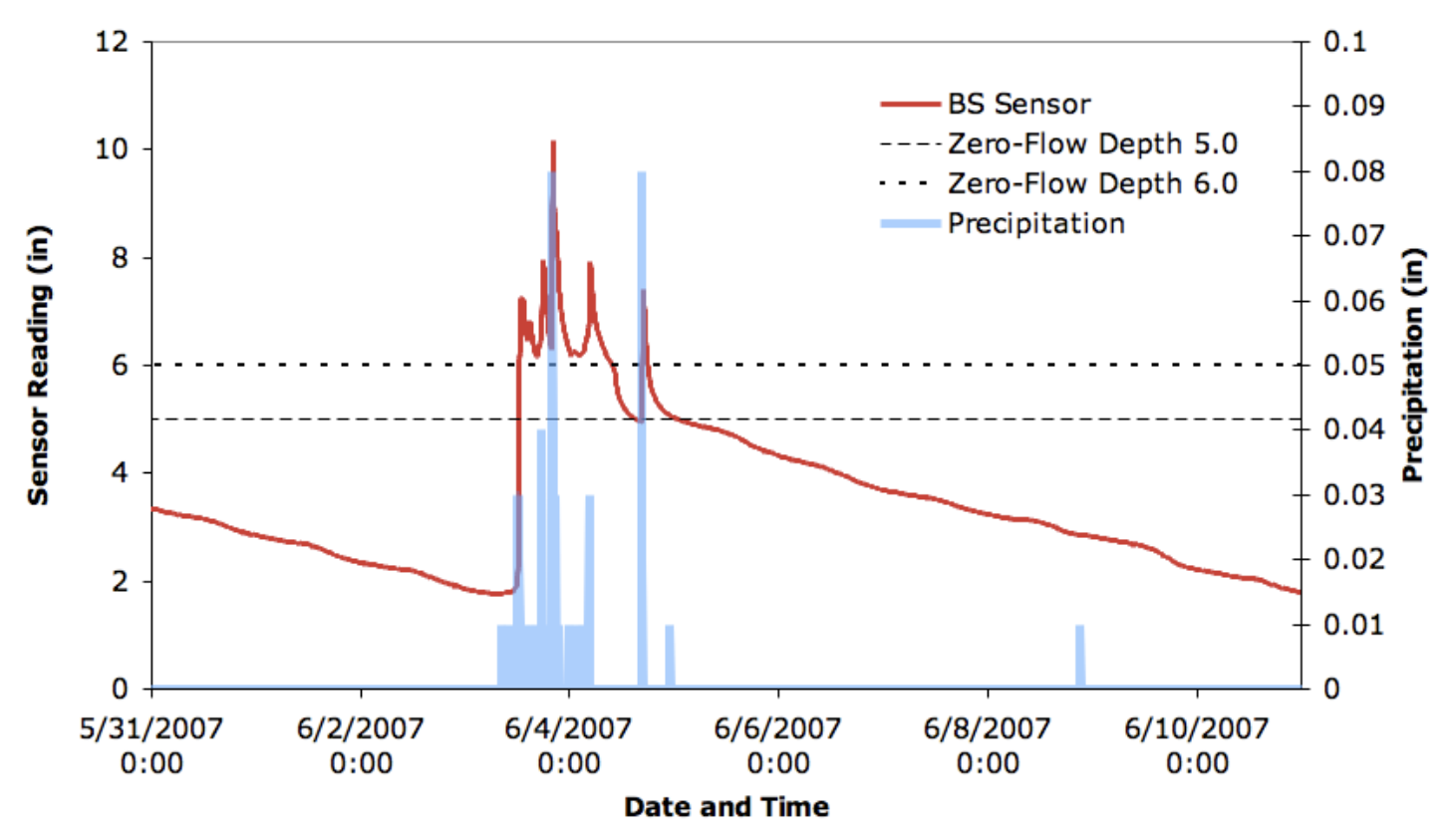

Figure 44. Determination of zero-flow depth for the weir at the bioswale (BS). 
Table 13. Hydrologic characteristics of the bioswale (BS) watershed assuming a weir height of 5.0 inches.

\begin{tabular}{|c|c|c|}
\hline Hydrologic Characteristics & 3-Jun & 4-Jun \\
\hline \multicolumn{3}{|l|}{ Precipitation } \\
\hline Total Depth (in) & 0.80 & 0.11 \\
\hline Duration (hrs) & 20 & 6.5 \\
\hline Intensity (in/hr) & 0.04 & 0.02 \\
\hline Storm Frequency & $>1-\mathrm{yr}, 2-\mathrm{hr}$ & $>1-\mathrm{yr}, 2-\mathrm{hr}$ \\
\hline Antecedent Dry (d) & 16 & 0.50 \\
\hline \multicolumn{3}{|l|}{ BS - Bioswale } \\
\hline \multicolumn{3}{|l|}{ RUNOFF QUANTITIES } \\
\hline Rainfall Volume (gal) & 12862 & 1769 \\
\hline Runoff Volume (gal) & 4168 & 203 \\
\hline Runoff Retention & $68 \%$ & $89 \%$ \\
\hline Zero-Flow Depth of 6.0 inches & $91 \%$ & $98 \%$ \\
\hline Peak Outflow (gpm) & 37 & 5.4 \\
\hline Zero-Flow Depth of 6.0 inches & 21 & 1.4 \\
\hline \multicolumn{3}{|l|}{\begin{tabular}{|l|l|} 
RUNOFF TIMING \\
\end{tabular}} \\
\hline Precip. Depth at Start of Runoff (in) & 0.20 & 0.10 \\
\hline Peak Delay (hrs) & 12 & 0.42 \\
\hline Duration (hrs) & 23 & 5.3 \\
\hline \multicolumn{3}{|l|}{ RUNOFF PARAMETERS } \\
\hline Curve Number & 92 & 99 \\
\hline Zero-Flow Depth of 6.0 inches & 84 & 98 \\
\hline C - Value & 0.17 & 0.03 \\
\hline Zero-Flow Depth of 6.0 inches & 0.10 & 0.01 \\
\hline
\end{tabular}

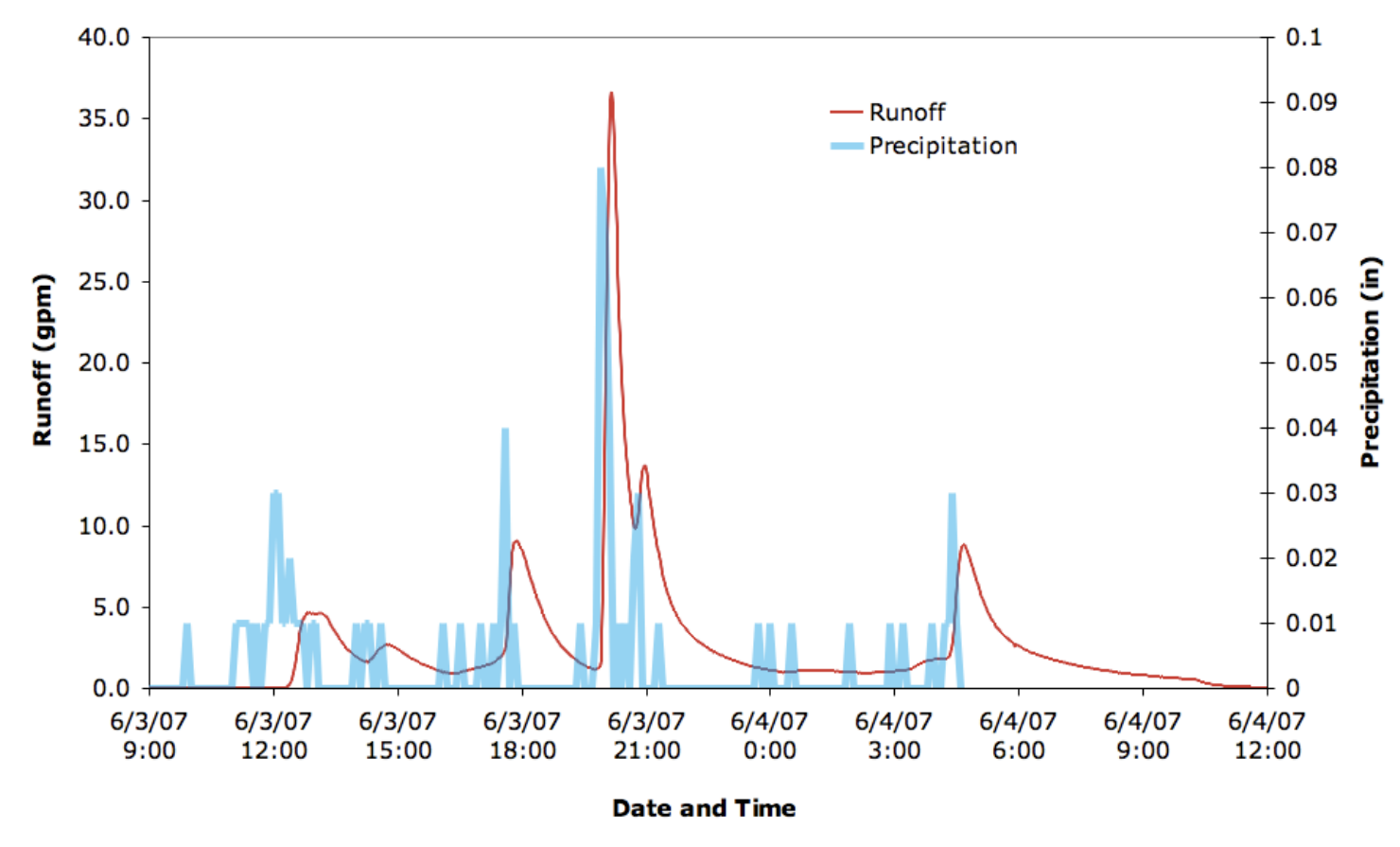

Figure 45. Runoff hydrograph generated from data recorded at the weir below the bioswale (BS) from precipitation beginning 3 June 2007. 


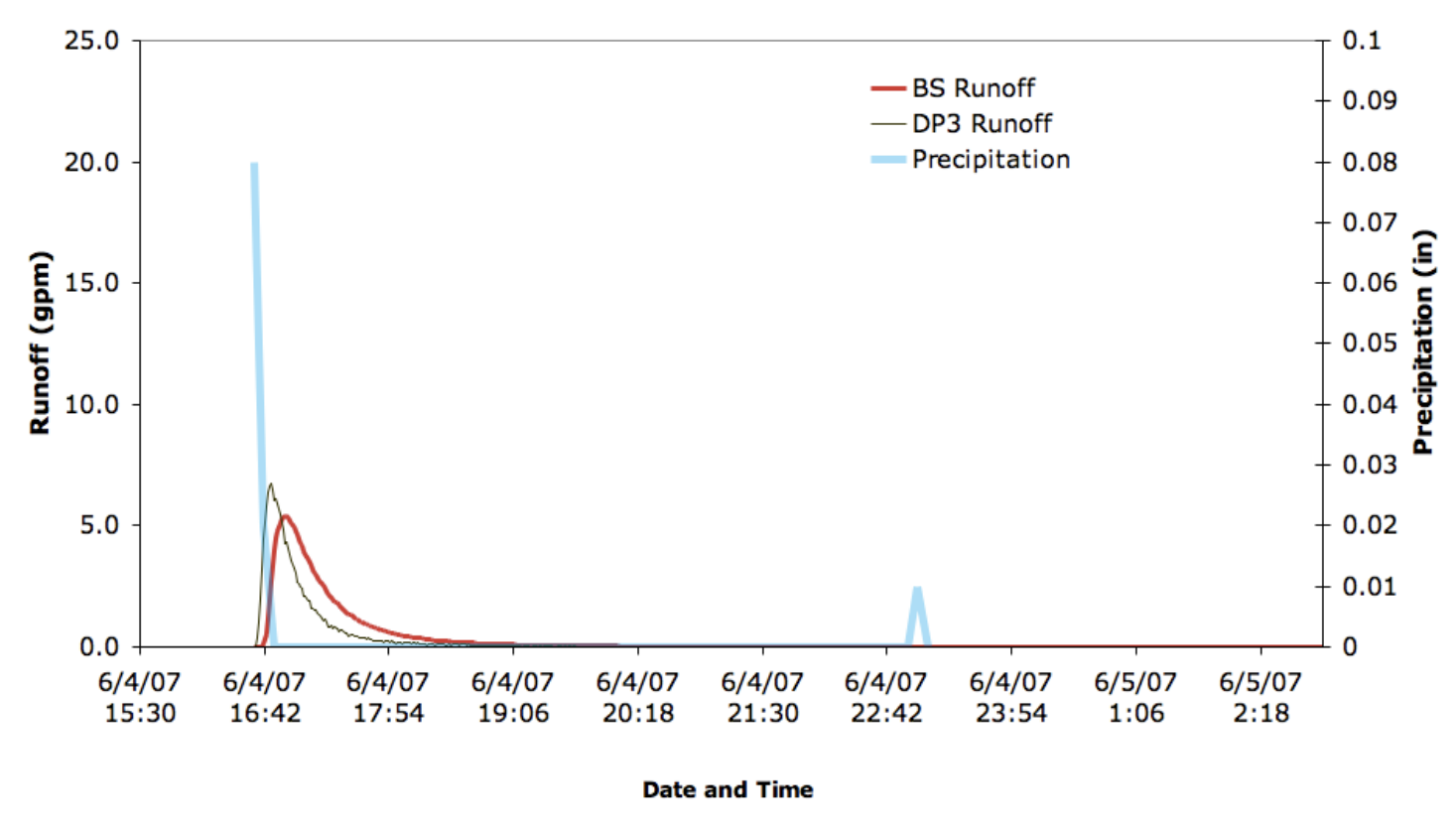

Figure 46. Runoff hydrographs generated from data recorded at the bioswale (BS) and DP3 from precipitation beginning 4 June 2007.

\subsubsection{Monitoring Points ORI and DP2 - Site Outfall}

The last two hydrographs (Figure 47 and Figure 48) are related to the outflow rate from ORI, accepting flow from the roofs, the rain garden and its subcatchment, and the GravelPave2 porous pavement above the underground gravelbed detention. This outflow is discharged directly into the adjacent stream after passing through the 1.625-inch orifice (restricting the runoff rate to $0.125 \mathrm{cfs}, 56 \mathrm{gpm}$, or less). Based on calculations described in Section 3.3.3.2 and a rough calibration of the offset to the height of the orifice, the orifice appears to be effectively releasing outflow slowly from the site. Figure 48 illustrates the timevariant change in elevation between the water surface in the adjacent stream and the orifice. It confirms that at no point during this storm event was the stream causing static or reverse flow conditions at the orifice (the depth of the stream above the DP2 sensor always remains lower than 1.24 feet). In such a case, the applied calculations would be incorrect and additional hydrologic modeling would be required. 


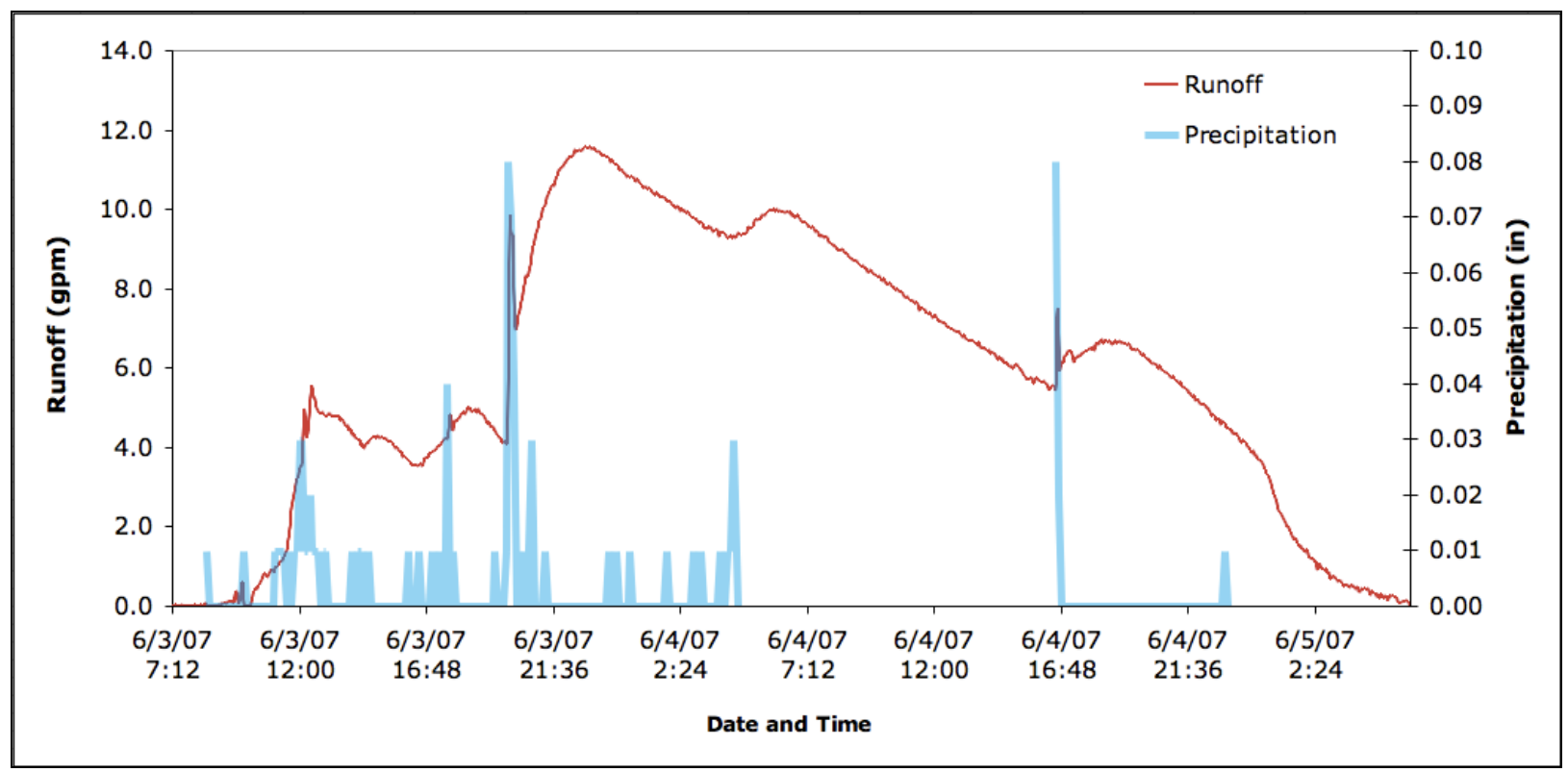

Figure 47. Outflow hydrograph from the orifice (ORI). Precipitation events beginning 3 and

4 June 2007 are combined.

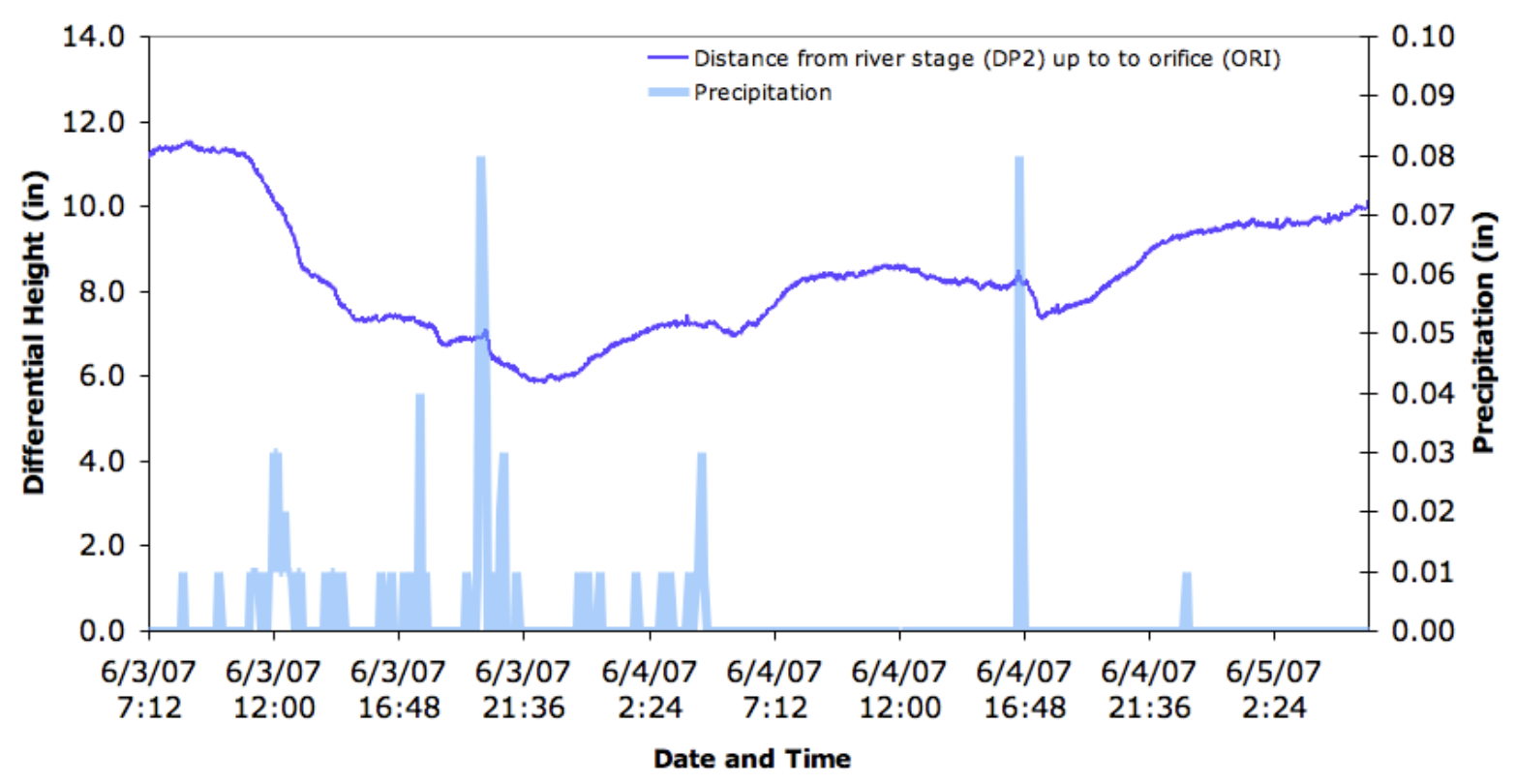

Figure 48. Change in elevation betwee the river stage adjacent to the Gainesville site and the orifice at measuring point ORI. Precipitation events beginning 3 and 4 June 2007 are combined. 


\subsection{Hydrologic Retention Identified in Other Studies for Comparison to the Gainesville Site}

Data compiled here is from systems that are sufficiently similar to LID features at the Gainesville site. The following sections are meant to provide data on hydrologic characteristics of LID features for direct comparison to results at the Gainesville site once more extensive and conclusive field data is collected.

\subsubsection{Bioretention and Bioswales}

Dietz and Clausen's (2006) underdrained rain gardens were $18.4 \mathrm{~m}^{2}$ in area, had a 6inch ponding depth, and were lined with impermeable material. The site in Haddam, CT received $312.2 \mathrm{~cm}$ (123 in and within the 30-year average) of precipitation from roof runoff over a 24-month period, a total volume of inflow of 392,530 liters (103,700 gallons). Overflow accounted for only $0.8 \%$ of the inflow, and $95.4 \%$ left through the underdrain. Therefore, the rain gardens only experienced $3.7 \%$ retention of the inflow in the two-year period. The removal was assumed to be through evapotranspiration. Transpiration occurred presumably during interevent periods when a vapor pressure gradient existed. This suggests that during a storm event, very little interception occurred. The shrub vegetation was likely to provide some leaf storage through the end of the storm event, and some evaporation may have occurred during the storm event between intra-event rainfall pulses.

Barber et al. (2003) conducted water quantity analyses on a full-scale physical model of an 'ecology ditch.' The design is similar to the Gainesville rain garden in its construction. It has a top layer of compost (rather than mulch) in which vegetation grows, a 6-foot layer of sand below that, a geomembrane, and a gravel-entrenched perforated underdrain pipe. Three storm sizes $(0.64,1.27$, and $2.54 \mathrm{~cm})$ exhibited trends in reduction and delay of peak discharge. Percent reductions in peak discharge increased with storm size (approximately 
$52 \%, 55 \%$, and $69 \%$, respectively). Delays in peak discharges decreased with increasing storm size (approximately $60 \mathrm{~min}, 25 \mathrm{~min}$, and $15 \mathrm{~min}$, respectively). For a 1.27 -cm storm, percent peak reduction and delay time followed similar trends related to storm duration. Durations of 1 hour, 3 hours, and 6 hours were tested, with resulting peak reductions of approximately $67 \%, 56 \%$, and 50\%, respectively, and delay times of $18 \mathrm{~min}, 20 \mathrm{~min}$, and 30 min, respectively. The experiment found that percent peak flow reductions depended on the media, the input hydrograph, the ditch size, and especially the duration of the peak input. Peak delay times were dependent on the media and ditch size, and were independent of a set of variable input hydrographs with the same peak intensities. Interestingly, the experiments showed that the effects of initial conditions were minimal on percent peak reduction and peak delay time for larger storms.

Li et al. (1999) conducted a study of a 'partial exfiltration trench,' called a PET, which is effectively the same configuration as the porous pavement subcatchments, where overland flow infiltrates into the porous pavement, down through a few feet of sand media, and into a perforated underdrain. Results from this site should be extremely compatible with results at the Gainesville site. Li et al.'s site was mostly used for calibration of a hydrologic model (see Section 6.2.1), so percent retention and peak outflow rates are not directly reported. However, the study determines water content profiles throughout the PET facility as a function of soil parameters and loading rates. These can aid in the interpretation of data from the Gainesville site and contribute knowledge about subsurface processes during rainfall events.

\subsubsection{Green Roofs}

Teemusk and Mander (2007) studied a green roof with a 45\% cover of sedum, and Villarreal and Bengtsson (2005) studied a green roof plot with only sedum vegetation. Both 
found that retention is increased with dry antecedent moisture conditions. Application of rainfall at constant intensity to Villarreal and Bengtsson's dry green roof did not produce runoff until between 6 and $12 \mathrm{~mm}$ (0.24 and $0.47 \mathrm{in})$ of rain occurred. Light rain was

effectively retained in both studies. In particular, Teemusk and Mander report that for a 2.1$\mathrm{mm}(0.08 \mathrm{in})$ rainfall event, retention was $85.7 \%$. In a larger rain event of $12.1 \mathrm{~mm}$ (0.48 in), runoff was delayed for up to 30 minutes and the runoff volume was the same as that of an impervious reference roof. Teemusk and Mander also evaluated snow melt from green roofs and distinguish two melting periods: a fast melting of snow cover (during a single day) and a 12-day melting of the frozen substrate. Teemusk and Mander (2007) is a good reference for particular rainfall events and their hydrologic effects. Villarreal and Bengtsson (2005) also report percent retention from three constant intensity rainfall events on a shallow 2-degree slope. Rainfall intensities of $0.016 \mathrm{in} / \mathrm{hr}$ for 60 minutes, $0.03 \mathrm{in} / \mathrm{hr}$ for 30 minutes, and 0.05 in $/ \mathrm{hr}$ for 30 minutes resulted in retention of $62 \%, 54 \%$, and $21 \%$, respectively.

\subsection{Summary and Conclusions: Maximizing LID Hydrologic Performance}

The following bulleted conclusions are the most significant findings from the hydrologic data. They inform the design of LID systems for maximum hydrologic performance, and all conclusions discussed in detail are related thereto.

o Underdrains are an effective LID option for compact sites and regions with clay soils;

o The physical characteristics of sub-base materials are significant parameters in the design of effective LID systems;

o Connected impervious surfaces significantly reduce the performance of an LID system; 
o Sequencing of LID features can increase the hydrologic performance of LID systems;

o Irrigation systems can significantly influence hydrologic performance;

o Antecedent moisture conditions preclude the rapid determination of overall percent retention for LID features;

o Accurate grading is imperative in LID site construction;

o Traditional hydrologic parameters, specifically curve numbers and C-values, may be inadequate for LID site design.

Preliminary results from the DP4-, DP3-, and BS-gaged watersheds are summarized in Figure 49. Storm characteristics for the runoff events analyzed are shown in Table 14.

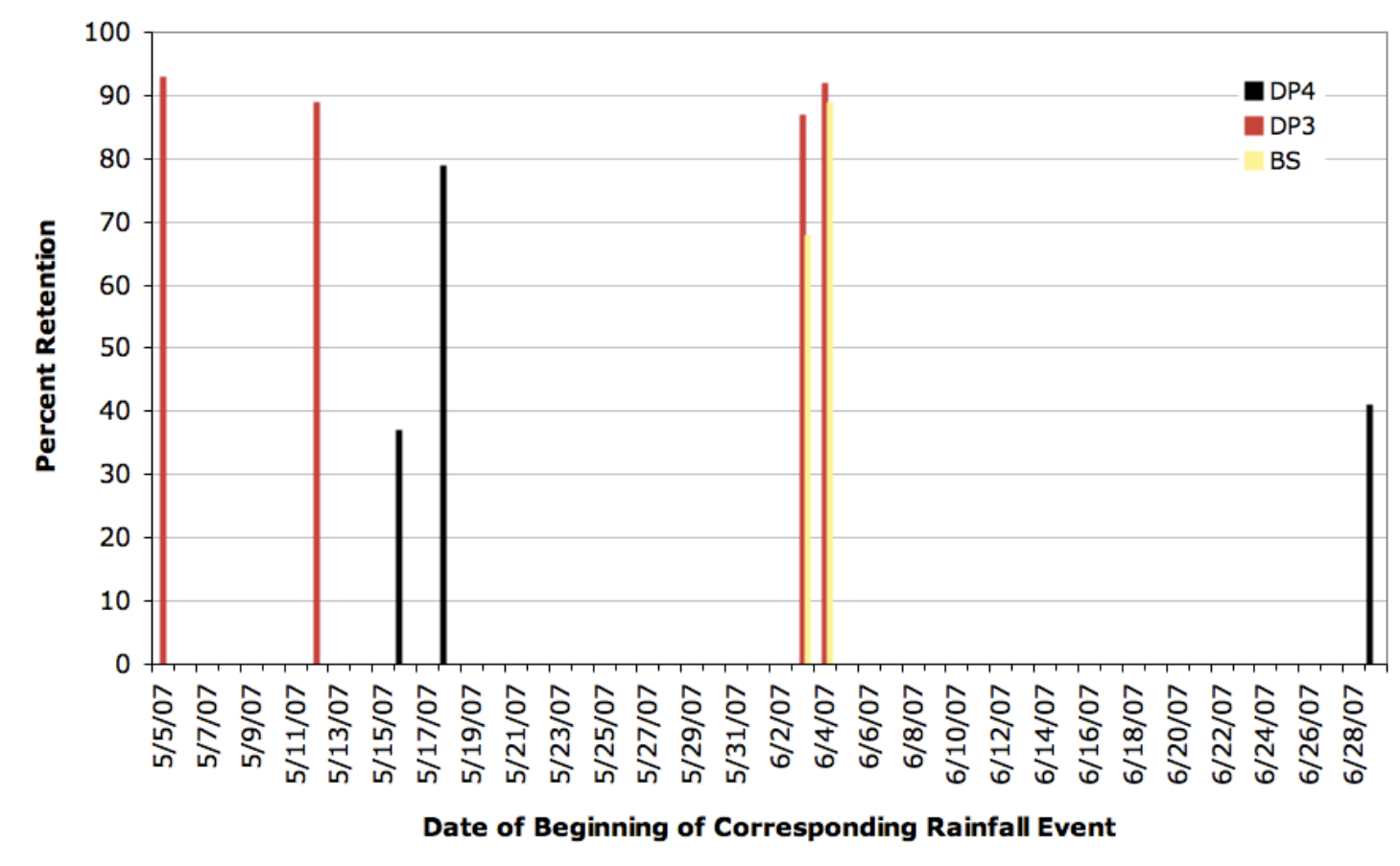

Figure 49. Results summary for percent retention experienced at the west outfall (DP3), northeast outfall (DP4), and the bioswale (BS). 
Table 14. Precipitation characteristics for storm events beginning on the following dates in the year 2007.

\begin{tabular}{|r|r|r|r|r|r|r|r|}
\hline $\begin{array}{l}\text { Precipitation } \\
\text { Characteristics }\end{array}$ & 5-May & 12-May & 16-May & 18-May & 3-Jun & 4-Jun & 29-Jun \\
\hline Total Depth (in) & 0.04 & 0.23 & 0.27 & 0.17 & 0.80 & 0.11 & 0.03 \\
\hline Duration (hrs) & 1.0 & 8.8 & 0.3 & 2.7 & 20 & 6.5 & 2.1 \\
Intensity (in/hr) & 0.04 & 0.03 & 0.90 & 0.06 & 0.04 & 0.02 & 0.01 \\
Storm Frequency & $>$ 1-yr, 2-hr & $>1-\mathrm{yr}, 2-\mathrm{hr}$ & 1-yr, 2-hr & $>1$-yr, 2-hr & $>1$-yr, 2-hr & $>1$ 1-yr, 2-hr & $>1$-yr, 2-hr \\
\hline Antecedent Dry (d) & 9.3 & 7.2 & 4.45 & 1.92 & 16 & 0.50 & 0.72 \\
\hline
\end{tabular}

Monitoring point DP3 (the larger of the two subcatchments with porous pavement and a small strip of native vegetation) responds more rapidly to runoff than does DP4. This may be due to the presence of asphalt in the DP3 watershed; there is none in the DP4 watershed. Further research might find this discrepancy also due to a difference in porous pavement applications. The subcatchment of DP3 uses GravelPave2, a noticeably more porous surface than the concrete paver design in the subcatchment of DP4.

Though the DP3-gaged watershed responds to precipitation more rapidly than any other subwatershed on-site, it also delays the peak runoff better than a traditional curb and gutter system. Gravelpave2, concrete pavers, and all LID features on the site are hydrologically effective in terms of delay of peak outflow and extension of runoff duration. Underdrained systems are an effective LID design for sites with clay soils and/or for compact urban retrofits.

Initial comparisons of hydrograph shapes and their relationship to the temporal precipitation data suggest that the bioswale and the rain garden provide the most peak delay, detention, and retention of all the LID devices at the Gainesville site. This implies that one of the key physical parameters for an effective LID feature is the porosity of the sub-base materials. Porous pavement features on the Gainesville site (and in general) consist of layers of various-sized coarse aggregate. The bioswale consists only of low porosity native clay 
soils; the rain garden has a 12 -foot sandy loam layer beneath which is 3 feet of sand before only a single coarse-aggregate drainage layer (Urban Engineering 2004).

The cistern is an actively functioning feature in the LID network. It responds to rain events quickly due to the direct piped connections from the large impervious reflective roof. The inflow characteristics of the cistern during dry events when excess green roof irrigation is occurring can be compared to inflow during a storm event when the reflective roof is contributing to runoff. The large impervious area of the reflective roof has an overwhelming impact on the LID system hydrology, rapidly filling the cistern. Figure 50 illustrates the balance of inflows to the cistern. Directly connected impervious areas provide relatively little to no detention of storm runoff. Intercepting these areas with strips of vegetation could have significant effects at low cost (Lee and Heaney 2003).

Figure 51 summarizes the balance of outflow from the cistern for the 3 June storm event. Outflow from the cistern is mostly discharged to the rain garden, rather than through the emergency outflow to the gravel bed detention. The positioning of the cistern between the roofs and the rain garden increases the treatment of the roof runoff that otherwise would discharge directly to the adjacent stream. In this way, low-intensity storm events that would otherwise use only a fraction of the rain garden's hydrologic capacity result in potentially maximum usage of the rain garden.

The sequencing of LID features creates additional detention, retention and treatment of stormwater runoff on this compact site. Runoff from more porous features (e.g., porous pavement) detain the runoff sufficiently enough to convey the water into less porous features (e.g., rain gardens) at a manageable rate. By connecting LID features with underdrains, the hydrologic use of LID features that have superior retention capacities may be maximized on compact urban sites. 


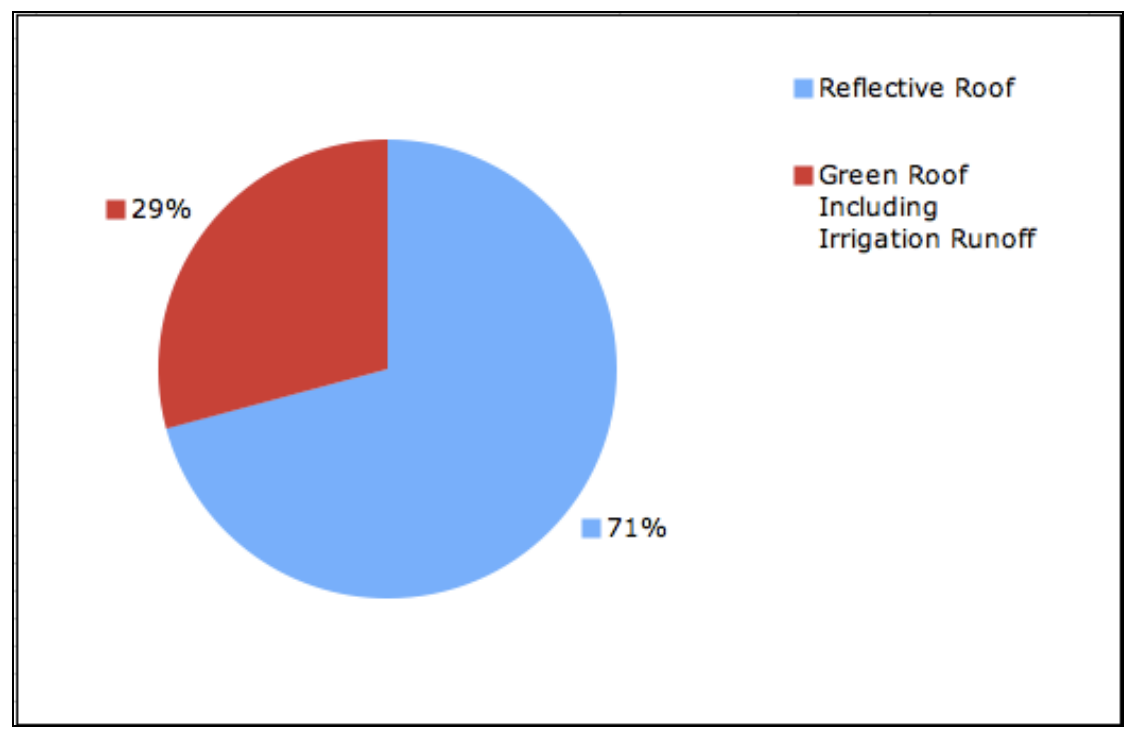

Figure 50. Proportion of inflow to the cistern from rain event beginning 3 June 2007 (0.8 inches, 20 hours, $0.04 \mathrm{in} / \mathrm{hr}$ ).

Figure 51. Proportion of outflow from the cistern from precipitation event beginning 3 June 2007 (0.8 inches, 20 hours, $0.04 \mathrm{in} / \mathrm{hr}$ ).

Excess green roof irrigation is reducing the hydrologic benefits of the cistern during rain events. Runoff reaches the cistern emergency overflow to the underground gravel bed detention from storm events of lower-intensity than the 1-yr, 2-hr and of depths as small as 0.24 inches because irrigation water has filled the cistern prior to the rain event. The design depth to be captured prior to overflow is twice as high at 0.5 inches. 
This occurrence also highlights the effects of antecedent moisture conditions. If the cistern is full prior to a storm event (e.g., due to excess irrigation or the previous storm event), the storage benefits of the cistern are void. Likewise, if the water upstream of the bioswale checkdams has not yet infiltrated or evaporated before the next storm event, even a small storm event can result in low percent retention. Antecedent moisture conditions preclude the simple averaging of percent retention across individual storm events for interpretation of hydrologic performance.

The large 63\% asphalt DP3-gaged subwatershed demonstrates unexpectedly high percent retention $(87 \%$ and greater). This could be partially a result of infiltration into the native clay soils beneath the porous pavement features, but clay soils have low infiltration rates. More importantly, an unknown quantity of runoff bypasses the Gravelpave 2 porous pavement feature. This bypass flow has caused erosion as well as loss of runoff capture and, therefore, detention. This illustrates the importance of accurate grading when directing sheet flow into porous features. Conveyance structures like curbs and gutters (largely absent from LID stormwater management designs) are less sensitive to grading mistakes or settling. To date, contractors are likely unfamiliar with the accuracy needed in LID grading and may need additional direction.

Curve numbers and C-values averaged for each watershed for which they could be calculated are summarized in Table 15. In some cases curve number values are higher than predicted, suggesting a mostly impervious watershed rather than a porous watershed (e.g., DP4 that is half native vegetation and half porous pavement). The DP3-gaged watershed (60\% asphalt) would have a higher $\mathrm{CN}$ value if the bypass flow were taken into account. It is possible that the $\mathrm{CN}$ values are high in the DP3- and DP4-gaged watersheds because of the high porosity (and infiltration capacity) of the porous pavement structures and the low deep 
infiltration through the clays underlying them. The site features do not have a high amount of retention capacity.

The slightly lower $\mathrm{CN}$ for the BS-gaged watershed is likely the result of the storage capacity behind the bioswale's rock-check dams as well as the lack of an underdrain. As a result conveyance is slower and deep infiltration is facilitated more than at the porous pavement features. However, high curve numbers may be a result of employing the $\mathrm{CN}$ equation outside of the calibrated range (e.g., in watershed sizes of less than 1-acre or for high-frequency, low-intensity storm events).

In all cases, $\mathrm{C}$-values were calculated to be lower than expected based upon the literature (Wurbs and James 2002). The rational method assumes constant intensity over the duration of the time of concentration (Wurbs and James 2002). A time of concentration used for the calculation of C-values was based on the design time of concentration of 5 minutes (an assumed design value). This time of concentration may be incorrect. In addition, the rational method was calibrated based upon sheet-flow, and it may be unable to account for vertical flow through the porous media of LID features. A greater number of storm events are needed to determine conclusively the accuracy of these empirical models.

Table 15. Curve numbers $(\mathrm{CN})$ and rational method $\mathrm{C}$-values generated from field data at the Gainesville site compared to C-values used by Urban Engineering \& Associates (2004) in the site design.

\begin{tabular}{|c|c|c|c|}
\hline Watershed & CN & C-Values & $\begin{array}{c}\text { C-Values from } \\
\text { Plan Sets }\end{array}$ \\
\hline DP4 & 99 & 0.09 & 0.48 \\
DP3 & 94 & 0.04 & 0.76 \\
BS & 96 & 0.10 & 0.76 \\
\hline
\end{tabular}




\subsection{Findings Related to the Hydrologic Measurement System}

The flow measurement system designed and applied here is the result of a thorough technical review of monitoring technologies. Instruments were installed in deep underdrains and can be accessed from grade (a seminal constraint). Currently, knowledgeable personnel can use the collected data to make valuable estimates of LID-feature hydrologic characteristics as well as understand the interplay between features. However, the collection and download of outflow hydrographs cannot yet be automated due to the instability of the zero-flow depth and the sensitivity of the calculations to the zero-flow depth.

The extreme sensitivity of the underdrain monitoring system to the zero-flow depth is the greatest concern. The most imperative next step with the monitoring system at Gainesville is to maximize the stability of the zero-flow depth reading. Instability may be the result of long-term sensor drift, leaking stilling wells, or solar-induced output peaks.

Green roof data in particular may still be exhibiting some evidence of solar-induced peaks. They are minor, but could be reduced. These effects may be particularly persistent at monitoring point GR because it is on the south-southwest facing side of the building.

Based on the stability of depth readings during multi-day interevent periods and the specified precision of the instrument (see Footnote 2), it is likely that the sensor calibration will eventually be stable between storm events at all monitoring sites. In addition, as experience with the LID network data increases and visual observations are used to reference sensor output, data interpretation will improve.

Weir measurements at the bioswale (BS) demonstrate lower sensitivity to zero-flow depth calibrations, and measurement points DP3 and DP4 are amenable to dual in-line measurement techniques using weir boxes. The discharge point of each pipe is at grade. Weir boxes can be assembled at these measurement points such that the flow regime across the 
stilling well is not affected, and the two in-line measurements can be compared. Large weir box designs and related excavation requirements precluded initial installation. As research at the site continues, the construction of additional weirs may be justified.

Specific next steps recommended for improving the Gainesville monitoring system include, but are not limited to, the following:

o Establishment of the long-term stability of sensor readings;

o Measurment of the as-built pipe slopes ${ }^{4}$;

o Confirmation of the accurate operation of irrigation systems (including installation of flowmeters on irrigation lines (monitoring points GIR and LIR);

0 Field observation of runoff trends suggested by the data;

o Identification and calculation (if needed) of backwater effects at DP3;

o Dual measurement of discharge points DP3 and DP4 with weir boxes;

o Elimination of the flow bypass at DP3;

o Re-evaluation of $\mathrm{C}$-values using the time of concentration calculated from field data.

${ }^{4}$ Just prior to publication, the slope at monitoring point DP4 was measured at 0.047 using an 8.4-inch run of pipe. This represents a change from the slope of 0.029 used in this document. 
This LID underdrain flow monitoring system design may be installed at additional underdrained sites for LID performance testing. The design will produce best results if the following considerations are taken:

o Zero-flow calibration is conducted extensively and iteratively with the runoff data and field measurements;

o Stilling well interfaces with existing pipe are smooth;

o Sensor stability is known and demonstrated prior to installation;

o Stilling wells are leak-proof;

o Manning's $n$ is determined as a site-specific parameter (e.g., specific to the stilling well configuration used);

o Slopes in the field are known from measured data. 


\section{Models Applicable to Site-Scale LID Networks with Underdrains}

The accepted use of LID will depend upon the availability of applicable hydrologic models for practitioners to use in design. For the purposes of modeling the Gainesville site, models need to be capable of modeling outflow hydrographs from individual events (a characteristic of event-based models and sometimes available through continuous simulation), and hydrologic processes need to be modeled at the site scale, sometimes referred to as the microscale. Models applicable to the Gainesville site are also likely to be applicable to most site-scale LID installations.

Event-based design and modeling is advantageous because it allows for the control of discrete runoff characteristics. A stream section adjacent to an LID site likely has a maximum allowable flow rate at which erosion is negligible. A monthly or seasonal average would not assure that all flows remain below the threshold.

Site-scale modeling requires adequate representation of physical processes and a sufficiently small grid size without extensively lumped parameterization. The largest watershed at the Gainesville site is about $40,000 \mathrm{ft}^{2}$, and the smallest is $4,000 \mathrm{ft}^{2}$. The total LID site is 3.87 acres $\left(170,000 \mathrm{ft}^{2}\right)$.

Hydrographs need to be generated to the precision of sub-hourly flow rates to determine LID characteristics such as peak outflow, detention time, and runoff volume. At WSSI, 1-minute interval runoff data has been recorded with which to compare model output.

Another valuable tool in any model applicable to the Gainesville site is the capacity to simulate underdrains. Subsurface flow models tend to be applicable to LID except that they do not always incorporate the physics of underdrains. MacQuarrie and Sudicky (1996) developed a method to include drains in three-dimensional, variably saturated groundwater 
models. Their technique may be an option if any particular model without underdrains is preferred. Another technique might be to model underdrains as a large, smooth macropore at a given depth. This method may never have been tested to date.

Elliott and Trowsdale (2007) performed a comprehensive review of models for LID. The ten models they reviewed use conventional methods for runoff generation and routing. Some of those models simulate groundwater recharge and/or infiltration specifically from LID devices or infiltration-based features that are effectively LID. However, many of the models reviewed are inadequate for simulating outflow hydrographs from individual events at the fine spatial and temporal scales required for the Gainesville site. Model characteristics that preclude their application include monthly (or longer) time steps, lumped-parameter surface characterization, watershed scale (on the order of square kilometers or square miles) rainfall-runoff transformation, and empirical runoff generation. From the models reviewed by Elliot and Trowsdale (2007), the U.S. Environmental Protection Agency (EPA) Storm Water Management Model (SWMM) (Rossman 2005) and DHI Software MOUSE (DHI 2002) are potentially applicable to the Gainesville site and have been included in the following review.

Additional models not reviewed by Elliott and Trowsdale (2007) are applicable to event-based, small-scale LID modeling and are reviewed here. These additional models may not have appeared in Elliott and Trowsdale (2007) because they do not have a history of use among practitioners and/or they are unconventional models developed specifically for LID. Overall Elliott and Trowsdale (2007) say, "In our opinion, [limitations of the models reviewed] preclude comprehensive predictions of the effects of LID on hydrology and water quality and the resulting ecosystem effects." Arguably, some of the models reviewed here provide more direct and comprehensive simulation of LID hydrology. 
Wholly empirical models are, as noted previously, not sufficiently accurate for site scale modeling on an event basis. Only models that are physically based are reviewed. Physically based models applicable to LID systems can be broken down into three groups: (1) models developed specifically for LID, (2) models with recent add-ons that represent elements of LID and/or have already been applied to LID, (3) models with no attempted representation of LID but have the appropriate mechanisms including temporal and spatial scales. In addition, some models simulate surface hydrology, subsurface flow (saturated and/or unsaturated), or both. If models do not represent both, two models would need to be coupled. Findings are summarized in Table 16. 


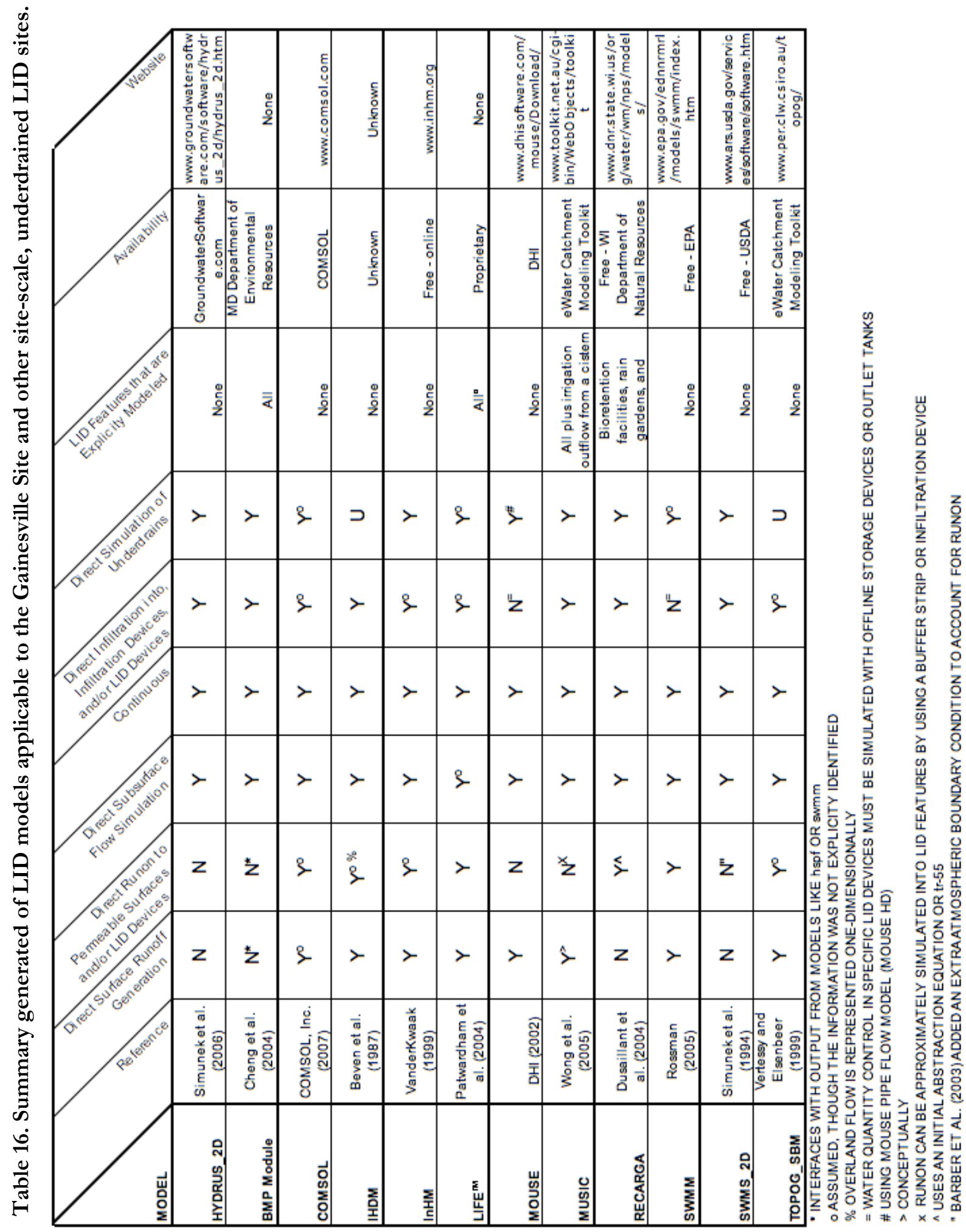




\subsection{Models Developed Specifically for LID}

These models are applicable to the small site-scale modeling and were developed specifically for LID. They are physically based, have sufficiently small time scales to generate hydrographs from individual events, and have working models (and user's manuals) available for use today. Two of the models are available for free.

\subsubsection{BMP Module}

Prince George’s County Department of Environmental Resources developed the BMP module specifically for LID (Cheng et al. 2004). The model uses conventional weir and orifice equations and Manning's equation. It accounts for infiltration based on the HoltanLopez semi-physical model where infiltration is proportional to the capacity of the soil to store water. It is a continuous model that outputs runoff hydrographs from each storm event over the given simulation period. The BMP module accounts for infiltration capacity recovery during dry periods and evapotranspiration. Time series runon ${ }^{5}$ and water quality information is input into the BMP devices from measured data or generated by runoff models such as HSPF (Hydrologic Simulation Program FORTRAN) or SWMM.

Two templates exist to model various types of BMPs. Class A BMPs retain water and release (or simulate) outflow through devices such as an orifice or weir; examples include stormwater detention ponds or reservoirs, catch basins, and bioretention basins. Class B BMPs are open channels including grass swales and stream buffers. Channel characteristics are defined to inform flow simulations. The model routes flow from subcatchments to BMP devices and between BMPs.

\footnotetext{
${ }^{5}$ Runon refers to surface runoff from the watershed into the LID feature.
} 
Water quality modeling is incorporated into the BMP module via a general loss/decay pollutant representation (Tetra Tech 2003). One disadvantage is that flow routing between BMPs is strictly one-to-one. At the Gainesville site, outflow from the cistern to both the rain garden and the underground detention cannot be modeled. The BMP module has empirical and/or simple mechanics to describe flow as compared to the other models in this category.

The BMP module has recently been incorporated into the ESRI ArcGISC environment for visualization and developing sequences of land uses, BMPs, and stream reaches (Cheng et al. 2006). ArcGIS also provides an interface for BMP placement, attribute data input, and for managing the decision optimization component. The system then launches the BMP module as a stand-alone hydrologic simulation model. This model is free from the Prince George's County, Maryland, Department of Environmental Resources.

\subsubsection{RECARGA}

RECARGA was developed as a design tool for bioretention facilities, rain gardens, and infiltration basins (Dussaillant et al. 2004). Site features can include surface ponding, up to 3 distinct soil layers, and underdrains. The user specifies precipitation, evaporation conditions, and land cover data. Runon into the facility can be calculated using an initial abstraction equation or TR-55. It is a continuous simulation model. It records soil moisture and water volume for each water budget term at each time step: infiltration, recharge, overflow, underdrain flow, evapotranspiration, and etc. The model uses Green-Ampt infiltration (Richards equation) for initial infiltration and the van Genuchten relationship for drainage between soil layers. The orifice equation is employed for underdrain flow (Atchison and Severson 2004). This model is freely available online from the Wisconsin Department of Natural Resources at http://www.dnr.state.wi.us/org/water/wm/nps/models/. 


\subsubsection{Low Impact Feasibility $\left(\mathrm{LIFE}^{\mathrm{TM}}\right)$ Model}

The LIFE ${ }^{\mathrm{TM}}$ model is a continuous-simulation model with sufficiently small time steps for event-based modeling that generates outflow hydrographs. It is based on physical processes occurring in many site-specific LID designs. It is considered a decision support tool for runoff volume control. Overland flow is routed using the kinematic wave approach based on Manning's formula (notably used also by SWMM and MOUSE). Channel processes and routing are 1-dimensional within a stream or reservoir. LIFE ${ }^{\mathrm{TM}}$ simulates runoff, interflow, infiltration, and baseflow. Model inputs are continuous rainfall data (one hour increments or less) and daily evapotranspiration data. Additional inputs include site design parameters and landcover, LID techniques, and soils information. The LIFE $^{\mathrm{TM}}$ model includes an optimization tool for BMP configuration that minimizes costs and meet volume, flow, and water quality criteria at the watershed scale. It is unlikely that a sufficient body of data verifies this model component. Optimization is based on genetic algorithms (Patwardham et al. 2004). The model uses 'Imagine That!' software (Imagine That, Inc. 2007). This model is proprietary. Student software licenses can be purchased for $\$ 25$ to $\$ 125$.

\subsection{Existing Models with Recent Incorporation of and/or Application to LID}

\subsubsection{Simulating Water Flow and Solute Transport in Two- Dimensional Variably Saturated Media (SWMS_2D)}

SWMS_2D simulates two-dimensional vertical planar subsurface flow. It was developed by Simunek et al. (1994) and is available under the Agricultural Research Service of the U.S. Department of Agriculture (USDA). It was tested against experimental data and could be calibrated effectively to fit that data (Simunek et al. 1994). The model couples the 
two-dimensional Richards equation with a two-dimensional advection-dispersion transport equation. SWMS_2D appears to be the most promising model in this category because both Barber et al. (2003) and Li et al. (1999) have already used it specifically for LID devices with underdrains. Barber et al. (2003) modeled a compost, sand, and gravel-laden vegetated swale with a perforated underdrain and geomembrane.

Runon from the catchment into the LID feature cannot be modeled directly (and is notably a common characteristic in models with potential for LID). Barber et al. (2003) applied an extra atmospheric boundary condition to account for runon. Li et al. (1999) modeled what they called a partial exfiltration trench; from the top down it consists of porous pavement, a sand column, and a wrapped underdrain. The grid elements can be as small as (and possibly smaller than) $6.1 \mathrm{~cm}$ by $6.1 \mathrm{~cm}(0.2 \mathrm{ft}$ by $0.2 \mathrm{ft})$. Grid elements can be rectangular or triangular, helping to account for variable underground LID geometry. SWMS_2D requires five input parameters whose values depend mostly on soil type (residual soil water content, porosity or saturated soil water content, empirical constant, saturated hydraulic conductivity) ( $\mathrm{Li}$ et al. 1999). Input also includes specifications for the finiteelement mesh, initial conditions, and boundary conditions. The user specifies time intervals for model output of nodal values of pressure head, water content, Darcy flux, and solute concentrations. The model is free and available from the USDA online at http://www.ars.usda.gov/services/software/software.htm or from http://typhoon.mines.edu/zipfiles/swms2.htm.

\subsubsection{Model for Urban Stormwater Improvement Conceptualization (MUSIC)}

MUSIC was developed by the Cooperative Research Center (CRC) for Catchment Hydrology's Urban Stormwater Quality Program (Wong et al. 2005). Elliot and Trowsdale 
(2007) do not consider research a potential use for the model, and it is referred to as a decision support system for stormwater managers. However, it is worth testing because some LID features have been directly incorporated into the model. Additionally, MUSIC is considered applicable for small catchments starting at $0.01 \mathrm{~km}^{2}$ (about 100,000 $\mathrm{ft}^{2}$ ) (and up to $100 \mathrm{~km}^{2}$ ) with modeling time steps from 6 minutes to $24 \mathrm{hrs}$ depending on catchment scale (Catchment Modeling Toolkit 2007).

Runoff is generated only conceptually. The model performs hydrologic routing through a drainage network with hydrograph outputs (Elliott and Trowsdale 2007). Simple level-pool routing is used for routing flows through hydrologic features. Routing between features is modeled using the Muskingum Cunge method, and flow can be routed to bypass features. Reservoirs must have vertical sides, and outlets have a simple configuration (Catchment Modeling Toolkit 2007).

Cisterns, infiltration trenches, swales, and bioretention/rain gardens/filtration devices are included in the model, but infiltration through runon can be only approximately simulated by using a buffer strip or infiltration device (Elliott and Trowsdale 2007). MUSIC is capable of allowing time-varying abstraction of water from devices enabling the simulation of irrigation from a cistern, a potentially crucial element in LID modeling (Wright et al. 2000). A model example demonstrates that the detention time of a swale would be defined by the hydraulic conductivity and the depth of the medium. Flow through the swale would be modeled via Manning's equation (Catchment Modeling Toolkit 2007). Infiltration or bioretention systems are modeled by replacing the low flow orifice or riser outlet with the hydrologic characteristics of the soil. Filtered flow is assumed to be collected by an underdrain and returned to the watercourse and not lost to groundwater (Elliott and Trowsdale 2007). Unfortunately, results are most sensitive to the fraction of imperviousness 
and the time step chosen and not to characteristics of permeable features (Elliott and Trowsdale 2007). The newest version (3) is available for $\$ 300$ from eWater Catchment Modeling Toolkit.

\subsection{Models without Explicit Representation of LID}

\subsubsection{EPA Storm Water Management Model, Version 5 (SWMM)}

SWMM is a single event or continuous rainfall-runoff simulation model for primarily urban areas (Rossman 2005). SWMM is spatially distributed, and it is compartmentalized into atmosphere, land surface, groundwater, and transport. The land surface compartment, or the collection of subcatchments, receives precipitation from the atmospheric compartment. It sends outflow to the groundwater compartment via infiltration. Surface runoff and pollutant loadings are sent to the transport compartment. A portion of the groundwater inflow can be redirected as outflow to the transport compartment. The transport compartment is made up of the conveyance elements including channels, pipes, and storage and treatment elements. All transport components, defined as links or nodes, send water to outfalls or treatment facilities. Time-steps are sub-hourly, allowing for the generation of flow rates and outflow hydrographs from individual storm events.

Runoff generation in SWMM is modeled using the NRCS CN, Horton equation, Green-Ampt infiltration, and/or groundwater/baseflow for runoff generation (Rossman 2005). Model subcatchments include an unsaturated upper soil zone. Evaporation can be modeled on subcatchment surfaces and for water held in storage units. Evaporation rates are input as a constant, monthly average, or daily time series. The groundwater reservoir is non-linear. 
Elliott and Trowsdale (2007) and Huber (2005) support the use of this model for LID simulation. However, some mechanics of LID systems must be modeled indirectly. Water quantity control in specific bioretention, rain garden, and filtration devices can be simulated with offline storage devices (rather than infiltration into the soil) that can then generate results indicating the percent of runoff (Elliott and Trowsdale 2007; Huber 2005). An outlet in the storage tank would simulate infiltration. Outlets require the input of headdischarge relationships. The model does not simulate infiltration and evapotranspiration from conveyances, including open channels (Huber 2005). Bioswale detention could be modeled through adjusted flow routing.

An advantage to SWMM is that it can simulate runon onto a subcatchment. In addition, many types of routing are available: routing to a drainage network, routing through LID devices, hydrologic routing in drainage network, and hydraulic routing (Elliott and Trowsdale 2007). This model is free and available from the EPA online at http://www.epa.gov/ednnrmrl/models/swmm/index.htm.

\subsubsection{Institute of Hydrology Distributed Model (IHDM)}

IHDM (Beven et al. 1987) was created in the UK through the Institute of Hydrology, renamed the Center for Ecology and Hydrology (CEH) Wallingford, and most recently the CEH National Environment Research Council. This physically-based rainfallrunoff model solves numerically both surface and subsurface flow (saturated and unsaturated) equations to generate storm hydrographs (Calver 1988). Hillslope sections and channel sections define the watershed surface. Saturation-excess and infiltration-excess runoff generation principles are used. Channel flow and overland flow are represented onedimensionally using a kinematic wave equation. Subsurface flow is modeled twodimensionally within vertical slices, and layers with variable physical properties can subdivide 
the subsurface. Unsaturated and saturated flows are modeled using Richards equation, incorporating Darcy's law and conservation of mass. Inputs include topography, precipitation (after interception and evapotranspiration losses), and physical properties of channel sections and soils (including channel slope, width, roughness and porosity, vertical and horizontal saturated hydraulic conductivity). The model also accounts for the relation between moisture potential and unsaturated moisture content and unsaturated hydraulic conductivity. Some key physical variables are hydraulic conductivity, porosity, initial moisture potentials, and surface roughness.

IHDM has not yet been applied specifically to LID devices. However, Calver (1988) used the model for a small $0.92 \mathrm{sq} . \mathrm{km}$. catchment with soil depths about $1-2 \mathrm{~m}$ deep. Small spatial variation is likely to be adaptable to the introduction of features such as bioretention, and specific subsurface characteristics can be defined. Conversion of flow from surface to subsurface is an advantage in this model. It is one of a few more complete models (along with InHM, see Section 6.3.4) that simulate subsurface flows and runoff generation combined with the spatial and temporal scales required for LID modeling. Access to the executable model files is unknown.

\subsubsection{MOUSE}

MOUSE is a model developed in Denmark at the Danish Hydraulic Institute (DHI). It is available as many different modules. The standard runoff module (MOUSE Runoff) is a more simplified version of the continuous runoff module (MOUSE RDII). MOSUE RDII is adaptable to urban, rural, and mixed catchments and accounts for storage in snow, surface, root zone, and groundwater (DHI 2002). The surface runoff module (Runoff) uses the timearea method, kinematic wave model, or linear reservoir model. Computed hydrographs can be used as input to the MOUSE pipe flow model (MOUSE HD). The Rainfall Dependent 
Inflow and Infiltration (RDII) module is a more detailed surface runoff model with continuous simulation. Precipitation can be modeled and routed as snow, surface water, root zone water, and ground water. MOUSE is spatially distributed with a link-node drainage network, and it is good for predicting flow rates from "small catchments" (Elliott and Trowsdale 2007). In each catchment a single linear lumped groundwater reservoir may be modeled.

Particular LID infiltration devices (rain gardens, bioinfiltration) would need to be represented indirectly as with SWMM, by an outlet tank (rather than infiltration into the soil) (Elliott and Trowsdale 2007). MOUSE does not allow for runon from impervious to permeable surfaces (Elliott and Trowsdale 2007). MOUSE demos are available for free online at http://www.dhisoftware.com/mouse/Download/.

\subsubsection{Integrated Hydrologic Model (InHM)}

InHM was developed by VanderKwaak of Integrated Hydrology, LLC

(VanderKwaak 1999). It is a complex mechanistic model with free source code (FORTRAN language) available online for compilation by the user; it is not conducive to practitioner usage. InHM is a three-dimensional, physically based, numerical model. It was developed to model applied irrigation, evapotranspiration, water flow, solute transport, two-dimensional land-surface features (e.g., basins), one-dimensional subsurface drains, and three-dimensional subsurface flow under variable saturation. InHM, like IHDM, simulates subsurface as well as overland flow; these two flow regimes are linked mathematically through first-order, physically based flux relationships, or continuity assumptions. The model employs the control-volume finite element method and uses the Richards equation and Darcy's flux. User-specified boundary conditions can vary as a function of space and time or as a nonlinear function of flow (VanderKwaak 1999). Laboratory (and field-scale) experiments 
were used for validation (VanderKwaak 1999). VanderKwaak and Loague (2001) applied the model to a $0.1 \mathrm{~km}^{2}$ watershed that expanded the spatial and temporal scale of the model. Mantanga et al. (2003) and VanderKwaak et al. (2003) also recently applied InHM. An exhaustive list of applications and the source code can be found at VanderKwaak's website: www.inhm.org.

\subsubsection{TOPOG_SBM (Simple Bucket Model)}

TOPOG_SBM is part of a body of TOPOG models developed in part by Vertessy and Elsenbeer of the Commonwealth Scientific and Industrial Research Organization (CSIRO) in Australia and the University of Cincinnati, respectively. TOPOG_SBM describes water flow over land surface and in the soil. It is fully distributed and process based. It was developed to model physical processes but minimize the number of parameters (Vertessy and Elsenbeer 1999). It includes: "(1) a contour-based element network for surface and subsurface flow, (2) a simple bucket model for handling soil water fluxes, (3) a onedimensional kinematic wave subsurface flow module for simulating downslope soil water movement, and (4) a one-dimensional kinematic wave overland flow module for simulating surface runoff" (Vertessy and Elsenbeer 1999). Model inputs are: topographic data, rainfall, soil depth $(1 \mathrm{~m})$, saturated hydraulic conductivity for the 0 - to 0.1 -m depth interval, an exponential rate of decay with depth in saturated hydraulic conductivity, Manning's $n$, and maximum and minimum soil-water content.

This model is a hybrid between TOPOG_dynamic (spatially explicit and fully dynamic) and TOPMODEL (aspatial, quasi-dynamic). TOPMODEL is notably inadequate at responding to small spatial variations in input data (Saulnier et al. 1997). However, TOPOG series models are intended for modeling small catchments, smaller than $1 \mathrm{~km}^{2}$ (but 
up to $10 \mathrm{~km}^{2}$ ) (CSIRO 2002). Time steps can be as fine as 5 minutes, and Vertessy and Elsenbeer (1999) modeled a catchment with a mean element area of 109 sq ft.

TOPOG is still a very new model, and Vertessy and Elsenbeer (1999) represent the first application of Topog_SBM. Results from Vertessy and Elsenbeer (1999) admittedly only predicted about half of the events correctly based on the model output hydrographs. However, the spatial scale and physical basis suggest it could be effective in LID modeling. User's manual, publications, and other support materials are all available online at the following website designated to the model: http://www.per.clw.csiro.au/topog/. TOPOG is available from the eWater CRC Catchment Modeling Toolkit. Access to the code is restricted until contact is made with Richard Silberstein or Joel Rahman of CRC.

\subsubsection{HYDRUS_2D}

HYDRUS_2D simulates water, heat, and solute movement in two-dimensional unsaturated, partially saturated, or fully saturated porous media (Simunek et al. 2006). It uses the Richards equation for water flow. Plant root-water uptake as a sink term is included in the flow equation. Soils may be non-uniform. Flow can occur vertically and horizontally. The model is strictly for subsurface flow, but runon can be simulated by user-prescribed time-variable head and flux boundaries or by free drainage boundary conditions. Boundaries can also be controlled by atmospheric conditions, but these would not allow for the effect of concentrated flow from a subcatchment. A Marquardt-Levenberg type parameter optimization algorithm allows for the estimation of soil hydraulic parameters from measured transient or steady-state flow data. Infiltration, evaporation, and transpiration are tracked throughout model simulations at each node and cumulatively. This model can also account for the effects of a snow layer. Ordering information for HYDRUS-2D can be found online at http://www.groundwatersoftware.com/software/hydrus 2d/hydrus $2 \mathrm{~d} . \mathrm{htm}$. 


\subsubsection{COMSOL}

COMSOL can be used to model "any physical process you can describe with partial differential equations" (COMSOL, Inc. 2007). The Earth Science Module is most applicable to LID simulations. COMSOL has applications to fluid mechanics, hydrology, subsurface flow through porous media, pore-scale flow, saturated and unsaturated media flow (including variably saturated). Flow regimes can be combined in single simulations (e.g., free flow and porous media flow). All physical properties, input terms, and boundary conditions can be represented by equations (e.g., functions of temperature or pressure). A.P. Davis at University of Maryland is using this model in order to develop a unit process based LID model, but the study is still in its elementary stages (Davis 2007). COMSOL 3.3A is the latest version and is available through purchase online at www.comsol.com.

\subsection{Prognosis for Future Modeling of LID}

A reasonable body of models exists that have already been applied to LID systems. Physically based models are superior for the small scale of LID installations, though they have not been implemented as widely as empirical models (especially those implemented by practitioners). The condition of underdrains at the Gainesville site is of particular consideration in model selection such that flows through the subsurface are tracked. Additionally, linkage between surface and subsurface flow is not a common model capability but is ideal for Gainesville. The models described above appear to have the modeling components requisite for application. Those elements include event-based modeling capabilities, short time steps such that accurate hydrographs can be produced, and small spatial scales. It is possible that a more in-depth exploration of any of these models will 
reveal an inability to address the modeling needs at Gainesville. However, these models provide a solid foundation from which to begin a more detailed selection process.

Models recommended for immediate testing are the BMP module an SWMS_2D. Buhl (2007) has already run simulations with the Prince George's County BMP module for the Gainesville site based on site-specific parameter data. However, the model has not been calibrated, validated, nor verified. SWMS_2D is likely to be an effective model because two teams of LID researchers have already used the model (Barber et al. 2003 and Li et al. 1999) for LID devices with underdrains. For similar reasons, RECARGA is also a priority model. It was designed specifically for LID modeling, includes underdrains explicitly, and is physically based (seemingly more mechanistically sound that the BMP module).

Plans and some specifications from the Gainesville site LID features are available directly on the WSSI website (www.wetlandstudies.com). To date, Jennifer Brophy-Price and Russell Dudley are water resources engineers who are available to answer questions and provide further site details, if needed.

The Gainesville site is a reasonable prototype of LID installations with regard to the spatial scale, temporal runoff patterns, and presence of underdrains. Models addressed in this section are equally valuable for experimental application to most LID designs. 


\section{Contributions of this Research to Overall LID Research Needs}

The following discussion relates the research performed here to the research needs of LID systems reported in Section 2.8: how some of the research needs were addressed as well as implications for broader impacts.

\subsection{Review of Measurement Technologies}

The technical review is a significant contribution to graduate students, faculty, and practitioners interested in monitoring and modeling LID underdrained systems. It evaluates measurement technologies with explicit regard for constraints in monitoring underdrains (e.g., variable flow regimes, pipe access). A synthesized collection of options for various LID techniques streamlines monitoring design and installation. Contributing to the efficiency of monitoring efforts is especially important to augment the currently small collection of postconstruction LID performance data.

\subsection{Design, Calibration, and Installation of an Underdrain-Flow Monitoring System}

The measurement technique utilized allows above-grade access to pipes that could otherwise not be monitored. The actual application of the underdrain monitoring technique, in addition to the laboratory calibration and sensitivity analysis of the measurement system, informs engineers and site designers of the advantages and disadvantages of the monitoring mechanisms utilized.

\subsection{Hydrologic Data from an Integrated LID Network}

This is the first comprehensive monitoring of an integrated, underdrained LID stormwater management network. Monitoring underdrains between connected LID features 
provides information on the interactions of LID components with each other and the resulting effects on the hydrology. This information contributes knowledge to researchers and designers about the synergistic effects of LID facilities, the optimal sequencing of LID features, the effects of underdrains on LID features, and the suitability of traditional stormwater design methodologies. Additionally, data from the field site highlight phenomena that do not present themselves under laboratory conditions (e.g., irrigation excess).

\subsection{Continuous Data Collection}

Continuous data collection from the Gainesville site tracks natural storm events and their corresponding inter-event periods. Field data contribute knowledge of the effects of antecedent moisture conditions to both practitioners and model developers. Prediction of hydrologic performance can be stratified based upon storm characteristics and antecedent moisture conditions. This represents advancement from the simple averaging of percent retention that does not account for the full range of hydrologic performance exhibited.

\subsection{Long-term Data Analysis}

Data is expected to be collected for an extended period. Wetland Studies and Solutions, Inc. (WSSI) contracted the LID design and installation, owns the site (circumscribing their office building), initiated the research, and has financed all capital costs and personnel, less the funding of continued graduate students. They expect to maintain the monitoring operations, and are likely to keep it active through their tenure in Gainesville. Data will be made available for the duration through a wireless data collection system uploaded to a realtime database that is publicly accessible through the Internet. Consistent, comprehensive, long-term, and accessible data will do much to evaluate the effectiveness of various LID techniques, as well as reveal long-term trends. 
A continued collaboration between Michigan Technological University and WSSI could enable efficient retrieval of detailed records for lifetime cost analyses and physical parameters of LID features for hydrologic modeling. System performance analyses combined with cost information will allow interested parties to answer questions about the tradeoff between cost and performance, as well as key differences between conventional and LID stormwater management techniques.

After the monitoring system operates over an extended period of time, a compilation of data from the Gainesville site will have the potential to contribute needed information to the following: regulatory agencies for assessing and evaluating LID systems accurately, developers for using LID cost-effectively, and property owners for understanding the hydrologic and ecological value of an LID system on their land.

\subsection{LID Modeling}

Models reviewed herein streamline the modeling effort for the Gainesville site and any other compact, underdrained, LID site. This review, unlike others, explicitly considers each model's capability to simulate hydrology on a small spatial scale and at time steps sufficiently short to estimate outflow hydrographs. 


\section{References}

Abida, H., Sabourin, J. F. (2006). "Grass Swale-Perforated Pipe Systems for Stormwater Management." J Irrigation and Drainage Egrg, 132(1), 55.

Almai, M.A., Ports, M.A. (2004). “Herding More Cats: Developing Vision, Principles, and Priorities for an Integrated Stormwater Management Program.” ASCE Conf. Proceedings, Critical Transitions in Water and Environmental Resources Management, 56.

Atchison, D., Severson, L. (2004). “RECARGA User's Manual v2.3.” University of Wisconsin, Madison, Civil and Environmental Engineering Department: Water Resources Group.

Barber, M. E., King, S. G., Yonge, D. R., Hathorn, W. E. (2003). "Ecology Ditch: A Best Management Practice for Storm Water Runoff Mitigation.” J. Hydrologic Egrg, 8(3), 111.

Beach, D.N.H., McCray, J.E., Lowe, K.S., Siegrist, R.L. (2005). "Temporal Changes in Hydraulic Conductivity of Sand Porous Media Biofilters During Wastewater Infiltration Due to Biomat Formation." J. Hydrology, 311, 230-243.

Beven, K.J., Calver, A., Morris, E.M., (1987). “The Institute of Hydrology Distributed Model.” Institute of Hydrology Report No. 98, Wallingford, UK.

Bishop, R.R., Jeppson, R.W. (1975). "Hydraulic Characteristics of PVC Sewer Pipe in Sanitary Sewers.” Utah State University. Logan, Utah. September.

Brown, T., Burd, Wl, Lewis, J., Chang, G. (1995). "Methods and Procedures in Stormwater Data Collection." Engineering Foundation Conference Proceedings, Stormwater NPDES Related Monitoring Needs, 194-206.

Brunner, G.W. (2006). “HEC-RAS, River Analysis System User’s Manual.” United States Army Corps of Engineers, Hydrologic Engineering Center. 
Buhl, A.R. (2007). "Simulation and Cost-Effective Analysis of Low-Impact Development Technologies for Stormwater Management.” MS Report, Michigan Technological University.

Burch, T. L., Phillips, J. M. (1995). "High-Accuracy CSO and Stormwater Flow Monitoring." Engineering Foundation Conference Proceedings, Stormwater NPDES Related Monitoring Needs, 609-616.

Calver, A. (1988). "Calibration, Sensitivity and Validation of a Physically-Based RainfallRunoff Model." Journal of Hydrology, 103, 103-115.

Catchment Modeling Toolkit. (2007). “MUSIC.” Website: http://www.toolkit.net.au/cgibin/WebObjects/toolkit.woa/wa/productDetails?productID=1000000 Copyright 2007, eWater Limited. Last accessed: June 20, 2007.

CSIRO (Center Commonwealth Scientific and Industrial Research Organization, Land and Water). (2002). “TOPOG Online.” Website: http://www.per.clw.csiro.au/topog/ Last updated: May $8^{\text {th }}, 2002$. Last accessed: June 20, 2007.

Chen, J-M, Tan, Y-C, Chen, C-H. (2001). "Multidimentional Infiltration with Arbitrary Surface Fluxes." J. Irrigation and Drainage Egrg., 127(6), 370-377.

Cheng, M-S, Akinbobola, C.A., Zhen, J., Riverson, J., Alvi, K., Shoemaker, L. (2006). "BMP Decision Support System for Evaluation Watershed-based Stormwater Management Alternatives." ASCE Conf. Proc., EWRI: Examining the Confluence of Environmental and Water Concerns.

Cheng, M-S, Coffman, L. S., Zhang, Y., Licsko, Z.J. (2003). “Comparison of Hydrological Responses from Low Impact Development with Conventional Development." ASCE Conf. Proceedings, Protection and Restoration of Urban and Rural Streams, 419. 
Cheng, M-S, Coffman, L. S., Zhang, Y., Riverson, J., Zhen, J. (2004). “BMP Model for LowImpact Development." ASCE Conf. Proc., World W ater Congress 2004, Critical Transitions in Water and Environmental Resources Management, 78.

Chow, V.T. (1959). Open Channel Hydraulics. New York: McGraw-Hill.

Christie, L. (2006). “100 Fastest Growing Counties.” CNNMoney.com, 16 March. http://money.cnn.com/2006/03/15/real estate/fastest growing US counties/index.htm. Date last accessed: 30 September 2006.

Christianson, R.D., Barfield, B. J., Hayes, J. C., Gasem, K., Brown, G. O. (2004). "Modeling Effectiveness of Bioretention Cells for Control of Stormwater Quantity and Quality." ASCE Conf. Proc., Critical Transitions in Water and Environmental Resources Management, 37.

Clar, M. (2005). "Pembroke Woods: Lessons Learned in the Design and Construction of an LID Subdivision." ASCE Conf. Proc., Managing Watersheds for Human and Natural Impacts: Engineering, Ecological, and Economic Challenges, 178(69).

Clark, S. E. (2007). "Evaluation and Verification of a Vadose Zone Model Being Applied to Stormwater Infiltration." Conference Presentation, $2^{\text {nd }}$ National Low Impact Development Conference, Wilmington, NC, 12-14 March.

Coffman, L.S. (2002). 'Low Impact Development: Smart Technology for Clean Water, Definitions, Issues, Roadblocks, and Next Steps.” ASCE Conf. Proc., Global Solution for Urban Drainage, 20.

COMSOL, Inc. (2007). “COMSOL.” Website: www.comsol.com. Last accessed: June $20,2007$. 
Cosgrove, J. F. Jr., Bergstrom, J. D. (2001). "Use of Bioretention Basins to Meet New Stringent Storm Water Regulations.” ASCE Conf. Proceedings, Bridging the Gap: Meeting the World's Water and Environmental Resources Challenges, 211(1).

Davis, A.P. (2007). “Unit Process Modeling of Bioretention Performance.” Conference Presentation, $2^{\text {nd }}$ National Low Impact Development Conference, Wilmington, NC, 12-14 March.

DCR (Department of Conservation and Recreation). (1999). "Virginia Stormwater Management Handbook, First Edition, Volume 1.” Division of Soil and Water Conservation.

Dechesne, M., Barraud, S., Bardin, J-P. (2005). "Experimental Assessment of Stormwater Infiltration Basin Evolution.” J. Envir. Engrg., 131(7), 1090-1098.

DHI. (2002). "MOUSE Surface Runoff Models Reference Manual.” DHI Software, Horsolm, Denmark.

Dietz, M. E., Clausen, J. C. (2006). “Saturation to Improve Pollutant Retention in a Rain Garden.” Environmental Science and Technology, 40(4), 1335-1340.

Ding, Y., Jia, Y. Wang, S.S.Y. (2004). “Identification of Manning's Roughness Coefficients in Shallow Water Flows." J of Hydraulic Engineering, 130(6), 501-510.

Dussaillant, A. R. Wu, C. H., Potter, K. W. (2004). "Richards Equation Model of a Rain Garden.” J. of Hydrologic Engrg, ASCE, 9(3), 219.

Elliot, A.H., Trowsdale, S.A. (2007). “A Review of Models for Low Impact Urban Stormwater Drainage.” Environmental Modelling \& Software, 22, 394-405.

Emerson, C. H., Welty, C., Traver, R. G. (2005). "Watershed-Scale Evaluation of a System of Storm Water Detention Basins.” J. Hydrologic Engrg., 10(3), 237-242. 
Esfandiari, M., Maheshwari, B.L. (1998). "Suitability of Selected Flow Equations and Variation of Manning's $\mathrm{n}$ in Furrow Irrigation." Journal of Irrigation and Drainage Engineering, 124(2), 89-95.

Fennessey, L.A.J., Hawkins, R.H. (2001). “The NRCS Curve Number, a New Look at an Old Tool." Proceedings of the 2001 Pennsylvania Stormwater Management Symposium, Rethinking Comprehensive Stormwater Management_Integrating Quality, Volume and Peak Controls, 17-18 October.

Fleming, M., Neary, V. (2004). "Continuous Hydrologic Modeling Study with the Hydrologic Modeling System.” J.Hydrologic Engrg., 9(3), 175.

Goswami, S.R. (1973). “Discussion of 'Manning’s Coefficient for Smooth Pipes.” Journal of the Sanitary Engineering Division, 99(4), 95-96.

He, Z., Davis, A.P., Ayres, D.M. (2007). "Unit Process Modeling of Bioretention Performance." Conference Presentation, $2^{\text {nd }}$ National Low Impact Development Conference, Wilmington, NC, 12-14 March.

Health Education Service. (1971). "Recommended Standards for Sewage Works (revised edition).” Health Education Service, Albany, NY.

Heasom, W. C. (2005). “Modeling a Bioinfiltration Basin.” ASCE Conf. Proc., 173(207).

Hinman, C. (2007). Presenter: $2^{\text {nd }}$ National Low Impact Development Conference, Wilmington, NC, 12-14 March 2007. Personal communication, 13 March.

Hsieh, C-h, Davis, A.P. (2005). "Evaluation and Optimization of Bioretention Media for Treatment of Urban Storm Water Runoff.” J. of Environ. Engrg., 131(11), 1521-1531. Huber, W.C., Wells, W.J., Besaw, I.K. (2005). “Application of SWMM5 for BMP/LID Quality Evaluation.” EWRI Conf. Proc., Impacts of Global Climate Change, 173(159). 
Hunt, W.F., Jarrett, A.R., Smith, J.T., Sharkey, L.J. (2006). "Evaluating Bioretention Hydrology and Nutrient Removal at Three Field Sites in North Carolina." Journal of Irrigation and Drainage Engineering, 132(6), 600-608.

Imagine That, Inc. (2007). "Imagine That!” Website: http://www.imaginethatinc.com/ Last Accessed: July 3, 2007.

Jarrett, A.R., Hunt, W.F., Horstman, M.T., Berghage, R.D. (2007). "Evaluating A Spreadsheet Model to Predict Green Roof Stormwater Management.” Conference Presentation, $2^{\text {nd }}$ National Low Impact Development Conference, Wilmington, NC, 12-14 March.

Job, S. (2007). “Applications of the Site Evaluation Tool: A Model for Assessing Site-Scale Development Impacts." Conference Presentation, $2^{\text {nd }}$ National Low Impact Development Conference, Wilmington, NC, 12-14 March.

Kim, H., Seagren, E.A., Davis, A.P. (2003). "Engineering Bioretention for Removal of Nitrate from Stormwater Runoff." Water Environment Research, 75(4), 355-367.

Koch, P. R. (2005). “A Milwaukee Model for LID Hydrologic Analysis.” ASCE Conf. Proc., Managing Watersheds for Human and Natural Impacts: Engineering, Ecological, and Economic Challenges, 178(71).

Kronaveter, L., Shamir, U., and Kessler, A. (2001). 'Water-sensitive Urban Planning: Modeling On-Site Infiltration.” Journal of Water Resources Planning and Management, 127(2), 78 .

Lee, J. G. and Heaney, J. P. (2003). "Estimation of Urban Imperviousness and Its Impacts On Storm Water Systems.” Journal of W ater Resources Planning and Management, 129(5), 419. 
Lehrer, T. (2006). Emerson Process Management. Personal Communication. July.

Li, Y., Buchberger, S.G., Sansalone, J.J. (1999). "Variably Saturated Flow in Storm-Water Partial Exfiltration Trench.” Journal of Environmental Engineering, 125(6), 556-565.

Liu, H. (1972). "Manning's Coefficient for Smooth Pipes.” Journal of the Sanitary Engineering Division, 98(2), 353-360.

Liu, H. (1973). "Closure of 'Manning's Coefficient for Smooth Pipes.”' Journal of the Sanitary Engineering Division, 99(4), 555-556.

LMNO (LMNO Engineering, Research, and Software, Ltd.). (2000). “Manning's n Coefficients for Open Channel Flow: The Fluid Mechanics Calculations Website.” Website: http://www.lmnoeng.com/manningn.htm. Last accessed: July 2007. MacQuarrie, K.T.B. and E.A. Sudicky. (1996). “Technical Note: On the Incorporation of Drains into Three-dimensional Variably Saturated Groundwater Flow Models.” Water Resources Research, 32(2), 477-482.

Mantanga, G.B., Buchnoff, K., Jacquemin, C.Y., Gessford, L.R., VanderKwaak, J.E., Sudicky, E.A., McLaren, R.G., Diener, J. (2003). “Integrated Hydrologic Modeling of Surface and Subsurface Water Flow and Solute Transport In Irrigated Agriculture: Model Application." USCID Conference Proceedings, $2^{\text {nd }}$ International Conference on Irrigation and Drainage: Water for a sustainable world - limited supplies and expanding demand. Phoenix, AZ, May 12-15, 377-388.

Mason, Y., Ammann, A.A., Ulrich, A., Sigg, L. (1999). 'Vehavior of Heavy Metals, Nutrients, and Major Components during Roof Runoff Infiltration.” Environmental Science and Technology, 33, 1588-1597.

Mays, L.W., and Bedient, P.B. (1982). "Model for Optimal Size and Location of Detention." J. Water Resour. Plan. Manage. Div., Am Soc. Civ. Eng., 108(3), 270-285. 
Mazer, G., Booth, D., Ewing, K. (2001). "Limitations to Vegetation Establishment and Growth in Bioinfiltration Swales.” Ecological Engineering, 17(4), 429-443.

Mikula, J.B., Clark, S.E., Long, B.V. (2007). "Evaluation and Verification of a Vadose Zone Model Being Applied to Stormwater Infiltration." Conference Presentation, $2^{\text {nd }}$ National Low Impact Development Conference, Wilmington, NC, 12-14 March.

Morzaria-Luna, H. N., Schaepe, K. S., Cutforth, L. B., Veltman, R. L. (2004).

"Implementation of Bioretention Systems: A Wisconsin Case Study." J. of the Amer. Water Resour. Assoc, 40(4), 1053-1061.

Musleh, F.A., Cruise, J.F. (2004). “Testing the Validity of Manning's n Calculated by Modeling the Flow Through Rigid Non-Submerged Vegetation.” ASCE Conf. Proceeding: Geo Jordan 2004: Advances in Geotechnical Engineering with Emphasis on Dams, Highway Materials, and Soil Improvement, 12, 145-157.

Neale, L.C., Price, R.E. (1964). "Flow Characteristics of PVC Sewer Pipe.” Journal of the Sanitary Engineering Division, ASCE Conf. Proceedings, 90SA3, 109-129.

NOAA (National Oceanic and Atmospheric Administration). (2007). "Quality Controlled Local Climatological Data, Hourly Observations Table: MANSAS RGNL/H P DAVS FD AP (03710) Manassas, VA (03/2007).” Website: http://cdo.ncc.noaa.gov/ulcdsw/ULCD. Last updated: December 2006. Last accessed: March 2007.

NVPDC (Northern Virginia Planning District Commission), ESI (Engineers and Surveyors Institute). (1992). "Northern Virginia BMP Handbook: A Guide to Planning and Designing Best Management Practices in Northern Virginia.” Annandale, Virginia. 
Patwardham, A. S., Graham, P., Thorpe, J., Medina, D., Jobes, T., CH2M HILL. (2004).

“Innovative Model for Designing Low Impact Developments (LIFE $\left.{ }^{\mathrm{TM}}\right)$. . ASCE Conf. Proc. 378.

Perez-Pedini, C., Limbrunner, J.F., Vogel, R.M. (2005). “Optimal Location of InfiltrationBased Best Management Practices for Storm Water Management.” Journal of Water Resources Planning and Management, 131:6(441).

PGCM (Prince George’s County, Maryland). (1997). Low Impact Development Design Manual. Department of Environmental Resources, Prince George's County, MD.

PGCM (Prince George's County, Maryland). (1993). The Bioretention Manual. Department of Environmental Protection, Landover, MD.

PWCDA (Prince William County Development Administration). (1985). "Prince William County Development and Construction Standards Manual.” Prince William, Virginia.

Ramesh, R., Datta, B., Bhallamudi, S. M., Narayana, A. (2000). "Optimal Estimation of Roughness in Open-Channel Flows." Journal of Hydraulic Engineering, 126(4), 299-303.

Rossman, L.A. (2005). “Storm Water Management Model, Version 5.0: User’s Manual.” National Risk Management Research Laboratory. United States Environmental Protection Agency, Cincinnati, Ohio, EPA/600/R-05/040.

Saulnier, G-M, Beven, K., Obled, C. (1997). “Including Spatially Variable Effective Soil Depths in TOPMODEL." Journal of Hydrology, 202, 158-172.

Scharffenberg, W.A., Fleming, M.J. (2006). “Hydrologic Modeling System HEC-HMS: User's Manual.” United States Army Corps of Engineers, Institute for Water Resources, Hydrologic Engineering Center. 
Schneider, L.E. and McCuen, R.H. (2006). “'Technical Note: Assessing the Hydrologic Performance of Best Management Practices.” Journal of Hydrologic Engineering, 11(3), 278.

Simunek, J., van Genuchten, M. Th., Sejna, M. (2006). "The HYDRUS Software Package for Simulating Two- and Three Dimensional Movement of Water, Heat, and Multiple Solutes in Variablye-Saturated Media. Technical Manual, Version 1.0.” PC Progress, Prague, Czech Republic.

Simunek, J., Vogel, T., van Genutchen, M. Th. (1994). "The SWMS_2D Code for Simulating Water Flow and Solute Transport in Two-dimensional Variably Saturated Media, Version 1.2." Research Rep. No. 132, U.S. Salinity Laboratory Agricultural Research Service, U.S. Dept. of Agriculture, Riverside, Calif.

Smith, J., Hunt, W.F., Jadlocki, S. (2005). "Monitoring of Retrofit Urban Stormwater BMPs." $13^{\text {th }}$ National Nonpoint Source Monitoring Workshop, Session: Detecting Change from Urban BMP Installation, September 20. North Carolina State University, Raleigh, NC. http://www.bae.ncsu.edu/programs/extension/wgg/nmp conf/presentations.html Last Date Accessed: July 13, 2006.

Sturm, T.W. (2001). Open Channel Hydraulics. New York: McGraw-Hill.

Tetra Tech, Inc. (2003). “Low-Impact Development Management Practices Evaluation Computer Module: User's Guide.” Prepared for Prince George's County Department of Environmental Resources.

Teemusk, A., Mander, U. (2007). "Rainwater Runoff Quantity and Quality Performance from a Greenroof: The Effects of Short-term Events.” Ecological Engineering, 30, 271277. 
Trimbath, K. (2006). “Water Quality: Study Proves Minnesota Rainwater Gardens Reduce Storm-Water Runoff.” Civil Engineering News, 76(12), 28-30.

Urban Engineering (Urban Engineering \& Associates, Inc.). December 23, 2004. Plans for “Virginia Gateway Addition.” Project Number 01-0437. Prince William County, VA.

Valavala, S., Montes, F., Haselbach, L.M. (2006). “Area-Rated Rational Coefficients for Portland Cement Pervious Concrete Pavement.” J. of Hydrologic Engineering, 11(3), 257. Van Veen, J.A., McGill, W.B., Hunt, H.W., Frissel, M.G., Cole, C.V. (1978). “Simulation Models of the Terrestrial Nitrogen Cycle.” In: Ecological Bulletins 33 - Terrestrial Nitrogen Cycles.: Processes, Ecosystem Strategies and Management Impacts. Eds. F.E. Clark and T. Rosswall. Swedish Natural Science Research Council, Stockholm, p. 25 - 48.

VanderKwaak J.E. (1999). "Numerical Simulation of Flow and Chemical Transport in Integrated Surface-Subsurface Hydrologic Systems.” PhD dissertation, University of Waterloo: Waterloo, Ontario.

VanderKwaak, J.E. and Loague, K. (2001). "Hydrologic-Response Simulations for the R-5 Catchment with A Comprehensive Physics-Based Model.” Water Resources Research, 37(4), 999-1013.

VanderKwaak, J.E., Sudicky, E.A., McLaren, R.G., Mantanga, G.B., Gessford, L.R., Buchnoff, K., Jacquemin, C.Y., Diener, J. (2003). “Integrated Hydrologic Modeling of Surface and Subsurface Water Flow and Solute Transport In Irrigated Agriculture: Model Overview." USCID Conference Proceedings, $2^{\text {nd }}$ International Conference on Irrigation and Drainage: Water for a sustainable world - limited supplies and expanding demand. Phoenix, AZ, May 12-15, 377-388. 
Vertessy, R.A., Elsenbeer, H. (1999). "Distributed Modeling of Storm Flow Generation in an Amazonian Rain Forest Catchment: Effect of Model Parameterization." Water Resources Research, 35(7), 2173-2187.

Villarreal, E.L., Bengtsson, L. (2005). "Response of a Sedum Green-roof to Individual Rain Events.” Ecological Engineering, 25, 1-7.

Villarreal, E.L., Bengtsson, A. S-D. L. (2004). "Inner City Stormwater Control Using a Combination of Best Management Practices. Ecological Engineering, 22, 279-298.

White, F.M. (1999). Fluid Mechanics, McGraw Hill, $4^{\text {th }}$ Edition.

Wilkerson, G.W., McNally, W.H., Martin, J.L., Ballweber, J.A., Collins, K., Savant, G. (2007). "LATIS: A Spatial Decision Support System to Assess Low Impact Site Development Strategies." Conference Presentation, $2^{\text {nd }}$ National Low Impact Development Conference, Wilmington, NC, 12-14 March.

Wong, T., Coleman, J., Duncan, H., Fletcher, T., Jenkins, G., Siriwardena, L., Taylor, A., Wootton, R. (2005). “MUSIC: User Guide.” CRC for Catchment Hydrology, Australia.

Wong, T. S. W., Zhou, M. C. (2002). "Re-Evaluation of Manning’s Roughness Coefficient for Runoff over Concrete Surface." ASCE Conf. Proceedings, Global Solutions for Urban Drainage: 9ICUD, 300.

Wright, L., Heaney, J.P., Weinstein, N. (2000). "Micro-scale Modeling of Low Impact Development." ASCE Conf. Proceedings, Building Partnerships - 2000 Joint Conference on Water Resource Engineering and Water Resources Planning and Management, 27(1).

Wurbs, R.A., James, W.P. (2002). Water Resources Engineering. Prentice Hall, Upper Saddle River, NJ. 
Yen, B.C. (1992). "Hydraulic Resistance in Open Channels.” Article in Channel Flow Resistance: Centennial of Manning's Formula. Ed. Ben Chie Yen, US Library of Congress.

Zhen, X.Y., Yu, S.L., and Lind, J-Y. (2004). "Optimal Location and Sizing of Stormwater Basins at Watershed Scale." Journal of Water Resources Planning and Management, 130(4), $339-347$. 